University of Louisville

ThinkIR: The University of Louisville's Institutional Repository

Electronic Theses and Dissertations

$5-2017$

\title{
The implications of a University of Louisville first year experience course on student success outcomes based on race and gender.
}

Nadine C. Petty

University of Louisville

Follow this and additional works at: https://ir.library.louisville.edu/etd

Part of the African American Studies Commons, Higher Education Commons, and the Latina/o Studies Commons

\section{Recommended Citation}

Petty, Nadine C., "The implications of a University of Louisville first year experience course on student success outcomes based on race and gender." (2017). Electronic Theses and Dissertations. Paper 2731. https://doi.org/10.18297/etd/2731

This Doctoral Dissertation is brought to you for free and open access by ThinkIR: The University of Louisville's Institutional Repository. It has been accepted for inclusion in Electronic Theses and Dissertations by an authorized administrator of ThinkIR: The University of Louisville's Institutional Repository. This title appears here courtesy of the author, who has retained all other copyrights. For more information, please contact thinkir@louisville.edu. 
THE IMPLICATIONS OF A UNIVERISTY OF LOUISVILLE FIRST YEAR EXPERIENCE COURSE ON STUDENT SUCCESS OUTCOMES BASED ON RACE AND GENDER

\author{
By \\ Nadine C. Petty \\ B.A., University of Rochester, 1996 \\ M.A.T., University of Rochester, 1997 \\ A Dissertation \\ Submitted to the Faculty of the \\ College of Education \& Human Development of the University of Louisville \\ In Partial Fulfillment of the Requirements \\ For the Degree of \\ Doctor of Philosophy \\ In Educational Leadership and Organizational Development \\ Department of Educational Leadership and Organizational Development \\ University of Louisville \\ Louisville, Kentucky
}

May, 2017 

THE IMPLICATIONS OF A UNIVERISTY OF LOUISVILLE FIRST YEAR EXPERIENCE COURSE ON STUDENT SUCCESS OUTCOMES BASED ON RACE AND GENDER

\author{
By \\ Nadine C. Petty \\ B.A., University of Rochester, 1996 \\ M.A.T., University of Rochester, 1997 \\ A Dissertation Approved on
}

March 23, 2017

By the following Dissertation Committee:

Jacob Gross, Dissertation Director

\begin{tabular}{c}
\hline Jeffrey Sun \\
\hline Glenn Gittings \\
\hline Meera Alagaraja
\end{tabular}




\section{DEDICATION}

This dissertation is dedicated to my mother

\section{Thelma C. Matheson}

who taught me the value of a good education and modeled resiliency in her daily life. 


\section{ACKNOWLEDGEMENTS}

I would like to thank the people that made this dissertation possible. First, my Dissertation Chair, Dr. Jacob Gross for his guidance and support and for suggesting further reading and resources as I worked on this endeavor. His encouragement was valuable as were his critiques of my writing and research. I appreciate his pushing me to produce better material at each step and the time he invested in getting me to my final defense. I am grateful for his expertise and recommendations and for gently coaching me to consider the different angles of my research. He kept me grounded when my footing was slippery and reminded me that the weirdness of the process was normal.

It was an honor having Dr. Glenn Gittings, Dr. Meera Alagaraja, and Dr. Jeffrey Sun on my dissertation committee. They each challenged and supported me in unique ways, and I am thankful and appreciative of the time they spent reading my chapters and their willingness to be a part of my journey. Dr. Sun has taught me to question everything, Dr. Gittings has taught me that there is often deliberate reasoning behind chaos, and Dr. Alagaraja has taught me to stretch outside my boundaries and to push back when needed. I thank you all for your contributions and your ripples in my pond.

I also am thankful for my former supervisor, Dr. Kathy Pendleton who caused positive ripples in her own way. Her flexibility, understanding, and willingness to allow me to schedule classes around my work responsibilities made the front end of this process manageable. Her many "you can do it" and "I have faith in you" remarks kept me going 
when I wanted to curl up in bed and sleep for a decade or two, as did our discussions about our experiences working towards our degree. It was helpful to know what I was experiencing was par for course for a doc student. It also was motivating to learn Dr. Pendleton had earned her doctorate under much more challenging circumstances than mine, and so I used her story as fuel for my fire.

I also would like to thank my mother who worked 14-hour days, seven days a week to provide me with the best opportunities she could. Her sacrifices were huge and she instilled in me the importance of education, the importance of integrity, the value of hard work, and the tenacity that has gotten me through difficult times. She was my lighthouse in the storm and although she is not here to see the culminating results of her efforts, I believe she somehow knows all her sacrifice and hard work paid off in the end. I think she would be proud.

Lastly, I would like to thank my husband, Carl for putting up with me over the last five years as I worked on my Ph.D. He often endured a grumpy and tired wife and I am eternally grateful to him for sticking it through with me, making me countless mugs of Yogi Energy Tea, and asking me how he could help and support me through this process. The cookies he snuck into my office and quietly placed next to my laptop were appreciated. I know putting his needs behind mine was not always easy, so I am immensely appreciative of his being there and understanding when my attention had to be on coursework and on dissertation writing and not on him or our marriage. I owe him many years of reciprocated patience. 


\begin{abstract}
THE IMPLICATIONS OF A UNIVERISTY OF LOUIS VILLE FIRST YEAR EXPERIENCE COURSE ON STUDENT SUCCESS OUTCOMES BASED ON RACE AND GENDER

Nadine C. Petty
\end{abstract}

March 23, 2017

Extant research has shown that across U.S. institutions, the first and second years of college are the most precarious because of high attrition rates. To address this, many colleges and universities implement First Year Experience (FYE) interventions with hopes of increasing first year GPA, retention rates, and overall college success. Over $90 \%$ of colleges and universities either offer or make these FYE interventions mandatory for their first-year/first-time freshmen. There is a large body of research regarding the association of FYE interventions and student outcomes, but the findings are mixed. Extant literature also does little to focus on FYE student outcomes based on race/ethnicity and gender, which is an identified gap and one this study fills.

This dissertation is a quantitative examination of a FYE at the University of Louisville, GEN 101. GEN 101 is an example of a First Year Seminar (FYS). FYS courses are a type of FYE. The contextual framework of this dissertation is based on Tinto's Student Integration Model and concepts of academic and social integration. GEN 101 is required for graduation. All incoming freshmen are encouraged to take it their first semester. Since this course is required and extant literature provides mixed findings about 
the efficacy of FYE courses, I analyzed associations between GEN 101 completion and first semester GPA along with fall-to-fall retention outcomes. My focus was how African American and Latino students fared in comparison to White students and how women fared in comparison to men.

My study results suggested fall GEN 101 completion resulted in higher first semester GPA's when compared with spring GEN 101 completion. It also suggested female students had a greater chance of being retained into their second year than their male counterparts, all else held constant. African American and Latino students had less of a chance of being retained than White students into their second year, but Latinos were retained at greater rates than African Americans. Taking GEN 101 in the fall was associated with greater outcomes than taking it in the spring and this association intensified when race/ethnicity and gender were considered. Specifically, being an African American male student was associated with greater FYE retention outcomes and being a male in general was associated with greater FYE GPA outcomes. 


\section{TABLE OF CONTENTS}

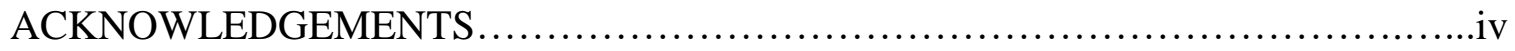

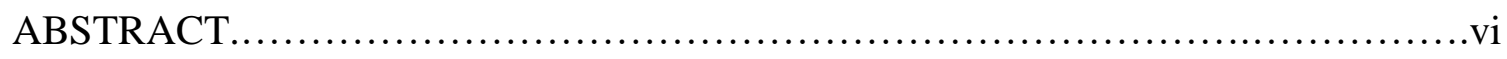

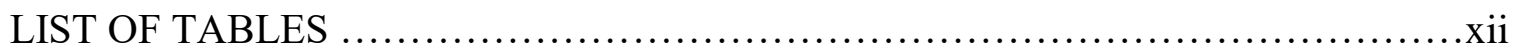

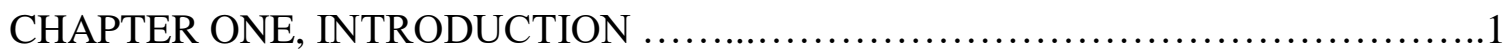

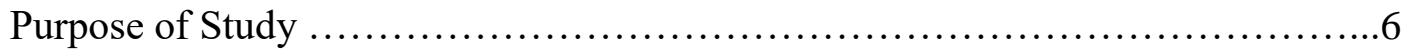

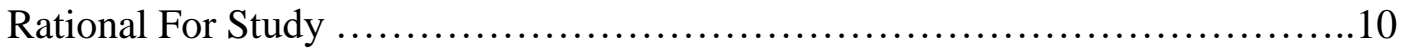

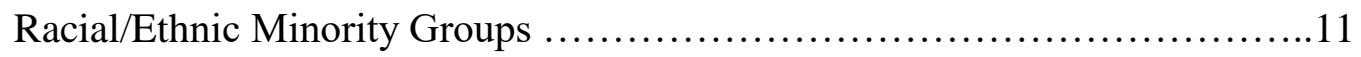

Gender ......................................................... 13

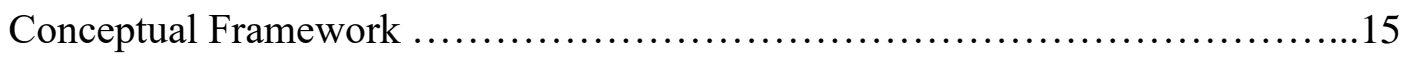

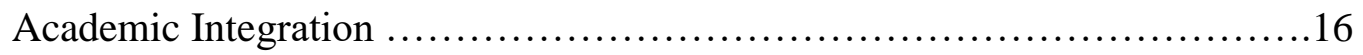

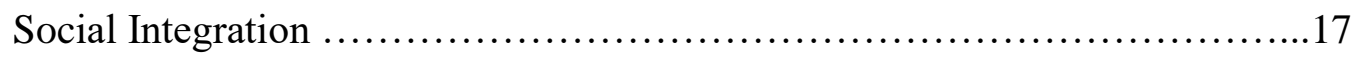

Corroborations and Critiques of Tinto's Student Integration Model ...........18

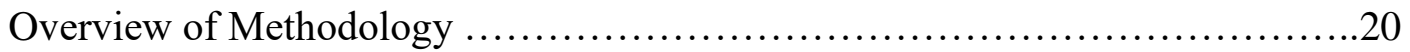

CHAPTER TWO, REVIEW OF THE LITERATURE $\ldots \ldots \ldots \ldots \ldots \ldots \ldots \ldots \ldots \ldots . . . \ldots . . . \ldots$

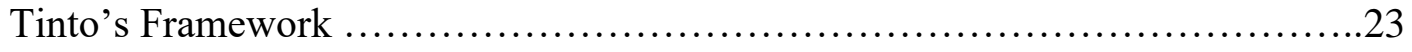

Critiques of Tinto's Conceptual Framework ..............................25

Corroborations of Tinto's Conceptual Framework ........................27

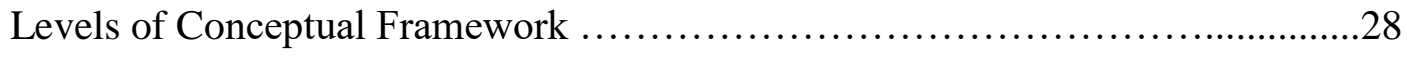




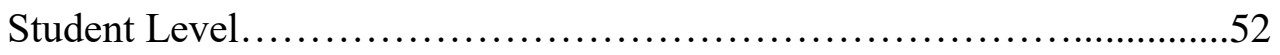

Environmental/External Level ...........................................58

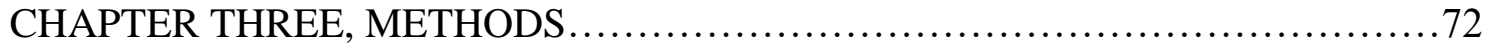

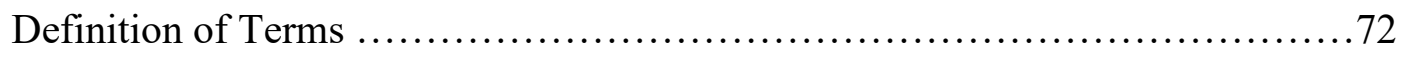

First Year Experience Course .............................................73

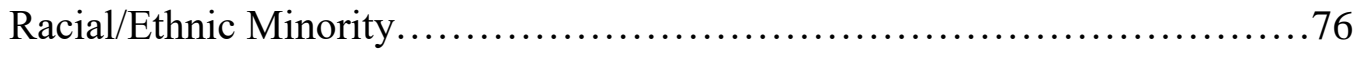

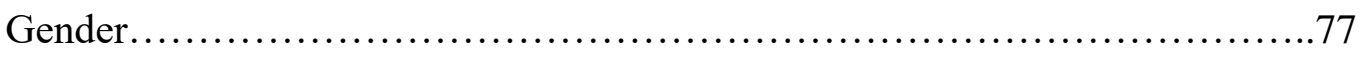

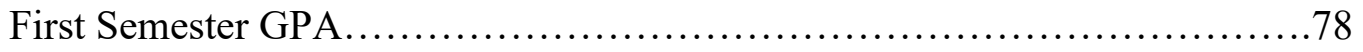

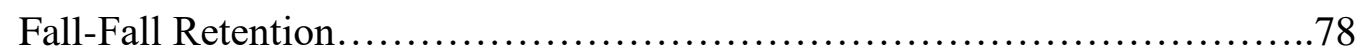

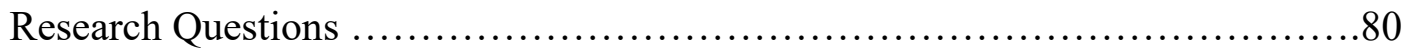

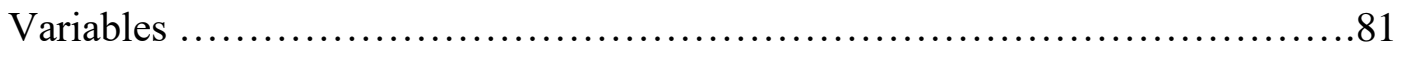

Dependent Study Variables............................................. 81

Independent Study Variables............................................ 82

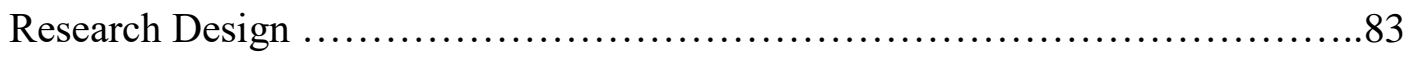

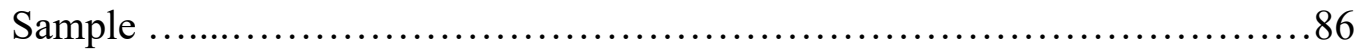

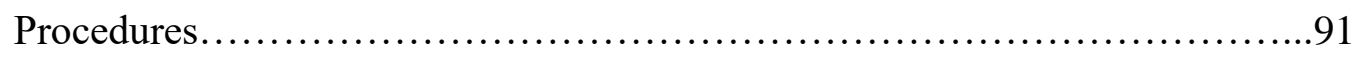

Statistical Analyses.................................................. 92

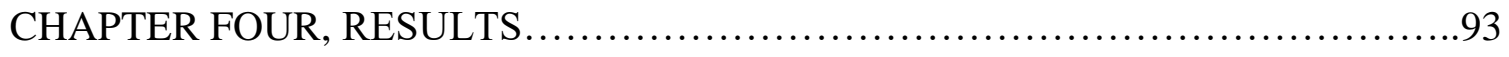

Variables Used in Regression Model ......................................93

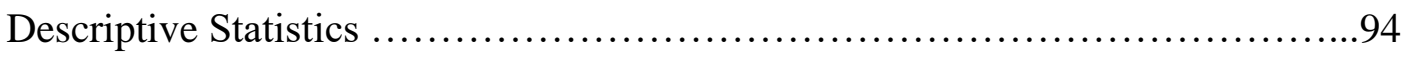

ACT Score and High School GPA Distribution.............................95

SES, First Generation, Residency, and Retention Distribution................95 
Race and Gender Descriptives.....................................97

Regression Analysis .......................................................98

Test of Assumptions................................................. 100

Pearson Correlation, Multiple Regression....................................100

Multiple Regression Analyses..........................................101

Practical Significance and Effect Size................................104

Interaction Effects, Multiple Regression.............................106

Logistic Regression Statistics.......................................109

Practical Significance and Effect Size, Main Effects.......................116

Interaction Effects, Logistics Regression.............................117

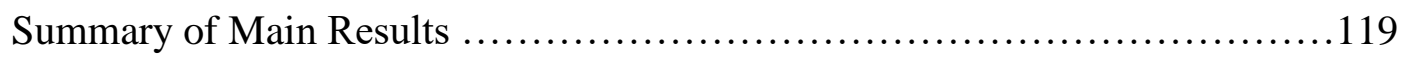

CHAPTER FIVE, DISCUSSION ........................................... 122

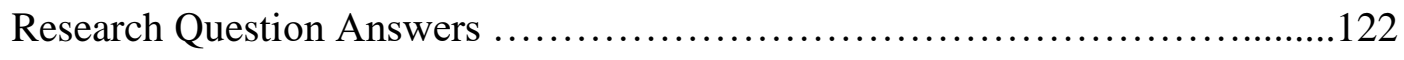

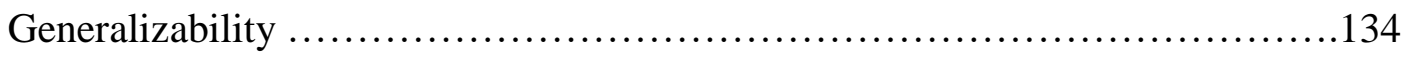

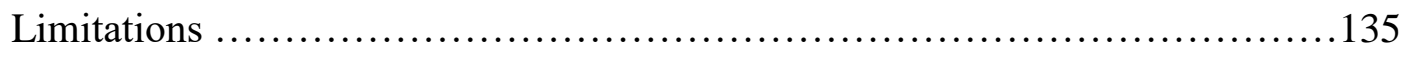

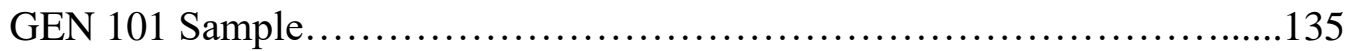

Federal Pell Grant as a Proxy for SES.................................138

First Generation Status.............................................139

Convenience Sampling............................................140

Threats to Internal Validity.......................................... 140

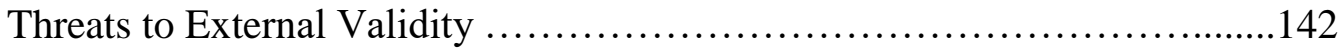

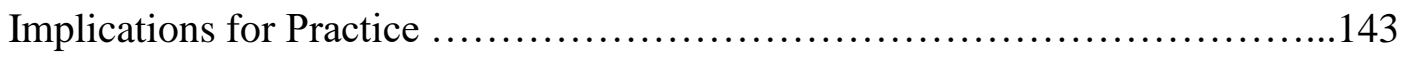

Recommendations for Content Change................................148 
Recommendations for Change in Requirement.........................153

Why This Study Matters ..............................................153

Recommendations for Future Research ................................ 155

REFERENCES ....................................................... 157

CURRICULUM VITAE................................................... 176 


\section{LIST OF TABLES}

TABLE

PAGE

1. Multiple Regression: Dependent Variable - First Semester GPA....................84

2. Logistic Regression: Dependent Variable - Fall-to-Fall Retention...................85

3. 3-way Interaction for Regression.......................................... 85

4. Comprehensive Sample Totals............................................ 87

5. Descriptive Characteristics Across GEN 101 Completion Groups....................88

6. ACT Composite Scores Across Completion Groups..............................89

7. Comprehensive ACT Ranges by Race/Ethnicity................................89

8. Variables in the Regression Model........................................93

9. Academic Characteristics of Students by Timing of GEN 101 Completion.............95

10. Group Comparisons: Frequencies Based on Low SES ..........................96

11. Retention by Campus Residency and GEN 101 Completion Across Cohorts.........97

12. Descriptive Statistics, Retention by Race, Gender, and GEN 101 Status............98

13. Multiple Regression Correlation: Race/ethnicity, GEN 101 Completion, Gender, and First Semester College GPA........................................ 101

14. Model Summary and ANOVA Table, Multiple Regression Model Two .............102

15. Models One, Two and Three Interaction Effects, Multiple Regression Values.......105

16. Model Summary, Multiple Regression Interaction Effects and ANOVA

Table. 106

17. Model Summary, Logistic Regression, Block One............................. 110

18. Omnibus Tests of Model Coefficients, Logistic Regression, Block One........... 110 
19. Binary Regression, Main and Interaction Effects for Fall-to-Fall Retention.........112

20. Binary Logistic Regression, Main Effects and Confidence Intervals..............115

21. Model Summary, Interaction Effects, Block One...............................117

22. Omnibus Tests of Model Coefficients, Interaction Effects, Block One..............117 


\section{CHAPTER I}

\section{INTRODUCTION}

For many colleges and universities within the US, increased student retention is a main challenge and focus of institutional administration - the significance of which is reflected in strategic plans and the many retention committees and task forces formulated to address it (Kalsbeek, 2013). Since the Obama Administration's 2020 goal to increase rates of degree completion in order to have the highest number of college graduates in the world and to maintain global competitiveness, the national conversation surrounding college student retention and degree completion has intensified along with broad initiatives to increase access and completion (Gross \& Berry, 2015; Kalsbeek, 2013). Higher education institutions, especially those that are state funded, are under ever increasing public scrutiny regarding educational attainment, student performance, and fiscal stewardship and transparency (Bettinger \& Baker, 2011; Kalsbeek, 2013).

Historically, on the state level, funding models provide incentives for colleges and universities to enroll as many full-time students as they can, but this model does not provide incentives for college completion. As per the National Conference of State Legislatures (2015), many states are transitioning from historical enrollment-based funding models to models that align with state retention and graduation goals. To illustrate, Kentucky Governor Matt Bevin has indicated his intention to push for performance-based funding for Kentucky institutions (WD Lewis, 2016). Performancebased funding along with the increased national conversation surrounding graduation 
rates has heightened public scrutiny. This calls for greater accountability from legislative groups and provides policy makers with the impetus to devote increasing resources to programs thought to be effective in providing students with the tools necessary for success, specifically those programs designed to target barriers to retention and timely graduation (Bettinger \& Baker, 2011; Kalsbeek, 2013).

Research indicates that across many U.S. institutions, the attrition rate is highest between the first and second years of college (Rogerson \& Poock, 2013). To address the pressures of remedying this, colleges and universities utilize student development theory to develop First Year Experience (FYE) interventions intended to increase retention and overall college success by connecting students to the university (Rogerson \& Poock, 2013; Soldner, Lee, \& Duby, 1999). The FYE is shown to be associated with increased student retention, positive student transition experiences, and increased graduation rates (Barton \& Donahue, 2009). FYE interventions include all college and university courses geared towards orientating first-time college freshmen. They include standard six to eight week, one to two credit courses that address campus resources, academic skill building, and community building. They are sometimes referred to as First Year Seminars (FYS), Freshmen Orientation Courses, Freshman Success Seminars, or other like terms, but all have a focus in addressing the needs of freshmen transitioning into college. Whatever they are called at perspective institutions, they have the collective purpose of increasing retention odds in first-time freshmen students. Although some colleges and universities have FYE courses for transfer students that address their own particular set of challenges, this study does not consider the transfer student experience. 
Due to the large number of institutions that offer or make mandatory FYE courses for their first-year/first-time freshmen, it is evident institutions have bought into the importance of FYE courses, but the history of their origins is inconsistent. Kentucky's Lee College is credited with offering the first freshman seminar in 1882 (University of South Carolina, "History of the first university seminar and the university 101 program"). Rogerson and Poock (2013 - 2014) indicate that Boston University hosted the first credit bearing first year seminar in the late 1880's, but the same recognition of being the first credit bearing first year seminar is also given to Reed College in 1911 (Davis, 1992). Regardless of its start, it was not until the early 1970's at the University of South Carolina (USC) that FYE courses gained momentum (Watts, 1999).

The 1960's was a period of unrest, particularly on college campuses where student protests surrounding the Vietnam War were common. Also common was an institutional focus on preparing students academically while ignoring holistic student development (Watts, 1999). The institutional milieu of the time created support for academic affairs because what was most accepted was a paradigm of "teaching the subject," not "teaching the student" (Watts, 1999). In response to both the popular paradigm and the riots occurring on the USC campus, Thomas Jones, president of USC decided to create a course that focused on student development in hopes of building institutional commitment in USC students and discouraging rioting on campus. Jones created University 101 with hopes of increasing student-professor bonding, addressing students' needs, and deepening student satisfaction with the USC experience (Watts, 1999). Jones entrusted faculty member, John Gardner to direct the University 101 course. According to Watts (1999), by 1974, Gardner tied the concept of "teaching the student" to college 
transition, consequently humanizing it. He also coined the name FYE, which stuck at USC and was picked up by other intuitions across the US. By the early 1990's, most colleges and universities had implemented some version of Gardner's University 101 course and were doing so using empirical studies to support its effectiveness and shape class content with hopes of increasing retention rates (Bai \& Pan, 2009; Bonner, 1996).

In their current state, FYE courses focus mostly on two main areas: academic integration and social integration and are directly connected to Tinto's $(1987,1993)$ theory of student development since they strive to help students form connections to campus culture, both academically and socially (Rogerson \& Poock, 2013-2014). This focus is to increase student odds of persisting from year to year and graduate in less than six years. A more recent trend has included elements of non-cognitive factors like selfefficacy or additions of diversity training modules within the purview of FYE courses. Regardless of the content focus, most FYE courses have been shaped by research on college student success (Barefoot, 2000). This research often involves predictive modeling that maintains certain student characteristics like low high school GPA and membership in a racial/ethnic minority group produce challenges that increase chances of dropping out while specific types of student experiences like high activity in campus life increase retention odds (Astin, 1975; Tinto, 1993). A segment of research suggests participation in FYE or similar freshman orientations or seminars is a good indication of increased first to second year retention probability, regardless of how little or great that increase (Berry, 2014; Singell \& Waddell, 2010; Titus, 2006; Turner \& Thompson, 2014). Retention research also has suggested that members of ethnic minority groups are 
retained at lower rates than their White counterparts (Rhee, 2008; Titus, 2006), but these findings are not consistent across racial groups (Chen, 2012; Oseguera, 2009).

FYE programs have various focuses like service learning opportunities, learning communities, and first-year seminars (FYS) (Berry, 2014), but regardless of the type there is a "strong emphasis on these courses in the collegiate experience" (Porter \& Swing, 2006, p. 90). According to a 2002 study conducted by the Policy Center on the First Year of College, 94\% of accredited 4-year colleges and universities offered some form of a FYE intervention program (Porter \& Swing, 2006; Rogerson \& Poock, 2013), most of which are based on completing a FYE course (Barefoot, 2000). FYE courses generally come in different forms with varying content, pedagogy, credit hours, or requirement status (Rogerson \& Poock, 2013). Although the content of these courses vary across higher education institutions, their collective purpose is to increase academic performance, persistence, and degree attainment through academic and social integration (Goodman \& Pascarella, 2006). Over the past 20 years, thousands of FYE programs were created with the purpose of increasing retention rates and some universities have experimented with elective FYE to address behavior problems like binge drinking (Barefoot, 2000). In other universities, successful completion of an FYE course is required for degree completion.

\section{Purpose of Study}

As previously stated, FYE interventions can have various content, weight, structure, and pedagogy (Rogerson \& Poock, 2013) and can target various first-year populations as well as transfer students. The purpose of this study is to predict the impact FYE programs that target first-time, first year-freshmen have on first to second year 
retention rates and the GPA of students who identify as members of a racial/ethnic minority group in addition to the impact these course have on students based on gender. The demographics of students on college campuses are changing to reflect increased enrollment of racial/ethnic minorities and women identifying as members of these groups (Clauss-Ehlers \& Parham, 2014). According to 2007 data taken from the National Center for Education Statistics, between the years 1976 and 2005, the rates of college enrollment for racial/ethnic minorities increased at astronomically higher percentages than that of Whites, as well as for women in comparison to men, i.e. $62 \%$ increase for African American men and 145\% increase for African American women; 275\% increase for Latino men and 530\% increase for Latina women; and 392\% increase for Asian men and $570 \%$ for Asian women; compared with 7\% for White men and $49 \%$ for White women (Clauss-Ehlers \& Parham, 2014). In 2012, the Western Institute Commission for Higher Education uncovered that a similar demographic profile exists in today's colleges and universities (Clauss-Ehlers \& Parham, 2014). Despite this trend of increased diversity, the "predominate structure of the first college year ... is the same basic structure that was designed for a population of White, middle- or upper-class males who constituted the vast majority of college students ...." twenty years ago (Barefoot, 2000, p. 13). For students identifying as racial/ethnic minorities, this creates "a serious lack of institutional fit" (13). Thus, it is important to conduct research that predicts the impact FYE courses have on students who do not identify as White.

In addition to the growing numbers of racial/ethnic minorities enrolled in colleges and universities, studying the impact of FYE courses on students who identify as a member of one of these groups is important because research also indicates that on a 
whole, racial/ethnic minorities do not do as well or graduate at the same rates as their White counterparts (Hunn, 2014). For example, within the content of the Commonwealth of Kentucky's racial profile, the Kentucky Council on Postsecondary Education indicates that in 2012, African Americans made up roughly 12\% of the population, but were awarded only $6 \%$ of both undergraduate and master's degrees and $8 \%$ of doctoral degrees given by Kentucky colleges and universities (Hunn, 2014). More alarming data show that nationwide, only $42 \%$ of African American students who begin college will ever graduate compared with $62 \%$ of White students (Hunn, 2014). With the growing number of racial/ethnic minorities in college and the challenges these students face, especially at Predominately White Institutions (PWI's), a study such as this one that considers the specific impact of a FYE course on first year retention and overall academic success of racial/ethnic minorities is important. This is especially true if states make appropriation decisions around performance-based funding models.

As suggested by Tinto (1993), research indicating racial/ethnic minority college students are not performing as well academically when compared with their White counterparts implicitly suggests this is due to some inherent shortcoming or weakness of the student. Tinto states student retention theories that are psychologically based tend to ignore the effects of outside influences on success and may indicate that being a member of a racial/ethnic minority group and/or a member of a particular gender in itself is what will make a college student more prone to dropping out. These theories place responsibility on only the students when they drop out or succeed and ignore effects of outside negative influences or positive support. Psychological theories are very different from societal theories of student departure because societal theories stress the importance 
of external factors like economic theories of educational attainment, individual costbenefit analysis, and institutional integration on student success (Tinto, 1993). For example, a psychological theory may propose that African American males complete college at lower rates than African American females because of the combination of their membership in a racial/ethnic minority group and their maleness, but might ignore that African American males have lower graduation rates when attending PWI's, thus negating the potential role of external factors on their success.

FYE courses are examples of external factors used in mitigating student characteristics and are intended to provide students with a preliminary foundation to increase their chances of success by increasing academic performance and persistence through academic and social integration (Goodman \& Pascarella, 2006). Goodman and Pascarella (2006) espouse that many studies suggest first year seminars provide positive benefits to students from varying backgrounds and are a "good all-purpose intervention to increase persistence from first to second year" (27). There also is indication these courses can be especially beneficial for racial/ethnic minorities or below average females (Berry, 2014; Jamelske, 2009). As such, it is logical to analyze how they impact students along gender and racial/ethnic lines since being male and/or a member of a racial/ethnic minority group is characterized as at-risk for increased drop out odds in predictive modeling (Jamelske, 2009; O’Keeffe, 2013). However, these at-risk characteristics do not get as much attention as other characteristics in the literature like low-income status, firstgeneration status, high school GPA, or college entry standardized test scores (see Chen, 2004; Soria \& Stebleton, 2012; Tinto, 1975, 1987). This creates the aforementioned gap 
in analyzing differences along racial and gender lines in the research. The research questions that guide this study are as follows:

1. How does successful completion of a FYE course predict fall-to-fall first year retention rates and GPA for African American and Latino college students in comparison to White college students?

2. How does successful completion of a FYE course predict fall-to-fall first year retention rates and GPA for college men in comparison to women?

3. How does the intersectionality of race and gender predict fall-to-fall retention rates and GPA for African American and Latino college men and women who successfully complete a FYE course?

For clarification, African American as used in this dissertation includes any person with origins from Black Africans including Afro Caribbeans. Latino is defined as any male or female with origins from Mexico, Puerto Rico, Cuba, Central America, South America or other Spanish speaking countries excluding those found in Europe. White is defined as those with origins from Europe or the Middle East.

\section{Rational for Study}

Colleges and universities in the United States see retention as an important aspect of institutional success and consequently allot time and resources to increase retention rates of their students (Porter \& Swing, 2006; Tinto, 2009). The University of Louisville (UofL) is no exception. Increased retention and graduation rates are main goals of UofL and they are included in the strategic plan. Since FYE courses are one of the methods used to help prepare first-time freshmen to successfully persist from semester to 
semester, this study aims to evaluate student outcomes of FYE courses at UofL across race and gender lines and to fill the gap in the research pertaining to racial and gender differences regarding these outcomes. The rational to use race and gender as main study variables is due to existing research that suggests in comparison with Whites, due to unique challenges, racial/ethnic minority groups experience college differently and benefit differently from courses aimed at academic and social integration, especially in light of sense of belonging (Hunn, 2014; Hurtado, Han, Saenz, Espinosa, Cabrera, \& Oscar, 2007). Sense of belonging is an important factor in successful college matriculation (Tinto, 2012) and is highly related to academic achievement and retention (Hurtado et al., 2007). Challenges of being African American or Latino at a PWI can manifest themselves in ways that negatively affect college experiences and academic performance (Hunn, 2014; Schwartz, 2012).

Sense of belonging challenges faced by members of racial/ethnic minority groups are experienced across gender lines and is evidenced by college females in male dominated subjects (Good, Rattan, \& Dweck, 2012). To illustrate, discrimination in education towards females contributes to lack of success when they choose to pursue math-related fields in college; however, the research suggests that this is influenced by environmental factors, not by lack of intellectual ability or inherent interest (Good et al., 2012). A study on male and female college students enrolled in a Calculus class revealed an overwhelmingly higher sense of belonging indicator for males in relation to females (Good et al., 2012). Although the Good et al., (2012) study focuses on the differences in sense of belonging between males and females in a math course, it clearly illustrates 
gender as a factor in college success and is a compelling reason to analyze how it might predict outcomes of FYE courses at UofL.

Based on a review of the literature, in studies seeking to determine specific student outcomes of FYE or similar freshman targeted retention courses, the student-level characteristic of race/ethnicity or gender are generally not analyzed as a main study variable unless the FYE course under inspection incorporates racial or gender homogeneity (see for example Brooks, Jones, \& Burt, 2013; Mamary, 2003). Consequently, much of the existing research does not focus on FYE retention outcomes like increased GPA or persistence from semester to semester across racial/ethnic minority groups when FYE courses do not use a homogeneous population model (see for example Alarcon \& Edwards, 2013; Raymondo, 2003).

\section{Racial/Ethnic Minority Groups}

There is a positive correlation between students who identify as belonging to a racial/ethnic minority group and precollege characteristics that traditionally pose barriers to students (Thompson \& Fretz, 1991; Tinto, 1993). According to Tinto (1993), minority student attrition tends to be a reflection of academic difficulties since they are more likely to come from disadvantaged backgrounds and inferior schools. For example, characteristics such as lower SES backgrounds, being first-generation students, and entering college from lower performing middle schools and high schools can result in being underprepared for college-level work and predict lower odds of persisting and graduating from college (Cabrera, Deil-Amen, Prabhu, Terenzini, Chul, \& Franklin, 2006; Swail, Cabrera, Lee, \& Williams, 2005; Thompson \& Fretz, 1991). These decreased odds are seen often in members of racial/ethnic minority groups where the 
effects of a lack of social and cultural capital are heightened (Hunn, 2014). For example, middle school Latinos from low SES backgrounds are at risk of placing into or taking high school math courses that do not adequately prepare them for college level work (Swail, Cabrera, Lee, \& Williams, 2005). These Latino middle school students were more densely grouped as "not qualified" for college level work compared with their White counterparts when using a college qualification index designed to approximate college admission criteria (Swail, et al., 2005). Swail, Cabrera, Lee, and Williams (2005) also found that Latino students who gain access to postsecondary education are retained at lesser rates than their White counterparts. There also is indication that Latino students, even highly academically inclined ones, find academic adjustment to college during their first year the most challenging aspect of their matriculation (Hurtado, Carter, \& Spuler, 1996).

Although FYE and similar courses can address the needs of transfer students as well as students on an honor's track, there is some indication that at-risk students, generally being more underprepared, receive the greatest GPA and retention benefits (Jamelske, 2009). The research also indicates that first-year college experiences pertaining to both academic and social integration for high performing Latino students can have a mediating effect on at-risk precollege characteristics, playing a greater role in determining retention into the second year of college and ultimately college success (Hurtado, Carter, \& Spuler, 1996). This trend is seen also in an analysis of African American students where precollege characteristics like high school GPA were not significantly tied to academic or social adjustment of African American first-year college students (Thompson \& Fretz, 1991). However, for African Americans, social integration 
or "sense of belonging" is articulated in study analyses as one of the key factors in retention (Hunn, 2014; O'Keeffe, 2013). As a caveat, the greatest gains in GPA and retention due to FYE courses and associated academic integration and social integration result from studies of homogeneously populated courses where it is impossible to use White comparison groups due to the nature of the course itself (see Brooks, Jones, \& Burt, 2013). Hopefully, this study can inform FYE curriculum and/or design at UofL in order to promote increased success at retaining students who identify as belonging to racial/ethnic minority groups.

\section{Gender}

Although gender is not often analyzed in the literature, from the few studies that discuss it, there is some indication that men and women have different college experiences and retention patterns (Astin, 1975; Mamary, 2003; Tinto, 1993). Early analyses of student characteristics that predispose students to greater odds of dropping out of college suggest that gender plays a significant role in both the likelihood of being retained and time to degree completion (Astin, 1975; Tinto, 1993). Tinto's (1993) research suggests that females are more likely than males to earn a degree after starting college and Astin (1975) found women were more likely than men to complete an undergraduate degree in four years. Astin also indicates women had a persistence rate about $5 \%$ higher than men (68.3\% vs. $62.4 \%)$. However, the reasons that males and females drop out are very different. Tinto cites that females tend to drop out from external pressures like being married and/or having children that put constraints on their ability to pursue an education, while Astin cites that marriage actually increases the likelihood of degree completion for males. The research also suggests females drop out of 
college for social reasons, while males drop out for academic ones (Astin, 1975; Tinto, 1993).

Although Tinto (1993) does not utilize gender as a main variable in any of his analyses, he does indicate differences between men and women in integration styles. Specifically, Tinto claims although both academic integration and social integration are effective means of increasing retention odds, they are not equally as effective between gender groups. His research demonstrated that academic integration techniques had a tendency to have greater positive retention effects on males, whereas social integration techniques had a tendency to have greater positive effects on females. Other studies seem to support the greater benefit of social integration on females than males (Bai \& Pan, 2009; Bean, 1980; Jones, 2010; Pascarella \& Terenzini, 1979). Interestingly, males and females of various racial/ethnic groups experience differences in the levels of social integration and academic integration they are exposed to during their first year of college. African American females report less social integration resulting from peer support than African American males, while White student data expressed reverse findings (Hausmann, Schofield, \& Woods, 2007). Hausmann, Schofield, and Woods (2007) also found that when compared with White students, peer support was important for both male and female African American students to foster "sense of belonging" and to increase social integration.

More recently, in her study of positionality and language in a first-year seminar course, Mammary (2003) points out the sexism that is pervasive on campus in both curricular and residential contexts and espouses that the "residential and curricular components of the FYS ... often [denied] women students of all cultural backgrounds 
genuine opportunities to live and learn to their fullest potentials" (456). She argues that the masculine discourse of these courses fail to empower women and fail to allow women to build true community with each other. She goes further to say that traditional first-year seminars were "an ideological system that was both harmful to [faculty] and many students. ..." (459). Although Mammary analyzes the first-year seminar using a feminist lens, it illustrates a viable way in which the experiences of women in these types of courses may differ from that of men.

The research suggests that women and men have different needs across academic and social integration (Bai \& Pan, 2009; Bean, 1980; Jones, 2010; Pascarella \& Terenzini, 1979). The research also suggests a complexity of the gender variable when other intersection of identities, like race and ethnicity, are considered (Hunn, 2014). For example, African American females are subject to experiencing both racism and sexism (Hunn, 2014). Except for Mamary (2003), the existing research on student outcomes related to gender incorporate cursory analysis or discussion, indicating a gap in the research and a need for further analysis of the role gender plays in analysis of retention outcomes of FYE courses.

\section{Conceptual Framework}

This study utilizes concepts of academic and social integration outlined in Tinto's Student Integration Model (1987, 1993), a societal theoretical approach explaining elements of college student retention and success. Of major importance to this study is Tinto's notion of academic integration and social integration. According to his model, both are necessary to some degree to decrease the odds of student dropout, but are not needed in equal degrees to ensure retention success. They will be addressed briefly here, 
but will be discussed in detail in Chapter 2 of this dissertation, along with criticisms of the model as it relates to racial/ethnic minority student social integration.

\section{Academic Integration}

One of the key areas of Tinto's (1975) initial theoretical framework is integration into the academic system of a university. Academic integration includes behaviors that foster student intellectual development such as faculty-student or student-student interactions in the classroom and laboratories and other academic involvements that would most likely positively influence grade performance. These types of interactions increase goal commitment, which is based on student expectations and the intensity of that expectation. Tinto illustrates this by arguing a student whose goal is to earn a Ph.D. would more likely complete a four-year degree program than would a student with lower aspirations. Academic integration also takes into account long term degree plans that influence the type of institution a student would attend and their commitment to that institution, and that this commitment is driven by financial commitments and time commitments. In this way, academic integration is not just about academic behaviors and interactions that help imbed students in the academic realm of a university, but also deals with a student's willingness to make sacrifices to reach an ultimate goal (Tinto, 1975). Studies utilizing Tinto's (1975) conceptual model indicate academic integration has the strongest impact on retention outcomes during the first two years of college (Terenzini \& Wright, 1987). However, although academic integration has a more powerful influence on retention outcomes during the first two years of college, it does not seem to be as influential during the last two years of college (Terenzini \& Wright, 1987). As such, it is 
arguable that the focus of FYE courses should be academic in nature to address the differing needs of students in their earlier college years.

\section{Social Integration}

Within Tinto's (1975) theoretical framework, social integration is viewed as interactions between a student with a specific set of characteristics (background, value system, institutional commitment, etc.) and others with either a similar or different set of characteristics. He notes that these social encounters, if successful, result is friendships, faculty support, and validation that become part of a student's cost-benefit analysis. These social rewards can add to the perceived benefits of attending college and positively influence institutional commitment and thus retention outcomes (Tinto, 1975). Many studies utilizing Tinto's framework focus on social integration because of his belief that social integration and "sense of belonging" were the stronger predictors of college student retention compared with academic integration (Davidson \& Wilson, 2013-2014; Good, Rattan, \& Dweck, 2012; Kelly, LaVergne, Boone, \& Boone, 2012).

Tinto (1975) notes social integration occurs mainly through informal peer group associations, extracurricular activities, and interactions with faculty and staff in the institution. However, in the preceding section, interactions with faculty were associated with academic integration. This is because Tinto's model does not suggest one integration type is mutually exclusive of the other. Instead, aspects of academic integration and social integration have permeable boundaries (Tinto, 1975). For example, there is a social aspect involved in the faculty-student and student-student interactions of academic integration and an academic integration aspect often involved in social integration activities. Studies seem to validate the Tinto framework and that academic 
integration is offset by social integration through a compensatory relationship and vice versa, indicating a lack of necessity of both in equal amounts, but that increased amounts of either are positive indicators of retention (Mannan, 2007). Tinto states both academic and social integration "involves notions of both levels of integration and of degrees of congruency between the individual and his social environment" (107). He also states, the higher the degree of both academic and social integration of a student into the college systems, the greater will be the institutional commitment and the goal of earning a degree.

There is a difference between the impact academic integration and social integration have on student retention in commuter versus residential institutions. Based on Tinto's (1975) theoretical framework, the importance of academic integration shifts depending on whether a student attends a two-year college or a four-year university. In a four-year university, complete academic integration may not be necessary as long as a student can integrate socially; however, in a two-year college where students are mostly commuters, this is not the case. Tinto (1998) stated that for commuter students, academic involvements are more important for retention than social ones since opportunities for social integration will be limited or non-existent. For commuter students, academic integration is often the sole retention avenue. As such, the analysis of both social integration and academic integration is not suitable for community colleges with nonresidential status, so applying his framework is best in a study utilizing some aspect of a residential setting like at UofL or other traditional residential institutions.

\section{Corroborations and Critiques of Tinto's Student Integration Model}


Since there is considerable agreement among scholars concerning the validity of Tinto's (1975) interactionalist Student Integration Model, it is the main paradigm around which studies on college student departure are framed (Braxton, Hirschy, \& McClendon, 2004). Braxton, Hirschy, and McClendon (2004) found strong empirical support for one of the main propositions underlying Tinto's theory, i.e. the greater the degree of social integration, the greater the level of institutional commitment. However, while some overall findings tend to support the theory's constructs and predictive validity (Nora, Attinasi, Jr., \& Matonak, 1990; Pascarella \& Terenzini, 1980), some claim it is more robust when integrated with the effects of the environmental factors or organizational attributes associated with Bean's (1980) Student Attrition Model (Braxton \& Brier, 1989; Cabrera, Nora, \& Castaneda, 1993) or that it does not account for differences in residential 4-year colleges versus commuter 2-year colleges (Braxton, Hirschy, \& McClendon, 2004). Other critiques note the influence of academic integration and social integration on student departure decisions are only robust in multi-institutional studies (Braxton \& Lien, 2000). The model also is criticized for failing to take into account nontraditional students (Tierney, 1992), but its most significant deficit (as it relates to this dissertation) appears to be with respect to African American and Latino students and their integration into PWI's (Braxton, Hirschy, \& McClendon, 2004; Hurtado, Carter, \& Spuler, 1996; Nora, 1987; Thompson \& Fretz, 1991; Tierney, 1992; Tierney, 1999).

Tinto's (1975) framework is theoretically flawed because it does not take into account the cultural differences or historical context of ethnic/racial minorities and is based on the assumption that ethnic/racial minorities experience the college transition the same way as Whites (Tierney, 1999). For students who identify as belonging to 
ethnic/racial minority groups, their cultures are not the same as the dominant culture of the social communities at the institution, so an affinity group or cultural enclave is important for sense of community and social integration (Braxton, Hirschy, \& McClendon, 2004). In a study of Latino students, Tinto's proposed pre-college and student background characteristics did not have as significant an effect on Latino students' college transition as their in-college experiences, suggesting that campus attitudes towards diversity or students' ability to cope with racial stressors were more important (Hurtado, Carter, \& Spuler, 1996). Another study found Tinto's model did not account for Latino (i.e. Chicano/a) students in community colleges since neither academic integration nor social integration had as significant an effect on retention for this student population (Nora, 1987).

Thompson and Fretz (1991) espouse a difference in how members of racial/ethnic minority groups assimilate in PWI's. African American students have to exercise academic strategies that are closely aligned with the dominate culture of PWI's, even if those strategies are in direct contrast with their cultural tendencies (Thompson \& Fretz, 1991). Thompson and Fretz suggest the academic integration of African Americans may rely on greater acceptance of foreign learning situations and the ability to respond positively to the demands of their environment than on intellectual ability. It seems then that African American cultural styles for coping or recognition of the "relevance of culture-specific adjustment strategies" is an important aspect (Thompson \& Fretz, 1991) missing from Tinto's framework.

\section{Overview of Methodology}


Since Tinto's (1993) Student Integration Model is a longitudinal model designed to predict retention, to align with the model, I used a longitudinal approach that includes first-time, first-year freshmen in fall 2012, fall 2013, and fall 2014. Similar approaches measuring retention across three cohorts also are utilized in the literature (see Braxton \& Brier, 1989; Laskey \& Hetzel, 2011; Soldner, Lee, \& Duby, 1999). I ran a multiple regression analysis using first semester college GPA as a dependent variable and included first-generation status, high school GPA, ACT scores, SES, race/ethnicity, gender, campus residency and completion of an FYE course in the first or second semester in the regression model. Not taking an FYE course in either the first or second semesters was used as the baseline. In the logistic regression, fall-to-fall retention rate was used as the dependent variable and GPA, first-generation status, high school GPA, ACT scores, SES, race/ethnicity, gender, campus residency, and completion of an FYE course in the first or second semester were included in the regression model. Not taking an FYE course in either the first or second semester also was used as a baseline. Regression analyses are common in retention studies predicting student outcomes specific to fall-fall retention and GPA (Allen, Robbins, Casillas, \& Oh, 2008; Caison, 2004; DeAngelo, 2014; Desjardins, Ahlburg, \& McCall, 2002; Gilardi \& Guglielmetti, 2011; Jamelske, 2009). Specifically, this study identifies if race/ethnicity and gender are strong predictor variables for FYE outcomes of retention and GPA.

All data were provided by UofL Institutional Research. The data collected are that of full-time, first-time freshmen in cohorts 2012, 2013, and 2014 who took GEN 101 in fall or spring of their first year. Baseline data were collected for students who neither took it fall or spring of their first year for identical cohorts. Only the College of Arts and 
Sciences students are considered in this study because students in the Speed School of Engineering, lower division nursing students, and business students have alternative FYE requirements that do not make enrollment into GEN 101 a requirement. GEN 101 is a required course for graduation for all College of Arts and Sciences students. All students are encouraged to take the course their first semester and most do; however, some take it their second semester or later due to schedule conflicts, unavailability of open sections, or other unmeasurable reasons like overconfidence in academic ability due to high school performance. My research methodology is discussed in greater detail in Chapter 3 of this dissertation. 


\section{CHAPTER II}

\section{LITERATURE REVIEW}

I will begin this chapter with a discussion of Tinto's (1975) model of student departure, later referred to as his interactionalist or student integration model $(1987,1993)$ as the theoretical focus that underpins the retention literature discussed in this review. This discussion will include critiques and corroborations of his model as they apply to appropriateness for use with racial/ethnic minorities. I will then discuss the three main levels or theoretical perspectives found in a review of the literature as they apply to Tinto's model, and I will organize my literature review based on these three levels. The first and broadest level I will discuss is the environmental level, which encompasses external variables dependent on economic climate and work/home commitments. The second more narrow level I will discuss incorporates variables on an organizational level like selectivity of an institution, institutional expenditures on instruction, and availability and effectiveness of first-year experience programming. The final level discussed in this chapter is the student level and is the narrowest and most widely referenced of the levels

in the literature. This level uses student specific pre-college variables like high school and college GPA and individual demographic variables like gender and race/ethnicity. It is important to note here that my focus is on the retention studies. Any mention of Tinto's theory is for the purpose of contextualization of the literature reviewed.

\section{Tinto's Framework}


Tinto's (1975) student departure theory has its roots in social psychology and the economics of education. Specifically, Tinto's model of student departure incorporates notions of cost-benefit analysis and social psychologist Emile Durkheim's (1961) theory of suicide (Tinto, 1975). Cost-benefit analysis, as it relates to the economics of education, addresses the costs of attending college (financial, emotional, mental, time away from family, conflicts with employment, etc.) versus the benefits (extra earning potential, prestige) (Tinto, 1975). Both Tinto's notions of cost-benefit analysis and Durkheim's theory of suicide as they relate to college student dropout were first hinted at in an analysis conducted by Spady (1970). Although Spady does not apply the direct methodology of cost-benefit analysis to his studies, he makes reference to broader concepts of rational choice that are its underpinnings. To illustrate, Spady found a difference between men and women and determined that due to the economic necessity for men to secure high-paying positions, they did not have as much freedom to drop out of college in comparison to women. For men, the cost of dropping out was too great. This was due to the need for them to pursue a high-paying career, or at the very least an occupation that would enable them to provide for their families, and was perpetuated by societal norms of the 1960's, the era in which Spady refers to in his analysis. However, this was not the case for women. Women who attended college in the 1960's did so for reasons based mostly on personal development. When synthesizing the reasons men and women dropped out of college, Spady concluded men tended to leave for involuntary reasons like academic dismissals, whereas women who dropped out did so voluntarily, illustrating the perceived cost (consequence) of dropping out was higher for men than for women. Tinto also looks at direct and indirect costs and benefits associated with dropout, 
but applies the cost-benefit methodology in more direct terms. Tinto found students will tend to withdraw once they determine other investments of time, resources, and money will result in greater personal benefits.

In addition to cost-benefit analysis, Tinto's (1975) model of student departure draws upon Emile Durkheim's (1961) theory of suicide, which holds that suicide risk is elevated when individuals are not sufficiently socially integrated. This poor integration occurs when an individual's values are very different from that of society on the whole and also when there is insufficient interaction between an individual and society members. Tinto attributes his connection of college student dropout with suicide to Spady (1970), who first formed the analogy of college to a social system and students as individuals in that social system. Spady argued that college dropout was analogous to an individual dropping out of society, i.e. suicide. He states, "the social conditions that affect [dropout] parallel those that produce [suicide]: a lack of consistent, intimate interaction with others, holding values and orientations that are dissimilar from those of the general social collectivity, and lacking a sense of compatibility with the immediate social system" (78). According to Tinto, it then follows that the reasons students drop out of college are based on lack of integration into the college society. He utilizes the analogy of suicide to college student dropout to formulate a descriptive model specifying the conditions under which dropping out occurs. Tinto also uses Spady's operational definition of "the college dropout" to include any student who leaves the institution at which s/he initially matriculated.

In addition to borrowing from Durkheim's (1961) theory of suicide, Tinto's (1975) framework for student departure was partially developed from the work of Arnold 
Van Gennep (1960), an anthropologist who studied the rites of passage of adolescence into adulthood in various cultures. Tinto adopted Van Gennep's concept of tribal "rites of passage" and likened it to the process of transitioning from high school to college. As part of that transition, Tinto suggested the need of individuals to disconnect from the society to which they belong (one's high school, neighborhood, family, friends, religion, etc.) to connect with a new one (college institution and related milieu) and tied this disconnect from one society to another into his concept of social integration.

\section{Critique of Tinto's Conceptual Framework}

In the literature outlining deficits in Tinto's framework, some researchers note Tinto's (1975) model was unfit for addressing the experiences of students who identify as racial/ethnic minorities as well as for non-traditionally aged students or students who take classes in non-traditional ways like via distance learning (Davidson \&Wilson, 20132014; Paulsen \& St. John, 2002). Traditional models like Tinto's focus on traditional college-aged students from traditional demographic and socioeconomic backgrounds, i.e. White, domestic, middle class, $18-21$ year-olds, and as such, are not directly applicable to current college students who are more diverse in backgrounds and in age (Paulsen \& St. John, 2002). More pointed criticism of Tinto's model is with respect to African American students and Latino students and their integration into PWI's (Braxton, Hirschy, \& McClendon, 2004; Hurtado, Carter, \& Spuler, 1996; Nora, 1987; Thompson \& Fretz, 1991; Tierney, 1992; Tierney, 1999). Some critics address the misappropriation of the theoretical frameworks that are the very foundation of his Student Integration Model (i.e. Van Gennep's aforementioned "rites of passage"), making his model theoretically flawed (Tierney, 1999). Tierney (1999) argues this misappropriation ignores 
"sense of belonging" for racial/ethnic minority students and instead suggests in order to be successful, non-White students must distance themselves from their own culture, which flies in the face of the "sense of belonging" necessary for the social integration Tinto espouses.

Tierney $(1992,1999)$ notes that Tinto misinterprets Van Gennep's (1960) anthropological meaning of ritual as applied to tribal culture and rites of passage within that culture. Van Gennep's notion of ritual dealt with members of specific tribal communities undergoing rituals that passed them from adolescence into adulthood within their same tribal culture, so in no way expected individuals partaking in those rituals to give up their values, beliefs, or traditions as a consequence of that rite of passage. Tierney (1999) states the social integration component of Tinto's model is problematic for racial/ethnic minority students because it purports their success in college is dependent on their ability to disconnect themselves from their cultural backgrounds, give up their values and beliefs, and integrate into a dominate culture that is unlike their own. As such, his framework is embedded within the belief that racial/ethnic minority students must strive to integrate into a foreign culture in order to be successful.

\section{Corroborations of Tinto's Conceptual Framework}

In their study of college students in a Midwestern university, Nora and Cabrera (1996) determined that the proposed need of severing ties with family, friends, and community in order to make a successful transition to college does not exist for students who identify as members of racial/ethnic groups, but it also does not exist for Whites. They found that for both student groups, parental connection and involvement positively affected college integration and persistence decisions. Despite this, Nora and Cabrera 
(1996) found that overall, Tinto's (1975) Student Integration Model was appropriate for use with ethnic/racial minorities. They conducted a study using several conceptual frameworks, including his model to analyze racial/ethnic minority and White college student adjustment. Their findings corroborated the importance of academic and social integration for racial/ethnic minorities.

In addition, researchers offer support to Tinto (1993) by indicating that he does point out the importance of family and peer groups supporting participation in college to aid transition (Nora, 2001-2002). Alternative interpretations of his framework suggest that while students must discard old ideas in order to embrace new ideas, this rejection of some beliefs and values should not imply a complete disengagement with prior relationships or bonds (Nora, 2001-2002). Further support for Tinto's model as appropriate for analyzing persistence decisions in racial/ethnic minorities is seen in a study by Cabrera, Nora, Terenzini, Pascarella, and Hagedorn (1999). They noted persistence indicators originally outlined by Tinto were similar for African Americans and Whites in addition to corroborating Tinto's assertion that African Americans tended to begin college less academically prepared than Whites (Cabrera, Nora, Terenzini, Pascarella, \& Hagedorn, 1999).

Lastly, in response to previously stated criticisms, Tinto (1993) revised his model and espoused that most colleges are made up of numerous "subcultures" and students need to connect to at least one of them to persist. He stated that membership in these subcultures do not require full assimilation, but only a degree of consensus. As such, he conceded the term membership into college may be more appropriate a term than integration into college (Rendón, Jalomo, \& Nora, 2000). This new moniker of 
"membership" allows for theoretical considerations of racial/ethnic minorities existing in two worlds (i.e. theirs and that of the dominant culture) without the full disconnect from their own cultures as previously theorized.

\section{Levels of Conceptual Framework}

As previously stated, a review of the literature indicates college student retention theory is categorized on three main levels: 1) The environmental level, which encompasses external variables dependent on economic climate and work/home commitments, 2) the organizational level like selectivity of an institution, institutional expenditures on instruction, and availability and effectiveness of first-year experience programming, and 3) the student level which most commonly addresses student variables like high school and first semester college GPA, scores on standardized college entry tests, gender, and race/ethnicity. Tinto's theoretical framework $(1975,1987,1993)$ encapsulates elements of all three aforementioned retention points of loci. It is the main theoretical framework under which the majority of existing retention literature operates and has over 775 citations (Braxton, 2004). The remainder of Chapter 2 will review existing studies as they relate to the aforementioned levels while connecting the literature back to Tinto and his framework.

\section{Environmental/External Level}

The broadest conceptual framework for student retention studies occur on an environmental or sociological level. Literature utilizing environmental frameworks include study variables related to student situations affected by current economic and/or social climate (Bean, 1980; Mixon \& Hsing, 1994). On the environmental level, retention theorists see college student retention as a by-product (at least partially) of work-force or 
other economic or sociological factors (Bean, 1980; Mixon \& Hsing, 1994; Tinto, 1975). This framework largely assumes that factors of college student retention are external and affect all students equally (Loomis \& Rodriguez, 2009). Tinto's (1975, 1993) conceptual framework is aligned with theories on this environmental level since his model incorporates ideas of cost-benefit analysis from the economics of education and concerns itself with individual decisions about investments in varying educational areas. Tinto (1993) states students drop out of college for financial reasons because "the benefits of continued attendance do not outweigh the costs" (88). This cost-benefit analysis is tied to a "social status effect" which argues that the higher a college or university's social status, the higher the perceived value a student will place on a degree from that institution. Consequently, on the environmental and sociological level, Tinto's student departure theory argues that dropout occurs at higher rates at institutions of lower quality or less prestige (Tinto, 1975).

The ability to finance college is also a factor in considering the costs and benefits of staying enrolled in college because the greater the ability of a student to pay, the less the associated "cost" of the education in the student's mind (Braxton, 2004). As such, economic concerns tied to the ability of students to finance their education also play a role in college student departure (Braxton, 2004; Paulsen \& St. John, 2002). Under these types of economic considerations, Perna (2002) espouses decisions to drop out or remain enrolled are reached by a comparison "between the present values of perceived lifetime benefits and the present value of perceived lifetime costs" (117).

Job market considerations and value of a college degree. On the environmental level, college student retention is affected by variables independent of students like the 
current job market, the value of the dollar, and ability of a college degree to foster social mobility. In a qualitative analysis of first-generation students, participants revealed their belief that college attendance and completion were linked to better jobs, careers, and greater opportunities for financial success (Gibbons \& Woodside, 2014). This belief is what drove the participants in the study towards successful retention and graduation and is tied to cost-benefit analysis as it relates to economic and social pressures placed on individual students. For example, the previously referenced pressure for males to be bread-winners and their resulting decreased occurrence of voluntary dropout in comparison to women is a prime example of how outside economic or societal influences can affect college dropout rates in certain student groups (Spady, 1970). Although, the economic considerations of Spady's (1970) conceptual analysis was based on an era (i.e. 1960 's) when males were predominately heads of households, the overarching idea that both environmental and societal factors drive the value of a college degree is still prevalent in more recent literature (Gibbons \& Woodside, 2014; Mixon \& Hsing, 1994; Waggoner \& Goldman, 2005). Studies indicate that the labor market affects students' choices of staying in school and also the school they ultimately choose to attend (Mixon \& Hsing, 1994). Many students decide to attend and remain in a particular institution based on the economics of attending that particular school in relation to possible future earnings (Gibbons \& Woodside, 2014; Waggoner \& Goldman, 2005). Cost-benefit analysis in this light would suggest an individual interested in becoming a pre-school teacher might not remain enrolled at an expensive college or university because the fiscal investment would not be worth potential future earnings. These students might instead choose to transfer and complete their degrees at a less expensive college or university, 
which becomes a positive course of action (Spady, 1970; Tinto, 1975). Both Tinto (1975) and Spady discuss this type of dropout based on logical economic considerations as a positive course of action for the student and warn against viewing all types of dropout as negative or suicide comparable. Bean (1980) similarly indicates that not all student dropout is necessarily a bad thing.

Tinto (1975) and Spady (1970) also both suggest that the idea of dropout itself is not easily defined because dropout from one institution does not necessarily equate to dropout from the system of higher education itself, which is the case for students who transfer out or stop out for a season. Astin (1975) in particular notes the fluidity of the term dropout and addresses this challenge by distinguishing between various dropout types in his study. The literature in general also encourages distinctions between dropouts, stop-outs and transfers to gain a more accurate understanding of the complexity of college student departure (Caison, 2004; Desjardins, Ahlburg, \& McCall, 2002; Herzog, 2005). Regardless of the definition used in the literature, what is clear is although a variety of benefits (economic and non-economic) are associated with different levels of educational attainment, the perceived and actual value of a college education is different for students across racial and gender lines (Perna, 2005), but influences both retention and attendance decisions of all students (Perna, 2000). To illustrate, women with college degrees have greater economic and non-economic payoffs (Perna, 2005). When compared with women with only high school diplomas, they have much higher incomes (45\% higher for a bachelor's degree and 81\% higher for an advanced degree), are more likely to be regular voters, and have a greater likelihood of having health insurance (Perna, 2005). Based on Perna's (2005) findings, college educated men, 
however, have comparable salaries across the board when compared with males who have only a high school diploma. This means the payoff of educational attainment tends to be higher for women than for men. Perna suggests her findings align with the overall higher college enrollment decisions and college attainment of women found in the literature, which reflects a "rational decision-making process" for them regarding the costs and benefits of higher education (45). It is important to note that Perna's study indicates a greater payoff for women who are college educated when compared with women who are not, but does not suggest greater economic status for college educated women when compared with college educated or high school educated men.

The literature also suggests members of various racial/ethnic groups have different perceptions about the benefits of a college degree. Perna (2005) indicates that Whites have higher perceptions of their salary potential after college graduation than African Americans or Latinos. This is especially true of African Americans and Latinos from lower SES backgrounds. When analyzed through the lens of cost-benefit analysis and the reasons a student would decide to persist and complete a college degree, these findings may arguably add to the challenges racial/ethnic minorities might face once they enter higher education, but offer only an equivocal explanation. The literature suggests rational human capital investment models do not fully explain racial/ethnic difference in college enrollment and persistence (Perna, 2005).

Employment commitments and family obligations. In addition to current economic climates and perceived value of a college degree, external factors like job commitments and family obligations affect college student dropout. Utilizing Tinto's (1987) interactionalist model as a conceptual framework, Gilardi and Guglielmetti (2011) 
performed an exploratory study analyzing the relationship between first-year college experiences and second-year retention. Their student group of interest were nontraditional students, defined as students who work at least part-time. Logistic regression indicted employed students were more likely to belong to dropout groups. Considering the mean age of employed students in the study was 30.63 , whereas the mean age of nonworking students was 21.64 , it is fair to presume older students have more employment commitments resulting in higher risks of attrition. This is echoed in an Australian mixed methods study by Grebennikov and Shah (2012) who found students who revealed more pressures from employment commitments and scheduling conflicts tended to be over 21 years old. In addition to identifying students most at risk of dropping out due to employment commitments and scheduling conflicts being non-traditionally aged, Grebennikov and Shah found two out of ten significant reasons students were not retained after their first year of college included employment commitments and scheduling conflicts. They also found family pressures and financial difficulties drove most of the drop-out decisions for these non-traditional student populations. Similarly, findings by Titus (2006) mirror the effects of employment and dropout behavior on retention. Using an organizational behavior/student outcomes college impact model (Berger \& Milem, 2000), Titus conducted a national study utilizing participant data from 400 four-year colleges and universities across 48 states. He discovered the chances of college completion is negatively associated with students working 11 to 20 hours a week, odds-ratio $=0.839, \mathrm{p}<.05$. This negative association increased as students worked more than 20 hours per week, odds-ratio $=0.658, \mathrm{p}<.001$ (Titus, 2006). 
Although the literature supports the idea that work and family obligations are positively associated with dropping out, Tinto (1975) suggests simple comparisons between groups in dropout analysis tend to hide the interactions that exist between various retention factors. He explains the interactions between institutional variables, student body composition, and individual student variables must be considered collectively. Since retention variables are not linear in nature and instead are interrelated, the use of complexity modeling when considering retention variables is suggested (Forsman, Linder, Moll, Fraser, \& Anderson, 2014). Consequently, a relationship between employment commitments, family pressures, financial difficulties, and scheduling conflicts can be assumed to work together in both obvious and not so obvious ways. For example, although low-income students are less likely to persist overall, this is especially true of low-income women when compared with men (Paulsen \& St. John, 2002). Paulsen and St. John (2002) believe this is tied to the labor market and that more families are headed by single mothers whose purpose is short-term education to meet immediate goals.

For students with work commitments, they place more meaning on the learning experience, but tend to utilize university resources the least (Gilardi \& Guglielmetti, 2011). This is a logical result of these students having less time to spend on campus due to work schedules. Employed students and students with children also spend less time actively interacting with faculty and other students for the same reason, which contributes to risk of drop-out. Gilardi and Guglielmetti (2011) found $92.6 \%$ of students who most actively interacted with peers and faculty on campus were retained, whereas $90 \%$ of students who did not interact at all dropped out. The connection of peer support for non- 
traditional students, defined as students who work more than 20 hours per week to support families, also is echoed by researchers outside the United States who claim support from peer groups is the only viable source of perseverance for them, especially since campus specific resources often cannot be accessed for support due to time constraints (Kurantowicz \& Nizinska, 2013). They indicate non-traditional students in Poland who are influenced by family circumstances or employment decisions are often on unfamiliar territory when on a college campus and may find campus culture alienating, confusing, difficult, and manifest self-perceived ideas of themselves as inadequate learners, making the social connections (social integration) key in retention of these students. It is clear the risk of dropout for employed students is complex and incorporates more challenges than work commitments directly pose.

Section summary of key points. In sum, on the environmental level, the research suggests enrollment decisions are based on the value students place on the cost of attending college, both fiduciary and otherwise (Paulsen \& St. John, 2002; Perna, 2000; Perna, 2005; Tinto, 1975, 1993). This cost-benefit analysis is based on the economics of education (Tinto, 1975, 1993) and does not operate in a vacuum because enrollment decisions are based on factors like the job market and a student's belief they can get a good paying job (Gibbons \& Woodside, 2014; Waggoner \& Goldman, 2005). Nontraditional students, especially low-income mothers, have the added pressure of homework-school conflicts that impact enrollment decisions and the ability to integrate into college in more challenging ways (Gilardi \& Guglielmetti, 2011; Kurantowicz \& Nizinska, 2013; Paulsen \& St. John, 2002). As such, decisions to remain enrolled or drop 
out is a convoluted collection of factors based on environmental effects and individual circumstances (Forsman, Linder, Moll, Fraser, \& Anderson, 2014; Tinto, 1975).

\section{Institutional/Organization Level}

Retention frameworks on an organizational level identify the ways institutional policy like curriculum requirements, academic and social policies, and institutional culture affect students and influence student retention decisions. The research of Bean (1980) incorporates institutional level variables. Specifically, Bean adapts a causal model of employee turnover in work organizations and applies it to higher education retention. Both his theory and that of Tinto's $(1975,1987)$ are based on the perspective that student attrition is associated with membership in a specific college or university and not in a general higher education system. Since both Tinto's model and Bean's model attempt to explain dropout from specific colleges and universities and not from the higher education system in general, they are closely related to an institutional/organization model.

Although Bean's model is more specific to organizational theory and employee turnover, his model remains theoretically consistent with Tinto's model. The consistency between Bean and Tinto's models exist because both highlight the importance of student background characteristics and consider the effects of interactions between the student and the institution along with the practical value of attending the school in question. They also both account for the influences that student-institutional interactions have on student satisfaction and resulting institutional commitment. Where Bean's and Tinto's models differ, however, are in the variables incorporated in their frameworks. Bean incorporates a greater number of organizational determinants in his model (19 to be exact) and also ones that Tinto do not like "routinization," defined as the degree to which the role of 
being a student is viewed as repetitive, "distributive justice," defined as the degree to which a student believes s/he is being treated fairly by the college or university, and "centralization," defined as the degree to which a student believes s/he takes part in the decision making process (Bean, 1980).

Although Tinto $(1975,1987)$ does not incorporate as many institutional variables in his student departure model in comparison to Bean (1980), he does consider an institution's selectivity and ensuing student body composition in his dropout analysis in what he refers to as the "frog pond" effect (Tinto, 1975). The "frog pond effect" was mentioned by Davis (1966) in a study involving college men and their career decisions. Davis found that "relative deprivation" was at work when results of his study indicated that GPA tended to affect career choice more than intellectual ability. In short, Davis proposed that in the absence of any objective information, students will judge their ability by comparing themselves with other students. As such, he argues that a direct relationship exists between the ability level of students in an institution and the personal expectations an individual student will have of him/herself as a result. More specifically, the smarter a student's peers, the lower that student's grades will be. The same student in an institution with students of less academic ability would be expected to earn higher grades due to heightened sense of personal ability. In other words, any frog in a pond of big frogs will feel smaller, and any frog in a pond of small frogs will feel bigger, which translates into Tinto's argument that the higher the ability level of a student's peers, the less that student will perceive his/her ability to be and the risk of dropout will increase. As such, institutional selectivity and ensuing student body aptitude are key components 
of his framework on this level. Institutional selectivity will be discussed in more detail further in the literature review.

Institutional culture of diversity. Diversity is tied to Tinto's $(1975,1993)$ notion of integration and its assumed positive effect on retention. Institutional climate relating to diversity initiatives and psychological dimensions of campus diversity also play a part in retention in relation to racial/ethnic minority students' ability to integrate socially and academically into their campus culture and develop commitment to their institutions (Braxton, 2004; DeAngelo, 2014; Tierney, 1999). Braxton (2004) espouses that for racial/ethnic minorities, social integration occurs best when opportunities to build community with affinity groups exist. Feelings of belonging were a significant motivator for college persistence for African Americans and Latinos, but not for Whites (Murphy \& Zirkel, 2015). However, there are inconsistent findings in the literature in relation to institutional diversity, diversity initiatives, and ensuing effects on racial/ethnic minority student retention (see Rhee, 2008; Thompson \& Fretz, 1991).

The claim that social and academic integration occurs best for racial/ethnic minorities in diverse institutions or institutions with a diversity culture is made throughout the literature (Astin, 1975; Braxton, 2004; Talbert, 2012; Thompson \& Fretz, 1991; Tierney, 1992, 1999). However, in an empirical study utilizing a combination of a reformulation of Tinto's (1993) model and Hurtado, Milem, Clayton-Pedersen, and Allen's (1999) conceptualization of campus diversity climate, i.e. diversity composition of student body initiatives, Rhee (2008) found no statistically significant relationship between institutions with high diversity priorities and dropping out or transferring. Other research suggests that greater academic adjustment for racial/ethnic minorities may be 
associated with greater responsiveness to and acceptance of traditionally White environments (Thompson \& Fretz, 1991). This contradicts the assertion that when higher education institutions enable students to affirm their cultural identities, their odds of graduation increases (Tierney, 1992). In fact, contrary to what Tinto theorized, students in institutions with high diversity priorities had higher odds of stopping out (Rhee, 2008).

In contrast to Rhee's findings, a recent empirical study found institutions that promoted opportunities for student engagement in intellectual discussions with others outside of their race showed statistically significant increased second-year retention compared with those that did not (DeAngelo, 2014). Although the literature is equivocal with regards to diversity priorities, what seems fairly consistent is that African American students who attend HBCU's have greater chances of persisting (Astin, 1975) and those who attend segregated high schools have greater chances of enrolling in a four-year college or university (Perna, 2000).

Talbert (2012) also utilized Tinto's model, but instead conducted an unusual analysis consisting of a review of preexisting enrollment, retention, and graduation (ERG) data from two- and four-year institutions in Minnesota. Instead of interviewing students about their experiences, which is the most common method qualitative retention researchers use in the literature, she surveyed various perspectives of educational leaders. Her questionnaire was designed to capture their strategic plans for increasing ERG rates for minority students. Talbert found colleges and universities in technical and community colleges in Minnesota were promoting culturally specific programs, aligning English as a Second Language programs with college readiness programs, and hiring staff who identify as members of racial/ethnic minority groups to address diverse campus culture 
and promote retention and graduation of racial/ethnic minorities. Based on Tinto's theory, all of these factors should increase retention, which aligns with her findings of a resulting gradual yearly increase for American Indian, Asian, African American, and Latino students in ERG rates and a closing of the achievement gap. To illustrate, graduate and transfer data from four-year Minnesota institutions in 2007 revealed $19 \%$ of African Americans and $22 \%$ of Latinos graduated in six-years compared with $20 \%$ of Whites (Talbert, 2012).

Although the literature on a whole suggests a positive correlation between a culture of diversity and student retention (Astin, 1975; Talbert, 2012; Thompson \& Fretz, 1991;Tierney, 1992,1999), there is systematic lack of consideration of the effects of individual student characteristics on specific types of diversity initiatives, specifically, there is a gap in the literature regarding the impact of gender and race/ethnicity on retention effects of promotions of diversity within FYE programs since few to none use race/ethnicity and gender as study variables. One exception is Musoba, Collazo, and Placide (2013) who conducted a study at a Hispanic Serving Institution (HSI) to investigate institutional factors that help Latino and African American students adapt to college and negotiate the campus environment. Specifically, Musoba et al. studied the impact of an FYE program on first-year Latino and African American students to determine its effectiveness. Only students who enrolled in the FYE course during their first semester participated. After data analysis, an overarching theme identified was students' sense of belonging, which participants reported occurred after they joined a peer social group. The FYE course helped them develop a sense of social connection with the university through "transition friends" where other students became part of their "family" 
(Musoba et al., 2013). Since family is important in many racial/ethnic minority cultures, Musoba et al. identified the FYE course as a way to build trust between students who identify as belonging to a racial/ethnic minority group and the institution.

A second overarching theme identified in Musoba, Collazo, and Placide's (2013) study was the need for the career exploration curriculum in the FYE programming to support racial/ethnic minority participants. The researchers found African American and Latino students lacked confidence about their choices of majors. This lack of confidence stemmed from the fact that most of the participants came from high schools that lacked career guidance focus. As such, African Americans and Latinos were seen as being at greater risk of dropping out due to improper choice of major, making career decision making an integral component of the FYE program at that specific institution. Musoba et al. also identified that the more effective FYE course sections had Latino and African American role models, i.e. FYE teachers or other racial/ethnic minority students working as mentors who were successful in college. This mirrors Talbert's (2012) previously mentioned findings that hiring diverse faculty was a strategic retention action.

Freshman programming and first year experience courses. Since seminal retention theories espouse support of students' academic and social integration to increase retention and persistence rates (Tinto, 1975, 1993), colleges and universities design FYE courses to help prepare first-time freshmen for college, build peer communities, and foster institutional commitment, to increase academic performance, persistence, and degree attainment through academic and social integration (Goodman \& Pascarella, 2006). Consequently, FYE and similar first-year intervention programs are implemented with the hopes of increasing retention rates (Bai \& Pan, 2009). FYE courses generally 
aim to increase student-faculty interactions outside of class, build student-student connections, and promote engagement (Barefoot, 2000). However, types of first-time freshman specific programming offered differ among institutions, as do specific curriculum content, and are generally courses that come in different forms with varying content, pedagogy, credit hours, or requirement status (Rogerson \& Poock, 2013). Although the content of these courses vary across higher education institutions, their collective purpose is to increase academic performance, persistence, and degree attainment through academic and social integration (Goodman \& Pascarella, 2006). Regardless of the actual components of the courses, the literature suggests participation in any FYE type program is a good predictor of retention (Singell \& Waddell, 2010; Soldner, Lee, \& Duby, 1999; Titus, 2006).

Consistent with theories outlined in Tinto's (1993) model and in light of the importance of social integration and academic integration on retention, any freshman specific course or program that provides students with the opportunity to interact in small, well-defined peer groups or promote effective academic behaviors may be an effective method of increasing retention (Singell \& Waddell, 2010; Turner \& Thompson, 2014). In a qualitative study by Turner and Thompson (2014), the first-year experience of millennial students reflected the importance of both academic and social integration. Results of this study indicated that $67 \%$ of participants felt activities that are freshman focused enable retention for first-year students, while $57 \%$ of participants indicated that a lack of interactive instructor-student relationship was problematic and decreased retention odds. Turner and Thompson also interviewed students who dropped out and $50 \%$ of participants who dropped out revealed they did not receive academic support 
while enrolled. In addition, $65 \%$ of freshmen indicated needing further development of effective study skills (Turner \& Thompson, 2014). This research points to the importance of FYE courses and other freshmen initiatives in retention since they address areas of study-skills deficiencies, provide academic support, and allow for interactive relationships between faculty and students.

Empirical studies examining the effectiveness of FYE courses generally incorporate both retention and GPA as outcome variables, and many of these studies indicate statistically significant improvements in GPA and/or retention for students completing an FYE course (Barton \& Donahue, 2009; Jamelske, 2009; Rogerson \& Poock, 2013; Tuckman \& Kennedy, 2011; Windham, Rehfuss, Williams, Pugh, \& Tincher-Ladner, 2014). For example, Tuckman and Kennedy (2011) conducted a quasiexperimental study where students were matched via cohort in a control group and intervention group. The intervention group consisted of first-semester freshmen enrolled in a FYE course geared towards teaching learning strategies. Results indicated the intervention had a statistically significant effect on overall GPA for course takers. Course takers also maintained their GPA average over non-course takers during the first year. Tuckman and Kennedy also found the odds of being retained for participants in the treatment group were more than six times that of those in the control group. The study results also revealed the odds of graduating in four, five, or six years for course takers were 1.69 times higher than those in the control group; however, this benefit was only statistically significant for those in academic distress (i.e. GPA's $<2.00$ ).

Similar to Tuckman and Kennedy's (2011) findings of increased GPA and retention, Jamelske (2009) also found students taking FYE courses had increased GPA 
and retention rates when compared with those who did not take FYE courses. Jamelske conducted a logistic regression analyzing the impact of FYE on student retention over a year and found statistically significant increases in GPA and retention probabilities in FYE sections taught by faculty in goal compatible courses, i.e. the student's academic goal (major) was aligned with the FYE curriculum. Jamelske found this effect was increased for students who were less academically inclined, especially if they were female. However, in a study conducted by Bai and Pan (2009), males were found to have increased benefits from FYE programs in comparison to females. Bai and Pan used Tinto's (1993) conceptual model as their framework to investigate the types of first-year intervention programs that work better for students with specific characteristics. They found FYE courses had greater retention effects for male students across a 3-year longitudinal study at a large Midwest urban university. Specifically, male students were $12 \%$ more likely to remain enrolled at the same institution if they participated in a FYE course.

Interestingly, Bai and Pan (2009) also looked at four additional types of freshman intervention programs: advising, academic help, general orientation, and social integration programs designed to promote student involvement, peer interaction, studentto-faculty interactions, and academic engagement and assistance. Advising programs were defined as those consisting of satellite advising centers and a career advising center. Academic help programs were specifically geared towards improving grades in specific courses. Social integration programs were designed to increase student interactions with peer and faculty through a learning community, and the general orientation program was a common orientation program meant to meet retention measures. Students in the 
orientation program in this same study served as a control group in order to test the uniqueness of the aforementioned special programs. The dependent variable was retention and was measured over 3 years from fall to fall. Covariates were age, gender, and institutional selectivity. Results indicated FYE programs worked better for older, non-traditional students and that although the FYE programs were more effective for males, the social integration programs were more effective for females. The greater effectiveness of social integration for females is echoed throughout the literature (Bean, 1980; Jones, 2010; Pascarella \& Terenzini, 1979) and will be discussed in greater detail in the student level section. Bai and Pan's results also indicated that students in social integration programs and advising programs were more likely to be retained at more selective institutions. Specifically, students in social integration programs were $25 \%$ more likely to be retained and students in advising programs were $22 \%$ more likely to be retained when compared with students in institutions of lower selectivity (Bai \& Pan, 2009).

Like both Bai and Pan (2009) and Tuckman and Kennedy (2011), Barton and Donahue (2009) found GPA to be significantly affected by FYE courses. Barton and Donahue conducted a quasi-experimental study on a sample drawn from the University of Maine at Farmington, a selective public liberal arts college. Incoming freshmen had the option to register for a pilot run of a FYE. Students not participating in the seminar had the chance to register for either a summer experience course or a fall orientation course as alternative options for first-year transitions courses. The treatment group consisted of students in the FYE course and the control group consisted of students in the summer experience course and the fall orientation course. Unlike Bai and Pan and Tuckman and 
Kennedy, Barton and Donahue did not find any significant effect of FYE courses on retention outcomes. However, they found that although retention rates were not significantly affected, students in the FYE pilot earned significantly higher GPA's than the control group and reported higher outcomes in self-reported surveys regarding time spent on academic work, discussing work with faculty and higher expectations for attending campus events and activities. Independent samples t-tests also revealed greater advancements in intellectual development in the treatment group as measured by the Perry Test, which is a development gauge assessing student intellectual development via a writing assignment. However, these advancements were not consistent and were time specific. FYE students scored higher on the Perry Test when the two test periods were combined $(t=1.9, p=.03)$, and for September's test administration $(\mathrm{t}=1.9, \mathrm{p}=.03)$, but not for December's test administration $(t=1.1, p=.15)$ (Barton \& Donahue, 2009). These findings might indicate mitigating factors that equalized performance at the end of the first semester.

Although retention was not affected significantly by taking the FYE course in Barton and Donahue's study (2009), other studies mirrored findings of Bai and Pan (2009) and Tuckman and Kennedy (2011) and indicated that FYE courses have statistically significant effects on retention and persistence. Windham et al. (2014) found that students who successfully completed a study skills course similar to those offered in FYE courses had a $64 \%$ higher chance of being retained in comparison with those who did not. An empirical study by Porter and Swing (2006) investigated FYE and the impact of course content on intent to persist. Findings indicated that if students' individual ratings of course effectiveness in a topic area increased one SD from their peers, the 
probability of indicating an intent to persist increased 1 - 6 percentage points (Porter \& Swing, 2006). The study also revealed students at schools with FYE courses with study skills and academic engagement as part of the course content had higher probabilities of intent to persist. For every SD change in the average rating of effectiveness in study skills, intent to persist ratings increased 16 percentage points (Porter \& Swing, 2006).

Effectiveness of FYE courses were also tested on the community college level. A qualitative study by O'Gara, Karp, \& Hughes (2009) explored the effectiveness of FYE student success courses in community colleges and revealed participants found the courses beneficial. Common themes extracted from participant responses indicated the courses were convenient one-stop locations for getting information about college. They helped with time management and study skills, they generated a support system and fostered group discussion among peers, and they helped students become comfortable within the campus environment. These factors are directly related to the academic and social integration Tinto $(1987,1993)$ espouses as important to retention. However, unlike in empirical studies previously mentioned, GPA and retention were not studied as dependent variables, so although students self-reported benefits, actual measurable evidence is lacking.

In one of the few studies using both gender and race as study variables in an analysis of FYE outcomes, Rogerson and Poock (2013) conducted a two-way between groups ANOVA to determine retention outcome of FYE courses. They found students who completed a FYE course across groups had an $80 \%$ retention rate compared with the $75 \%$ retention rate of students who did not. The study also revealed a difference in the value students placed on FYE courses in relation to gender. Specifically, females were 
found to value study skills, goal setting, and academic skills they learned in the course more than males. Race/ethnicity was not found to be a significant variable affecting student outcomes of the FYE course.

FYE course effects are also studied in comparison to other first-year freshman targeted programs. To illustrate, Hoffman, Richmond, Morrow, and Salomone (2003) studied how FYE courses and learning communities affected retention. They analyzed how students' sense of belonging was influenced by these types of freshman specific courses. Sense of belonging is important when considering Tinto's $(1975,1987)$ argument of the positive correlation between social integration and retention. Hoffman et al. measured five factors on a Sense of Belonging instrument. These factors were perceived peer support, perceived faculty support/comfort, perceived classroom comfort, perceived isolation, and empathetic faculty understanding. These factors explained $63.3 \%$ of the variance of the 26 items on the measure (Hoffman, Richmond, Morrow, \& Salomone, 2003). Hoffman et al. found students participating in both learning communities and FYE courses reported lower levels on the isolation factor of the measure than students in standalone FYE courses. To illustrate, students who participated in standalone FYE courses had isolation means .78 points higher than those who participated in both learning communities and FYE courses. Students in both learning communities and FYE courses also scored better on all five scales of the Sense of Belonging Instrument overall. Findings suggest that combining learning communities and FYE courses are more effective for creating sense of belonging and decreasing dropout risks than FYE courses alone. However, Hoffman et al. fail to distinguish differences between groups based on gender, race, SES, or first-generation status. 
Although the literature shows a general trend of a positive correlation between FYE programs and/or retention and GPA, FYE interventions are mostly effective with students who have preexisting at-risk predictors. Specifically, FYE courses are most effective for students who are from low SES backgrounds and have first-generation status (Glenn \& Schultz, 2008) or live off campus (DeAngelo, 2014; Potts \& Schultz, 2008). Potts and Schultz (2008) performed an ANOVA on two groups of students: one living on-campus and one living off-campus. Their analysis revealed off-campus students had statistically significant differences across most areas. Specifically, a control group of offcampus students not taking the FYE course revealed a $42 \%$ first-year retention rate, but results indicated a $74 \%$ retention rate for off-campus students who took the same course. These findings are similar to those of DeAngelo (2014) who found that FYE courses are more beneficial for students who live off-campus because they are more at risk of dropping out after the first year. Studies like these reveal that commuter students get the most out of freshman specific courses aimed at increasing retention. In order to make accurate assumptions about the impact of FYE courses, it is important that studies analyzing the effectiveness of retention based courses control for residency variables. The majority of the studies, however, do not do this and instead control for more common retention variables like SES, gender, race, and first-generation status (Breier, 2010; Chen \& St. John, 2011; Jones, 2010). The idea that FYE courses work best for students in atrisk populations is echoed in Tuckman and Kennedy's (2011) findings that FYE courses are most effective for those students who are in poor academic standing. It logically follows that FYE courses may have more positive effects on racial/ethnic minorities given that they tend to be from lower SES backgrounds and enter college more 
underprepared than Whites because there is a tendency for them to come from inferior schools (Swail, Cabrera, Lee, \& Williams, 2005; Tinto, 1993).

Although a great majority of the literature indicates a positive correlation between FYE course enrollment and increased GPA and retention, some do not. For example, in an analysis of a retention course targeting first-time freshmen using propensity score adjustments, Clark and Cundiff (2011) found no GPA differences between students who took the course and students who did not and only slight and insignificant increases in retention rates for students who did. Raymondo (2003) found similar trends in ineffectiveness of FYE courses in increasing retention and GPA using gender as a study variable. Slightly higher GPA's were found for males after course completion, but was not statistically significant and the effect was not sustained over time, while no difference between males and females on the retention variable existed (Raymondo, 2003).

A few empirical studies regarding the effectiveness of FYE courses are inconsistent. However, the literature indicates FYE course factors like credit weight of course, grading system, and pedagogical strategies differ across FYE and other freshman specific courses and may have differing effects on student motivation to enroll in the course or learn, (Jessup-Anger, 2011). This decreased motivation may have detrimental effects on GPA and retention outcomes. For example, Jessup-Anger (2011) found components of FYE courses that are tied to personal analysis and reflection (e.g. journaling) increase student motivation to learn. However, course characteristics like the course being worth only one credit or graded on a pass/fail system were barriers to motivation to be successful. Ultimately, FYE courses can become ineffective if their very structure decreases student motivation. 
Institutional expenditures and selectivity. The underlying theories of Tinto's student departure theory (1975) and subsequent interactionalist and student integration models $(1987,1993)$ are used as the contextual rational for expenditures on FYE courses. FYE curriculum focuses not only on improving study skills and helping freshmen navigate their campuses, but offer group and team building practices for the purposes of both social/peer and institutional connection. Implementing FYE programs comes at a fiscal cost and is categorized as an academic institutional expenditure. However, retention studies focus on the impact of these types of institutional expenditures on graduation rates with inconsistent results.

In an empirical study by Ziskin, Hossler, and Kim (2010), the role of institutional policies and practices in student retention was analyzed. The researchers surveyed public and private 4-year institutions in California, Georgia, Indiana, New York, and Texas and found that increased institutional spending on instructional expenses resulted in significant positive effects on retention rates $(\beta=.448, p<.01)$. Required meetings with advisors also resulted in significant positive effects $(\beta=.148, p<.05)$ (Ziskin, Hossler, \& Kim, 2010). The importance of institutional expenditures on instruction in relation to retention is illustrated in other studies as well. Using a multilevel event history model to identify main student and institutional characteristics related to student dropout over a 6year span, Chen (2012) found that students who drop out tend to come from colleges and universities with lower levels of institutional expenditures on instruction, academic support, and student service support as well as lower selectivity.

What seems fairly consistent in the literature is the suggestion that greater institutional selectivity is positively associated with retention and persistence rates. One 
empirical study suggested that graduating from college is positively related to enrollment at high selectivity institutions, odds-ratio $=1.334, p<.01$ and negatively associated with enrollment in low selectivity institutions, odds-ratio $=0.834, p<.05$ (Titus, 2006). However, Titus fails to offer insight as to why these findings exist. Like Chen (2012), and Titus (2009), Oseguera (2009) found higher dropout rates are related to lower institutional selectivity. Oseguera suggests that increased probabilities of retention are associated with enrolling in more selective colleges and universities (4.8\%) and with having higher percentages of peers with strong high school GPA's (7.6\%). Oseguera indicates increased quality of the student body has positive educational outcomes for students. In light of this, there seems to be some conflicting evidence for notions of the aforementioned "frog pond effect" (Davis, 1966; Tinto, 1975), which argues that dropout rates increase in institutions of higher selectivity.

When incorporating student-level variables of race and gender as control variables, some studies found increased academic expenditures had a positive and significant effect on cohort retention when controlling for gender and race/ethnicity, but student service expenditures did not have a statistically significant effect (Gansemer-Topf \& Schuh, 2006; Ryan, 2004). Ryan (2004) suggests a $1 \%$ increase in instructional spending equates to more than a quarter percent increase in cohort graduation and Gansemer-Topf and Schuh (2006) found the amount of academic institutional expenditures significantly predicted retention rates across institutions regardless of level of institutional selectivity. As determined by Ryan, this increased retention and graduation effect is heightened in Historically Black Colleges and Universities (HBCU) where instances of and opportunities for student involvement, engagement, and 
integration are maximized for racial/ethnic minority students. However, these studies fail to use gender and race/ethnicity as independent variables and instead use them as control variables, creating a gap in the literature in understanding the specific effects of race and gender on the effect institutional academic spending on first-year experience courses has on retention and graduation rates of these student groups. Gansemer-Topf and Schuh in particular remove all student characteristics from their model, once again reflecting the lack of consideration of specific student characteristics when studying the effects of academic institutional spending on retention.

Section summary of key points. Colleges and universities that have a culture of diversity tend to retain racial/ethnic minority students at increased rates due to heightened ability for these students to socially integrate, increase sense of belonging, and have their culture affirmed either through institutional practices or through community building (Astin, 1975; Braxton, 2004; DeAngelo, 2014; Murphy \& Zirkel, 2015; Perna, 2000; Talbert, 2012; Tierney, 1999). Increased institutional spending and selectivity have a positive correlation with retention rates (Chen, 2012; Oseguera, 2009; Titus, 2006; Ziskin, Hossler, \& Kim, 2010). One of the key areas of institutional spending to address retention deficits is in FYE courses (Bai \& Pan, 2009; Goodman \& Pascarella, 2006). FYE courses differ in structure and content, but have the main purpose of increasing retention through academic and social integration (Goodman \& Pascarella, 2006). The literature overall indicates that FYE courses have increased GPA and/or retention benefits for students (Jamelske, 2009; Rogerson \& Poock, 2013; Singell \& Waddell, 2010; Soldner, Lee, \& Duby, 1999; Titus, 2006; Tuckman \& Kennedy, 2011; Turner \& Thompson, 2014). The research also suggests FYE benefits are enhanced for traditionally 
at-risk student populations (Glenn \& Schultz, 2008), those in academic distress

(Tuckman \& Kennedy, 2011) and commuter students (DeAngelo, 2014; Potts \& Schultz, 2008) and especially for females who are less academically inclined (Jamelske, 2009).

\section{Student Level}

Although Tinto's $(1975,1993)$ model accounts for both environmental and institutional level variables, since he also attributes college attrition to student readiness and other individualized student-level variables, it is also applicable to student-level retention theories. To reiterate, Tinto's model addresses a mix of institutional and student characteristics, and as such has been referred to as his interactionalist model. Tinto (1975) states that his "theoretical model of dropout. . . argues that the process of dropout from college can be viewed as a longitudinal process of interactions between the individual and the academic and social systems of the college. ..." (94). He continues to suggest that a person's experience with these interactions will change and cause constant change to a person's institutional commitment and that these changes will either lead to persistence or different forms of dropout.

Because Tinto $(1975,1993)$ posits student persistence is caused by an interaction between the individual student's personal characteristics and their academic and social experiences of institutional systems, his models are often referenced simultaneously in the literature as his interactionalist or student integration model (Bai \& Pan, 2009; Woosley \& Shepler, 2011). Tinto's (1993) student integration model is a longitudinal model of student dropout that focuses on the concept of integration. In it, Tinto includes variables like academic and social integration, family background, aptitude, goal and institutional commitments, institutional satisfaction and external commitments, along 
with a measure of student behaviors. In fact, his revision of his original concepts (1975, 1987) includes a more thorough analysis of the connection between student behavior and perception and how they become more socially and academically integrated. Tinto's revised framework also makes note of residency status and focuses on how students' commitment to their institutions are strengthened through social and academic integration within the institutional system. However, he theorizes that the levels of integration, and consequently dropout risks, are affected by personal variables like financial resources, personal dispositions, pre-entry characteristics like race/ethnicity, gender, and environmental variables (Tinto, 1993). Its focus relies more heavily on individual students' pre-entry characteristics and the behaviors they bring with them to colleges and universities in comparison to his initial 1975 framework or 1987 conceptualization.

Race and ethnicity. Tinto's (1993) student integration model focuses on student pre-entry characteristics and student behaviors and consequently more holistically captures the drop-out patterns of racial/ethnic minorities than his previous models (1975, 1987). His model speculates that non-cognitive variables, along with background variables, can be used to explain and predict minority students' decisions to persist (Tinto, 1993). Non-cognitive variables tied to self-efficacy have been shown in the literature to be important for understanding racial/ethnic minority student retention patterns (RigaliOiler \& Kurpius, 2013). In a study investigating if racial/ethnic identity was related to persistence decisions, five racial/ethnic minority groups were surveyed: Latino, African American, Asian American, Native American, and biracial students along with students from European backgrounds. In this study, private and public regard was tied to selfefficacy and measured using a modified version of the Multidimensional Inventory of 
Black Identity. Private regard was defined as feelings about one's race and being a member of that race while public regard was defined as how one perceives how others feel about your race (Rigali-Oiler \& Kurpius, 2013). For racial/ethnic minority students, private and public regard were positively correlated to perceptions of university environment. The study concluded that race and ethnic identity predicted student perceptions of the university environment for non-Whites, but not for Whites. The findings support Tinto's view that integration and feeling welcomed is essential for persistence of minority students, especially at PWI's.

Racial/ethnic minorities also tend to have higher incidences of low SES backgrounds, as evidenced in a quantitative study done by Paulsen \& St. John (2002). Their research suggests that racial/ethnic minority performance is tied to income levels, especially for low-income Southeast Asians who had lower academic performance than other racial/ethnic minority groups in their analysis. This is particularly important when analyzing the challenges of minority groups in higher education since the literature suggests lower SES students face greater dropout risk (Allen et al., 2008; Brier, 2010; Chen, 2012; Chen \& St. John, 2011; Desjardin et. al., 2002; Ishitani, 2006; Stratton et al., 2007).

Other studies also suggest that race/ethnicity is a predicator of college retention, but do not attempt to investigate why this is the case (Allen et al., 2008; Chen \& St. John, 2011). Findings across empirical studies generally imply minorities are more likely to drop out compared with Whites. To illustrate, in a longitudinal study, the chances of graduating college was negatively associated with being African American (odds-ratio = $0.764, p<.05)$ (Titus, 2006) while another study indicated racial/ethnic minority students 
had a 1.23 greater chance of dropping out and 1.12 greater chance of transferring (Rhee, 2008). However, these findings are not always consistent across Asian groups (Caison, 2004; Chen, 2012; Chen \& St. John, 2011; Desjardins et al., 2002; Murtaugh, Burns, \& Schuster, 1999; Oseguera, 2009). Oseguera (2009) found Latino students have a $6.1 \%$ lower chance of persisting compared with White students, but Asians have a 3.6\% higher chance compared with White students. Chen and St. John (2011) found that Native Americans and African Americans dropped out at the highest rates compared with other racial/ethnic groups, $57.89 \%$ and $53.73 \%$ respectively. Asians and Whites, however, had higher persistence rates across the board, $69.15 \%$ and $59.30 \%$ respectively (Chen \& St. John, 2011). Ishitani (2006) found Latino students were 64\% more likely to drop out during their second year than White students. Similarly in a univariate analysis conducted at Oregon State University, Murtaugh, Burns, and Schuster (1999) found African Americans, Latinos, and American Indians have higher chances of withdrawing than Whites. In that same study, Asians demonstrated the lowest withdrawal risk ratio. Murtaugh et al. (1999) conducted the aforementioned study using multivariate measures. Results indicated withdrawal risk factors decreased for African Americans, Latinos, and Native Americans. Interestingly, African Americans in the multivariate analysis showed less odds of withdrawing than Whites and other racial/ethnic minorities except for Asians, who kept the lowest odds of withdrawing in both univariate and multivariate analyses. These findings are an anomaly in that the literature mostly suggests racial/ethnic minorities are at greater risk of withdrawal, regardless of the statistical analysis employed. The inconsistencies in the Murtaugh et al. study can be explained by the very large sample size, which may have inflated significance across variables. As is 
the case with Caison (2004), researchers often treat Asians as Whites and code race variables dichotomously, i.e. using racial/ethnic minority excluding Asian as one level and White including Asian as the second.

Like Caison (2004), Laskey and Hetzel (2011) used dichotomous coding for the race variable, i.e. Blacks and Other, but unlike Caison and Murtaugh et al. (1999) they found no statistically significant difference based on ethnicity (69\% retention rate for both groups). However, I suspect their findings may have been affected by their additional inclusion of groups in the Other category besides Asian and White (Latinos and bi-racial students were also included). It is evident that race/ethnicity is an important variable in retention studies utilizing Tinto's (1993) model. Race/ethnicity is often used in the literature as a main study variable or as a covariate controlling for main variables. However, literature specifically addressing the effects of FYE programs based on race/ethnicity is scarce and existing studies tend to look at FYE programs specifically designed for minority groups (with the exception of Musoba, Collazo, and Placide, 2013). One such longitudinal study assessed the effectiveness of an undergraduate retention program geared towards African American males and found the program resulted in a statistically significant difference in increases of academic integration, but there was no statistically significant difference in areas of social integration important to the retention framework (Brooks, Jones, \& Burt, 2013).

Gender and institutional commitment. Tinto's (1975) interactionalist framework stresses the importance of both academic and social integration and suggests they are key in forming institutional commitment, which in turn promotes a student's willingness to persist. However, his earlier (1975) theoretical model postulates that 
institutional commitment may more directly affect social integration, whereas academic integration may more directly affect goal commitment. He states that institutional commitments "are often substantial and are frequently important factors influencing a person's persistence in college and/or decisions to transfer to alternative institutions" (94). The significance of institutional commitment regarding retention is supported across the literature and is often analyzed in light of personal student characteristics either including or excluding gender (Bean, 1980; Wilcoxson, Cotter, \& Joy, 2011).

A longitudinal study conducted by Wilcoxson, Cotter, and Joy (2011) examined college student experiences during the first three years of college across six structurally diverse universities. They found lack of institutional commitment, along with lack of academic confidence, to be a significant first-year predictor of dropout behavior. However, during the second year, the importance of institutional commitment declined and was replaced with course/degree commitment. There also was a greater emphasis on personal ability during the second year and on value of the degree during the third year (Wilcoxson et al., 2011). Most noteworthy is that by the third year, institutional commitment was no longer affected by academic or social integration, but by institutional factors like status and reputation. Wilcoxson et al., however, excluded gender as a variable in their study, which some argue aligns with Tinto's (1975) framework. This argument can be seen as valid since although Tinto mentions the effect of gender on institutional commitment, he fails to provide any in-depth discussion of the factor. Some researchers argue this is a deficit in the model since many studies suggest males and females place varying importance on elements of integration and consequently are integrated differently; however, the literature is inconsistent. 
Although Tinto $(1975,1993)$ fails to discuss gender as thoroughly as some would like, he did report existing gender differences and similarities in the retention outcomes of students. For instance, his analysis of relevant research during the formulation of his original student departure theory (1975) found participation in extracurricular activities had a direct relationship to college persistence for both males and females. However, faculty interaction was more important for females, given their placing greater importance on intellectual development than males. Faculty interaction became important for male students only when the faculty were members of their major area of study. His analysis (1993) also examines gender differences in regards to college matriculation and degree completion. His analysis suggests a higher percentage of females (72.4\%) matriculate into college than males $(69.1 \%)$ and that a higher percentage of females (45.9\%) graduate in six years than males $(42.3 \%)$ (Tinto, 1993).

Despite Tinto $(1975,1993)$ not engaging in a thorough discussion of gender in his model, since he does include it as a student level variable, it is often included in retention studies. For example, Bean (1980) incorporated gender in his causal model and his study found that men and women differed in the importance placed on institutional commitment. Although lower institutional commitment was negatively correlated with retention for both genders, institutional commitment created by social integration (peer groups) was the most important retention indicator for females (Jones, 2010), whereas male student retention was most dependent on academic integration, i.e. faculty relationships and goal setting and commitment (Bean, 1980; Pascarella \& Terenzini, 1979). However, the importance of mentoring was illustrated in a few studies that found faculty mentorship was key for the college success of first-generation women and women 
overall, but not for first-generation men or men overall, which contradicts Pascarella and Terenzini's findings that faculty relationships were not significant for women (Gibbons \& Woodside, 2014; Nora, Cabrera, Hagedorn, \& Pascarella, 1996).

Bean's (1980) findings were mirrored by Jones (2010) who conducted a study using eight private religiously affiliated institutions and found the impact of social integration on institutional commitment was conditional on gender. Specifically, Jones's findings suggest although social integration has a positive statistically significant impact on institutional commitment for both males and females, social integration has a 6.5 times larger magnitude for females. The same study reports when social integration has a zero value, females' subsequent institutional commitment falls below that of males, suggesting social integration plays a bigger role in institutional commitment for females than for males. One noteworthy limitation of Jones's study, however, is the existence of three instances where his sample differed from the population from which it was drawn with regards to gender.

Results indicating females have statistically significant greater odds of persisting to their second year of college are mirrored throughout the literature (DeAngelo, 2014; Porter \& Swing, 2006). In one study of a freshman cohort using an event history model at a Midwestern university, females were not only retained at higher rates, but also were more likely to graduate (Desjardins et al., 2002). However, there are small differences in the literature. For example, some studies found that although females generally are retained at higher rates than males, the differences are not statistically significant (Chen, 2012; Laskey \& Hetzel, 2011), while others suggested that females are being retained at significantly greater rates than males, but also have greater instances of reenrollment or 
transferring after stopping out (Caison, 2004). One study in particular revealed that males and females share the same chances of dropping out at age 18, but the chances significantly increase for males as they grow older (Stratton et al., 2007), while others demonstrated that gender has no statistically significant association with retention at all (Murtaugh et al., 1999). In addition to studies conducted with participants from four-year institutions, the literature also explains results of gender effects on retention in research conducted in community college settings. For example, Windham et al. (2014) conducted a post-facto quasi-experimental study to investigate variables that predict retention at a community college. They found the greatest prediction of retention was gender, with females being retained at a $94 \%$ greater instance than males, which is similar to higher rates of retention for females found in previously mentioned studies (Caison, 2004; Chen, 2012; DeAngelo, 2014; Desjardins et al., 2002; Laskey \& Hetzel, 2011; Porter \& Swing, 2006).

Although the studies previously mentioned suggest being female predicts greater odds of both being retained and graduating, a recent study by Alarcon and Edwards (2013) contradicts these general findings. In their study examining the impact of ability and motivation on retention, odds ratio indicated that the odds of dropping out of college were 1.59 times greater for females. A regression model demonstrated gender is one of four variables that significantly predicts dropout. However, it is important to note that this study is a survival analysis of three points during one academic year and does not capture second year attrition trends. This study also used gender as a control variable based on its association with student retention in preceding studies and not as a main 
study variable. In addition, neither race nor SES status data was included or controlled for, introducing a strong possibility of confounding variables on the gender factor.

Academic and social integration and campus residency. As previously

mentioned, a main consideration of Tinto's $(1987,1993)$ interactionalist framework is a student's ability to integrate both academically and socially into the college environment. This integration has been positively correlated with increased retention rates in empirical studies (Berger \& Milem, 1999; Forsman et al., 2014). According to Berger and Milem, females are more likely to be socially integrated $(\beta=.13, p<.05)$ and social integration has a statistically significant effect on persistence $(\beta=.14, p<.01)$. The exploratory study by Forsman et al. utilized a factor analysis to identify variables related to student retention. Forsman et al. found that the most influential variables were aligned with both academic and social integration. For example, variables like student satisfaction with the institution, faculty support, satisfaction with courses, and feeling of belonging were identified as most significant (Forsman et al., 2014). This notion is echoed by Thomas (2011) whose review of academic and practitioner studies on college pre-entry programs found poor fit and lack of institutional commitment, poor academic experiences, and lack of social integration contributed most to student dropout. The importance of social connectedness also is noted in a longitudinal empirical study that investigated how motivation, academic performance, and social connectedness measured at the start of the freshman year affected third-year enrollment (Allen et al., 2013). In this study, the effects of social connectedness positively and significantly affected third-year retention and was found to be the best predictor of persistence along with institutional commitment. 
In addition to increased retention caused by social connectedness, a study by Braxton, Jones, Hirschy, and Hartley (2008) suggested greater degrees of social integration increased levels of student commitment to their colleges and universities. A one level increase in institutional commitment raised retention odds for the subsequent semester by 3.08 times (Braxton, Jones, Hirschy, \& Hartley, 2008). Additionally, student perception of the extent their institutions are committed to their welfares has a positive influence on social integration $(\beta=449, p=.001)$. Another study by Kelly, LaVergne, Boone, and Boone (2012) found similar effects of integration factors on persistence. Integration factors studied were social in nature and included, but were not limited to, family encouragement, positive relationships with professors, recreational facilities, parties, experience in major, availability of peer tutoring, and desired social status. Students in the study reported a 90\% agreement that positive relationships with their professors encouraged persistence and $86 \%$ agreed positive course experiences in their major field of study encouraged persistence. Lack of social integration also was found to be one of ten main contributing factors of student attrition in a mixed methods study by Grebennikov and Shah (2012).

A first-year students' ability to integrate also is shown to be affected by their living either on-campus or off-campus. Studies show that on-campus residency is key in providing first-year students with the social opportunities and relationship building necessary for increased retention probabilities and self-reported intent to persist to the second year (Porter \& Swing, 2006; Schudde, 2011), but it is difficult to ascertain if the perceived benefits of on-campus housing play a role in increased retention or if other variables are at play. Schudde (2011) argues that studies seeking to investigate if social 
and academic integration are strengthened by on-campus living are misleading if models that do not control for educational information are used because some typically unmeasured student differences may affect results. For example, her study found that students from higher income households tend to live on-campus at higher rates than students from lower-income households. Since SES is a proven predictor of first to second year retention in regression analysis, positive retention effects of on-campus living may have more to do with the SES backgrounds of on-campus students than any actual benefits from on-campus living itself. Schudde controls for SES and other variables using propensity score matching and still finds that on-campus living has a positive (although less so) effect on retention.

The literature also investigates the effects of residency on the effectiveness of FYE courses. Potts and Schultz (2008) performed a study on two groups of students: one living on-campus and one living off-campus. Their analysis revealed no statistically significant difference in mean GPA, credits earned, or retention rates for the on-campus students who took an FYE course. However, the same study showed off-campus students revealed statistically significant differences across most areas. To clarify findings, a control group of off-campus students not taking the FYE course revealed a $42 \%$ first-year retention rate, but results indicated a $74 \%$ retention rate for off-campus students who took the same course. These findings are similar to those of DeAngelo (2014) who used a logistic regression model with completion of a FYE course and campus residency as interaction variables. DeAngelo found that FYE courses are more beneficial for students who live off-campus because they are more at risk of dropping out after the first year. Studies like these reveal that commuter students get the most out of freshman specific 
courses aimed at increasing retention. In order to make accurate assumptions about the impact of FYE courses, it is important that studies analyzing the effectiveness of retention based courses control for residency variables. The majority of the studies, however, do not do this and instead control for more common retention variables like SES, gender, race, and first-generation status (Breier, 2010; Chen \& St. John, 2011; Jones, 2010).

High school GPA and first-semester college GPA. In his student integration model, Tinto (1993) proposes that high school GPA has a strong positive correlation with persistence. The literature supports Tinto's claims of the positive correlation between GPA and retention, indicating high school GPA and first semester college GPA also positively correlate with retention (Allen et al., 2008; Caison, 2004; Chen \& St. John, 2011; Murtaugh et al., 1999; Oseguera, 2009; Porter \& Swing, 2006; Singell \& Waddell, 2010). Compared to students with low high school GPA's, odds ratio results indicate students with higher high school GPA's tend to have significantly higher college persistence rates, odds ratio $=1.53, p<0.01($ Chen $\&$ St. John, 2011). Using a Hierarchical Generalized Linear Model (HGLM) for student-level characteristics, Oseguera (2009) found for a unit increase in high school GPA, there was a 5.9\% increase in probability of degree completion, providing support for Tinto's claim that persistence is positively influenced by academic preparation. Similarly, Porter and Swing (2006) found that students with better high school GPA's were more likely to express intention to return to college for a second year. The trend of higher high school GPA's of retained students also was mirrored in a longitudinal study that investigated the effects of academic self-discipline, institutional commitment, and social connectedness on third- 
year enrollment (Allen et al., 2008). In this study, mean high school GPA's were analyzed across 23 Midwestern and Southeastern four-year institutions. Allen et al. (2008) found mean high school GPA's were highest for students who were retained into the third year of college in comparison to dropouts. The mean high school GPA for retained students was 3.34 whereas the mean high school GPA for dropouts was 3.04 (Allen et al., 2008).

High school GPA is also connected to student involvement in the literature, which is said to affect retention (Berger \& Milem, 1999). In their study of first-year persistence, Berger and Milem (1999) used a hybrid conceptual framework based on Astin (1984) and Tinto's (1993) ideas of student involvement and student integration respectively. Drawing from Astin, Berger and Milem defined student involvement as the physical and psychological energy a student devotes to class, homework, and other academic experiences. They examine how this involvement contributes to social and academic integration and ultimately to persistence. In their longitudinal panel of data collected as part of an earlier study, Berger and Milem found that students with higher high school GPA's were less likely to be uninvolved $(\beta=-.14, p<.01)$ and consequently more likely to be retained. The researchers also found student perceptions of institutional support were positively predicted by high school GPA $(\beta=.11, p<.05)$ (Berger \& Milem, 1999). These findings suggest higher high school GPA's are positively associated with involvement and institutional commitment, and consequently persistence.

In addition to high school GPA, college GPA is also an important variable in retention studies. Allen et al. (2008) analyzed the effects of first-year college GPA on retention. Their findings were consistent with literature indicating that first-year college GPA is correlated with retention, $r=.52$ (Allen et al., 2008). In the same study, they 
noted first-year academic performance was the strongest predictor of remaining enrolled or dropping out. In another study conducted by Chen and St. John (2011), evidence from an empirical analysis integrating retention theories of Tinto $(1975,1987)$, Bean (1980) and others explored the association between state policies and college student persistence. Results indicated that every one SD increase in college GPA was associated with a 93\% increase in the odds of persistence versus dropout, odds ratio $=1.93, p=<0.001$ (Chen \& St. John, 2011).

The vast majority of the literature utilizing GPA as a retention variable make it a dichotomous variable, i.e. passing or failing, generally indicated by classifying GPA's as either $>2.0$ or $<2.0$ with the exception of Chen and St. John (2011) and Shaw and Mattern (2013). Chen and St. John defined their high school GPA variable on three levels: 1) students who received grades between B- and B+ (middle level), 2) those who received grades above a B+ (high level), and 3) those whose grades were lower than a B(low level). Shaw and Mattern conducted a study where first-year GPA was used to classify students on three levels: 1) underperformed, 2) performed as expected, 3) and over performed. The researchers utilized a HGLM analysis of predicted first year GPA and the observed value of first year GPA and found that in the prediction model, the expected probability of students returning for a second year for students who underperformed was $80 \%$ with a residual of -1.5 compared with a $90 \%$ probability of returning for students who performed as expected with a residual of 0.0 (Shaw \& Mattern, 2013). In this portion of the analysis, the decreased prediction probabilities for underperforming students follow findings of other studies, however, Shaw and Mattern found that for students who over performed, the probability of returning for a second year 
was $65 \%$ with a residual of 1.5 . If GPA is positively correlated with retention as indicated by existing literature, this prediction is unexpected. However, after analysis of observed GPA values in the same study, it was clear that students who earned higher first-year GPA's were more likely to return their second year, but those who either over performed or underperformed had less probability of returning in their third or fourth years when compared with students who performed as expected (Shaw \& Mattern, 2013).

Section summary of key points. Tinto's (1975) model is based on a system of interactions between the student's personal and pre-college characteristics and the environment, including the college itself. These personal and pre-college characteristics like gender, race/ethnicity, and high school GPA can challenge a student's ability to integrate academically or socially into their college or university (Tinto, 1975; 1993). The research suggests that membership in racial/ethnic minority groups, specifically identifying as African American and Latino results in decreased retention rates in comparison with Whites (Allen et al., 2008; Caison, 2004; Chen, 2012; Chen \& St. John, 2011; Murtaugh, et al., 1999; Oseguera, 2009; Rhee, 2008; Titus, 2006). The literature suggests various reasons like increased low SES membership among minorities as well as challenges associated with sense of belonging.

In addition to race/ethnicity, institutional commitment is a retention predictor and the research suggests institutional commitment is most important during the first year of college in regards to persistence (Bean, 1980; Wilcoxson, et al., 2011), but points out this commitment is gained differently by men and women due to difference in integration styles. Social integration (peer groups) and mentoring from faculty are the most important retention indicators for females (Bean, 1980; Gibbons \& Woodside, 2014; 
Jones, 2010), whereas academic integration (goal setting, faculty connections) are most important for men (Bean, 1980; Pascarella \& Terenzini, 1979) in retention measures. The research also indicates greater graduation and persistence rates for women overall (Caison, 2004; DeAngelo, 2014; Desjardins et al., 2002; Laskey \& Hetzel, 2011; Porter \& Swing, 2006; Windham et al., 2014). Although academic integration is important to retention, social integration is seen as the most important factor in persistence longitudinally and in general (Allen et al., 2013; Braxton et al., 2008; Grebennikov \& Shah, 2012; Kelly et al., 2012). Although living on campus in relation to social integration is key in the research (Power \& Swing, 2006; Schudde, 2011), in FYE course effectiveness, commuter students show the greatest positive gains (Potts \& Schultz, 2008).

Lastly, the research unequivocally shows that one of the strongest predictors of college student persistence is high school GPA (Allen et al., 2008; Caison, 2004; Chen \& St. John, 2011; Murtaugh et al., 1999; Oseguera, 2009; Porter \& Swing, 2006; Singell \& Waddell, 2010). In addition, it shows that a higher high school GPA indicated increased tendency of college involvement and greater social integration and institutional commitment (Berger \& Milem, 1999). 


\section{CHAPTER III}

\section{METHOD}

This study predicted the efficacy of the University of Louisville's (UofL) First Year Experience course, GEN 101 as it relates to retention and GPA of first-time students at UofL in fall 2012, fall 2013, and fall 2014 cohorts. FYE courses like GEN 101 are designed to address students' academic integration and social integration with hopes of increased retention and improved academic performance (Goodman \& Pascarella, 2006; Bai \& Pan, 2009). The extent to which race/ethnicity and gender impact GEN 101 outcomes was explored. The results of this study contribute to existing research on the influence of student characteristics on predicting retention and academic success, but adds new information specific to the potential influence of FYE courses based on race/ethnicity and gender. Research indicates that racial/ethnic minorities generally do not do as well in college as their White counterparts (Rhee, 2008; Titus, 2006). It also indicates there is a difference in persistence rates of men and women as well as differences in how men and women integrate into institutions of higher education (Astin, 1975; Bean, 1980). Consequently, this study is important in helping to inform college and university freshman orientation curriculum.

\section{Definition of Terms}

This study utilizes the terms FYE courses, racial/ethnic minority, gender, first semester GPA, and fall to fall retention. It also utilizes high school GPA, first-generation 
status, ACT test scores, SES, campus residency, and FYE completion as part of the analysis.

\section{First Year Experience Courses}

Although Chapter 1 outlines the history of FYE and the literature review in Chapter 2 provides a general discussion of FYE courses, neither chapter captures variations in the structure and content of these courses among institutions. However, the data used specifically for this study is not inclusive of all FYE courses, but instead is specific to a UofL FYE course called GEN 101: A\&S Orientation. GEN 101 is an eightweek, one credit hour course designed to acclimate new UofL students to college and "help [them] gain an increased awareness of academic support services . . . increase [their] access and awareness of curricular and extra-curricular activities on campus and explore [their] academic and social self-awareness to create the best strategy for [their] career at the University" (Retrieved from http://louisville.edu/artsandsciences/advising/gen101). Students in the course receive information about how to choose a major, plan appropriate courses to take, and how to get involved on campus. This is accomplished through schedule planning, teaching UofL academic policies and requirements, career and major advising, and teaching students about resources available to them. It also is designed to familiarize students with the Arts and Sciences (A\&S) advisors and advising process. Some of the specific topics and activities include how to use the library and a library tour, reading assigned articles and writing reflections on the readings, developing short and long-term goal plans, and taking part in extracurricular events or diversity related events for extra credit. 
According to the University of South Carolina's National Resource Center for First Year Experience \& Students in Transition (2015), more than 75\% of U.S. higher education institutions have a freshman seminar or freshman orientation course (Zech, 2015). Research indicates that taking part in a single freshman orientation related program (even a short-term one like GEN 101) can increase the chance of success in college, especially for women and racial/ethnic minorities who benefit from getting to know other students who share similar traits (Barefoot, 2000). In one study, a one-credit, seven-week freshman orientation course in a private liberal arts college in Kentucky resulted in higher GPA's for males who took a FYE compared with males who did not (Raymondo, 2003). It is important to note, however, that retention did not seem to be affected for either males or females in this study. In another study analyzing data from an eight-week FYE in a large community college district in the Midwest, successful completion of the course resulted in both increased retention and a higher GPA for the following semester (Zech, 2015).

Additionally, some experts argue that linking the curriculum with extracurricular expectations (as reflected in the previously outlined GEN 101curriculum) "creates a synergy that potentially compounds student learning" (Barefoot, 2000). For students who are not sufficiently academically prepared, FYE programs that offer developmental components that assist with academic integration "make the essential difference in [atrisk students'] ability to attend, and ultimately graduate from, a college or university" (Barefoot, 2000). In light of the above, although GEN 101 is only a single eight-week course, it has the potential of creating a trajectory of success for women and racial/ethnic minorities as well as underprepared college students, which makes it an important course 
for UofL's retention and graduation numbers. This is especially true given that the fall 2016 freshman cohort is comprised of roughly $23 \%$ minorities, making it the most racially diverse in UofL's history (http://louisville.edu/oapa/institutional-research-andplanning/quick-facts/201617JusttheFactsweb_FINAL.pdf).

Although all first time freshmen entering UofL are required to take a FYE course, they are not all required to take GEN 101. To illustrate, students who are accepted to the Speed School of Engineering are required to take an FYE course called ENGR 100: Introduction to Engineering that covers team building, diversity issues, and freshman experience modules along with an introduction to the engineering profession. Lowerdivision pre-nursing students are required to take NURS 101: Success Tips and Techniques, which focuses on campus culture and teaching students about resources available to nursing students. Business students may take GEN 101 if they choose, but are generally directed to take another FYE course by their advisors, and so on. This study focuses solely on data of students who took GEN 101 as an A\&S student and so excludes business students as well as any other student who completed the course outside of A\&S. GEN 101 students are representative of the majority of students who enroll at UofL since the greatest number of undergraduate students enroll in the College of Arts and Sciences. Of the roughly 16,000 undergraduate students currently enrolled, 6,937 are enrolled in A\&S, roughly 2,748 of which are first-time, full-time students who enrolled in fall 2016 (K. Adamchik, personal communication, August 29, 2016). Since A\&S alone enrolls $43 \%$ of the undergraduate population, this makes the GEN 101 students an appropriate study sample. Limitations of this sample will be discussed later. 
All incoming freshmen are instructed to take GEN 101 in the fall. Most, but not all A\&S students take GEN 101 their first semester. Enrollment occurs during summer freshman orientations on a first-come, first-served basis until all fall GEN 101 course sections are filled. Those who take it in the spring do so for a number of reasons like scheduling conflicts, they are spring admits, they feel as though they may not need the course, the fall sections are filled, or for a variety of other reasons (K. Adamchik, personal communication, June 14, 2016).

\section{Racial/Ethnic Minority}

As previously stated, research indicates that race/ethnicity plays a role in student outcomes. As such, one of the variables included in the regression model will be racial/ethnic minorities defined as any student who identifies as African American or Latino. The other racial category for which data will be collected will be White and will be used as a baseline comparative group. Excluded from the analysis are international students, regardless of the ethnic/racial group to which they identify. International students are left out of the analysis to model more closely Tinto's (1993) own analysis of the patterns of student dropout from higher education. Tinto leaves out international students to avoid muddying the waters due to cultural phenomena and to more closely model student trends of full-time American college students. Astin (1975) lumped all non-Black students into the category of White, therefore categorizing Chicanos, Puerto Ricans, Native Americans, and Asians as White; however, this study will avoid treating racial/ethnic minorities as White. Students who self-report as White, African American, or Latino will be grouped accordingly. Because UofL does not disaggregate race/ethnicity deeper than these three categories, I am unable to distinguish between 
ancestral origin and related cultural differences that might affect study outcomes. As such, Puerto Ricans, Mexicans, Cubans and students from other Spanish speaking countries are categorized as Latinos. Likewise, students from the Caribbean or Africa (non-international) are classified as African American. It is important to note that although racial/ethnic subpopulations are collectively grouped in this study, there exists differences in the educational attainment of the subpopulations within these groups. For example, the educational progress of Cuban Americans is greater when compared with Mexican Americans (Schmid, 2001). Asians, Native Americans, bi-racial, and unidentified students were not included in the sample if they did not self-report as either African American, Latino, or White. This current study also eliminates part-time students and non-degree seeking students in order to capture a more traditional student population in the sample.

\section{Gender}

Gender is addressed in this study in its binary term, man or woman. It does not distinguish between cisgender and those identifying as man or woman from LBGTQIA perspectives. Cisgender, specifically cis male or cis female, refers to a man or woman whose gender identity aligns with their reproductive organs (their assigned sex) at birth (Aultman, 2014). This follows Tinto's (1993) use of the term gender in his own theoretical model as well as other early seminal retention studies (Astin, 1975; Spady, 1970). Although the college student LGBTQIA experience and retention of students who identify as belonging to this population is important and is gaining more research interest, it is not the purpose of this study. In addition, LGBTQIA data were not available for students in the GEN 101 sample. 


\section{First Semester GPA}

First semester GPA data utilized in this study is defined as college semester GPA for students after their first semester of college. First semester GPA is analyzed for students who took and completed the GEN 101 course successfully. Successful course completion is further defined as earning a $\mathrm{C}$ or better in the course. First semester GPA also is analyzed for students who did not take GEN during their first or second semester. College GPA, be it first semester or otherwise, is often used in retention studies to determine student outcomes and specifically is used in studies that address FYE course outcomes (Brooks, Jones, \& Burt, 2013; Clark \& Cundiff, 2011).

\section{Fall-to-Fall Retention}

In the literature, fall-to-fall retention is a common method of measuring student outcomes in FYE courses and in less focused retention studies (Brooks, Jones, Burt, 2013; Shaw \& Mattern, 2013; Windham, Rehfuss, Williams, Pugh, \& Tincher-Ladner, 2014). First time freshmen in the fall 2012, fall 2013, and fall 2014 cohorts are used for this study. Enrollment and successful completion of GEN 101 is associated with the fall and spring semesters of their cohort years and this study will examine fall-to-fall retention for each cohort.

As discussed in Chapter 2, critiques of Tinto's (1993) model are many. Braxton and Lien (2000) point out lack of support for the single-institutional longitudinal model. They find although Tinto's model is based on a single-institution approach, singleinstitutional tests of the academic integration construct in relation to subsequent institutional commitment had only modest statistical support (64\%) (Braxton \& Lien, 2000). There was greater empirical support for the academic integration construct in 
multi-institutional studies, i.e. those using various institutional types. For example, Braxton and Lien (2000) found multi-institutional tests had 75\% statistical support. The type of institution also changed the robustness of the academic integration construct with 4-year commuter schools offering the greatest empirical support. Rendón, Jalomo, and Nora (2000) also offer critiques based on minority student retention. They indicate three main conceptual issues with Tinto's model, which are (1) an overemphasis on individual student responsibility to change or adopt, (2) problems associated with ignoring how student involvement is different for traditional students (who are more likely middle upper class and White) vs. non-traditional students (who are more likely to be working class, first-generation or minorities), and (3) Tinto espouses external forces and distinct cultures are always problematic and have a negative impact on student involvement when this is not necessarily the case.

Despite the criticisms, retention studies have corroborated, to a large extent, Tinto's (1993) argument that student characteristics predict retention odds; however, more current literature indicates retention may have more to do with what students are experiencing on campus than with the students themselves (Hunn, 2014; Kalsbeek, 2013). Still, there exists a gap in the research pertaining to how student characteristics, specifically race and gender, might predict FYE course outcomes. Some studies indicate that inclusive communities (i.e. all racial/ethnic minority classes or learning groups) are instrumental in promoting racial/ethnic minority student retention (see Tierney, 1999). This suggests homogeneous FYE courses would be the most impactful model; however these studies do not explicitly use FYE in their analysis (see Tierney), nor do they apply 
it to 4-year institutions (Zamani, 2000). Those that do and use race as a main study variable focus on FYE courses geared towards racial/ethnic minorities, but do not include gender in their analysis (Brooks, Jones, \& Burt, 2013). As such, studies using race and gender as main study variables specific to FYE outcomes and that are applicable to 4year institutions are rare and indicate a gap in the available research.

\section{Research Questions}

The study has three main research questions that address student outcomes of members of ethnic minority groups, women, and men. The research questions that guide this study are as follows:

1. How does successful completion of a FYE course predict fall-to-fall first year retention rates and GPA for African American and Latino college students in comparison to White college students?

2. How does successful completion of a FYE course predict fall-to-fall first year retention rates and GPA for college men in comparison to women?

3. How does the intersectionality of race and gender predict fall-to-fall retention rates and GPA for African American and Latino college men and women who successfully complete a FYE course?

As previously stated, African American is intended to include any person with origins from Black Africans including Afro Caribbeans. Latino is defined as any male or female with origins from Mexico, Puerto Rico, Cuba, Central America, South America or other Spanish speaking countries excluding those found in Europe. White is defined as those with origins from Europe or the Middle East. 


\section{Variables}

The variables chosen for this study were based both on Tinto's (1993) Student Integration Model and on variables often addressed in retention literature. The literature indicates campus residency has an impact on FYE outcomes (DeAngelo, 2014), and is included as a study variable to measure social integration. The same construct also is being measured through GEN 101 involvement since it is structured to address aspects of social integration. For example, GEN 101 courses are designed to be small to foster intimate group dynamics and promote incoming students making peer connections.

\section{Dependent study variables}

In this study, the dependent variables are college GPA (multiple regression analysis) and fall-to-fall retention (logistic regression analysis). College GPA was

measured at the end of the first semester for each cohort of participants in the sample: fall 2012, fall 2013, and fall 2014. Fall-to-fall retention was measured based on enrollment status of each participant at the beginning of the start of the following fall semester. It does not capture participants' enrollment status in the spring semester immediately following their first semester enrollment. Fall-to-fall enrollment is a common timeframe measurement for retention studies that are not longitudinal in nature like Barton and Donahue, (2009) and Tuckman and Kennedy (2011), or in studies that test retention at various semester points like Alarcon and Edwards (2013) who also include fall-to-fall in their wider time-frame analysis. 


\section{Independent study variables}

The independent variables included in the regression models were FYE course status (completed or not completed), race/ethnicity, gender, first-generation status, high school GPA, ACT score, SES, and campus residency.

High school GPA and ACT scores are important to include in both regression models. Research indicates that high school performance (as indicated by GPA and test scores) are strong predictors of college behavior and success (Caison, 2004; Jamelske, 2009; Shaw \& Mattern, 2013). Average ACT scores alone can account for three-fourths of the variance in institutional graduation rates (Kalsbeek, 2013). High school GPA and ACT scores are highly correlated with fall-to-fall retention and first semester college GPA, but are not significantly correlated with each other, which is important when running regression analyses. These variables are common in existing studies on college student retention and have been vetted for use by prior researchers like Chen and St. John (2011), Caison (2004), DeAngelo (2014), and Shaw and Mattern (2013).

First-generation status and SES also are important regression variables and are often used in retention literature (Alarcon \& Edwards, 2013; Allen, Robbins, Casillas, \& Oh, 2008; Braxton, Jones, Hirschy, Hartley, 2008; Breier, 2010; DeAngelo, 2014; Nora, 1987). A first-generation college student is defined as a student "whose parents have had no college or post-secondary experiences" (Saenz \& Barrera, 2007, p. 1). In some institutions, that definition is expanded to include students whose parents might have attended college, but who have not earned a college degree. At UofL, if a student's parent attends even just a semester of a 4-year college, that student is not considered firstgeneration. 
The literature suggests that first-generation students have increased odds of withdrawing and not returning, with the greatest rate of attrition occurring during their second year in college (Caison, 2004; Ishitani, 2006; Stratton et al., 2007). Because of the correlation between parents' education levels and their earning potential, first-generation students also tend to be from low SES backgrounds, compounding their risks of not being retained (Allen et al., 2008). First-generation students also are susceptible to greater attrition because of cultural capital, which is an asset students bring with them to college that may give them an advantage (e.g. appearance, social aptness, prior knowledge, ability to fit in, etc.) and is specifically defined by Aschaffenburg and Maas (1997) as "proficiency in and familiarity with dominant cultural codes and practices ..." (as cited in Collier \& Morgan, 2007). Research shows that colleges and universities tend to promote cultural capital, which reproduces the inequalities found in the wider society, causing first-generation students to be unfamiliar with college jargon, cues, and expectations, thus setting them up for greater challenges and retention issues (Ziskin, Hossler, \& Kim, 2010).

Institutional Research captured SES status by identifying if participants in the study are Pell recipients. One limitation of using Pell as a proxy for SES is that not all Pell recipients are low-income students. This will be discussed further in the limitations section. First-generation status is self-reported on admissions applications by students.

\section{Research Design}

A multiple regression model was used to predict first-semester college GPA and a logistic regression model was used to predict fall-to-fall retention. The multiple 
regression model utilized first-semester college GPA as the dependent variable. Firstgeneration status, high school GPA, ACT scores, SES, race/ethnicity, gender, fall-to-fall retention, campus residency, and successful FYE completion were introduced as predictors into the multiple regression model. These variables were chosen for the model based on my familiarity with retention studies and research based on college student success outcomes. Choosing variables based on "substantive knowledge" for multiple regression models is a good method for selecting a strong set of predictors (Stevens, 2009). Stevens (2009) also notes that working with a smaller more manageable amount of predictor variables assists with scientific parsimony, improves the $\mathrm{n} / \mathrm{k}$ ration which helps with cross validation, and helps to avoid the trap of using so many variables that the incremental validity of new variables is no longer significant.

Table 1

Multiple Regression: Dependent Variable - First Semester College GPA

\begin{tabular}{lllll}
\hline Student & College Readiness & Background & FYE & Residency \\
\hline Race/ethnicity & ACT scores & SES & Completed & On campus \\
Gender & High school GPA & First gen & Not completed & Off campus \\
\hline
\end{tabular}

Standardized Beta weights will be reported in the results section. As per Stevens (2009), the standardized predication formula to use in this study is as follows:

$$
\begin{aligned}
& \hat{y}=\beta_{0}+\beta_{1} \chi_{1}+\beta_{2} \chi_{2}+\beta_{3} \chi_{3}+\beta_{4} \chi_{4}+\beta_{5} \chi_{5}+\beta_{6} \chi_{6}+\beta_{7 \chi_{7}+} \beta_{8} \chi_{8}+e_{i} \\
& \hat{y}=\beta_{0}+\beta_{1 \text { (first-generation status) }}+\beta_{2 \text { (high school GPA) }}+\beta_{3 \text { (ACT scores) }}+\beta_{4}(\text { SES })+\beta_{5 \text { (race/ethnicity) }}+ \\
& \beta_{6 \text { (gender) }}+ \\
& \beta_{7 \text { (FYE })+} \beta_{8}(\text { campus residency) })+\text { error of prediction }
\end{aligned}
$$

Fall-fall retention rate was the dependent variable for the logistic regression.

Additional variables included in the logistic regression were first-semester college GPA, 
first-generation status, high school GPA, ACT scores, campus residency, SES, race/ethnicity, gender, and successful completion of FYE course. Data were collected from UofL Institutional Research as part of a convenience sampling process.

Table 2

Logistic Regression: Dependent Variable - Fall-to-fall Retention

\begin{tabular}{lllll}
\hline Student & College Readiness & Background & FYE & Residency \\
\hline Race/ethnicity & ACT scores & SES & Completed & On campus \\
Gender & $\begin{array}{l}\text { High school GPA } \\
\text { College GPA }\end{array}$ & First gen & Not completed & Off campus \\
& & & & \\
\hline
\end{tabular}

The logistic regression formula used in this study is as follows:

$$
\operatorname{Logit}=p(x) / 1-p(x)=\beta_{0}+x \cdot \beta
$$

or to solve for the probability of an event with several predictors as per Stevens (2009),

$$
\operatorname{Prob}(\text { event })=1 / 1+\mathrm{e}^{-\mathrm{z}}
$$

In this formula, $\mathrm{Z}$ is the linear combination of the independent variables

$\beta_{0}+\beta_{1} X_{1}+\beta_{2} X_{2}+\beta_{3} X_{3}+\beta_{4} X_{4}+\beta_{5} X_{5}+\beta_{6} X_{6}+\beta_{7} X_{7}+\beta_{8} X_{8}$ and $e$ is the root of natural logs (Stevens, 2009).

Both models were repeated to determine 3-way interaction effects. In the first iteration, race/ethnicity, gender, and FYE completion were crossed to determine the interaction effects on GPA. The second iteration used race/ethnicity, gender, and FYE completion to determine interaction effects on fall-to-fall retention.

Table 3

3-way Interaction for Regression

\begin{tabular}{lll}
\hline Iteration & \multicolumn{1}{c}{ 3-way Interaction Formula } & Values \\
\hline 1 & $\mathrm{Y}=\mathrm{b} 0+\mathrm{b} 1(\mathrm{X})+\mathrm{b} 2(\mathrm{Z})+\mathrm{b} 3(\mathrm{~W})+\mathrm{b} 4(\mathrm{XZ})+\mathrm{b} 5(\mathrm{XW})$ & $\mathrm{Y}=$ First semester GPA \\
& $+\mathrm{b} 6(\mathrm{ZW})+\mathrm{b} 7(\mathrm{XZW})$ & $\mathrm{X}=$ Race/ethnicity \\
& & $\mathrm{Z}=$ Gender \\
& $\mathrm{W}=$ FYE completion \\
\hline
\end{tabular}




$$
\begin{aligned}
& Y=b 0+b 1(X)+b 2(Z)+b 3(W)+b 4(X Z)+ \\
& b 5(X W)+b 6(Z W)+b 7(X Z W)
\end{aligned}
$$

$\mathrm{Y}=$ Fall-to-fall retention

$\mathrm{X}=$ Race/ethnicity

$\mathrm{Z}=$ Gender

$\mathrm{W}=\mathrm{FYE}$ completion

\section{Sample}

The study utilized ex post facto data on UofL first time freshmen from the fall 2012, 2013, and 2014 cohorts who enrolled in GEN 101 their first fall or spring semester. The study also gathered data from first time freshmen from the same cohorts who did not enroll in GEN 101 their first or second semesters. I elected to use these cohorts because they were the most recent cohorts with information available to me at the onset of the study. The sample was drawn exclusively from UofL because of convenience sampling and the analysis deals specifically with predictive outcomes of a FYE unique to UofL. Although most institutions have comparable freshman experience or freshman orientation type courses with similar content, to decrease the chances of study bias and increase study fidelity, keeping the sample within one institution was important.

At UofL, students who apply and are accepted to the university are scheduled to attend an orientation session that ranges from June - early August. During these orientation sessions, students are strongly encouraged to enroll in GEN 101 by their advisors. According to Kathryn Adamchik, Director of Advising and Student Services at UofL, the majority of first time students enroll in GEN 101 their first semester (K. Adamchik, personal communication, June 14, 2016). Those who do not, do so for reasons ranging from schedule conflicts to forgetfulness or over confidence in their abilities to be successful without the course. GEN 101 is required for graduation, so all students eventually take it. 
In 2012, 2013, and 2014, the total number of incoming freshmen at UofL was 3,954; 4,029; 3,893 respectively (University of Louisville, Just the Facts, 2012, 2013, 2014). This generates a total of 11,876 incoming students during the years under analysis. After data was requested from IR, the total number of incoming freshman study participants who took GEN 101 the first semester of their first year totaled 3,009. The total number of participants who took GEN 101 their second semester was 97. The total participants who did not take GEN 101 the first or second semester of their first year totaled 4,427 for an initial participant total of 7,533. The participants in this study did not include transfer students or international students, nor did it include part-time or nondegree seeking students or those student admitted to colleges other than the College of Arts and Sciences which explains the decreased amount of participant numbers pulled for the study in comparison to the 11,876 students available in the cohort years under analysis.

Of the 7,533 total students in the sample, 805 identified as African American (10.7\%), 311 identified as Latino (4.1\%) and 6,417 identified as White (85.2\%). Of the total 7,533 students, 3,783 participants were female (50.2\%) and 3,750 were male $(49.8 \%)$.

Table 4

Comprehensive Sample Totals

\begin{tabular}{llllll}
\hline Total N & Af. Am. & Latino & White & Male & Female \\
\hline 7,533 & 805 & 311 & 6,417 & 3,750 & 3,783 \\
\hline
\end{tabular}

Further breakdown indicated that for students who took GEN 101 in the fall of their first year and earned a C or better, 392 were African American (13\%), 154 were Latino (5.1\%) and 2,463 were White (81.9\%). Of these 1,368 were male (45.5\%) and 1,641 were 
female $(54.5 \%)$. Of the 97 participants who took GEN 101 in the spring, 15 were African American (15.5\%), 3 were Latino (3.1\%), 79 were White (81.4\%), 65 were male (67\%) and 32 were female (33\%). There were 4,427 students who neither took GEN 101 in the fall nor the spring of their first year. Of this group, 398 were African American (9\%), 154 were Latino (3.5\%), and 3,875 were White (87.5\%). Of this group, 2,317 (52.3\%) were male and 2,110 (47.7\%) were female.

Table 5

Descriptive Characteristics Across GEN 101 Completion Groups

\begin{tabular}{lllllll}
\hline GEN 101 Completion & $\mathrm{N}$ & Af. Am. & Latino & White & Male & Female \\
\hline Fall of First Year & 3,009 & 392 & 154 & 2,463 & 1,368 & 1,641 \\
Spring of First Year & 97 & 15 & 3 & 79 & 65 & 32 \\
Not Taken First Year & 4,427 & 398 & 154 & 3,875 & 2,317 & 2,110 \\
\hline Totals & 7,533 & 805 & 311 & 6,417 & 3,750 & 3,783 \\
\hline
\end{tabular}

When considering sample size, it is important to use as large a sample as possible in order to decrease sampling error (Creswell, 2012). It also is important to keep in mind that inflated statistical significance can be found with increased sample numbers. When considering the difference between the numbers of African Americans versus Latinos versus Whites in each GEN 101 completion category, it is clear that statistical significance may be compromised. This concern will be minimized, however, by keeping the main discussion of this study between fall completers and non-completers where the numbers do not drastically deviate.

An analysis of the ACT variable revealed the ACT scores of the study participants ranged from $12-35$ for those who took it in the fall, $17-34$ for those who took it in the spring, and 15- 36 for those who did not take GEN 101 their first year.

Table 6 
ACT Composite Scores Across Completion Groups

\begin{tabular}{ll}
\hline GEN 101 Completion & ACT Score Range \\
\hline Fall of First Year & $12-35$ \\
Spring of First Year & $17-34$ \\
Not Taken First Year & $15-36$ \\
\hline
\end{tabular}

There is a reasonably congruent range between non-completers and those who took it in fall; however, variances within groups were slightly greater. Disaggregated data showed the following ranges of ACT scores for the perspective groups: African American (1230 for fall completers, 17 - 25 for spring completers, and $15-33$ for non-completers); Latino (16 - 33 for fall completers; 22 - 26 for spring completers, and 17 - 36 for noncompleters); and White (16 - 35 for fall completers, 19 - 34 for spring completers, and 16 - 36 for non- completers). The lowest ACT scores were seen in the African American group. A priori theory holds that lower standardized test scores are more prominent for those identifying with racial/ethnic minority groups (Thompson \& Fretz, 1991), but this did not hold true for Latinos in this particular sample. Also noteworthy is that in this sample, students taking the GEN 101 course in the fall had lower ACT scores overall when compared with those who took the course during a later semester.

Table 7

Comprehensive ACT Ranges by Race/Ethnicity

\begin{tabular}{ll}
\hline GEN 101 Completion & ACT Score Range \\
\hline African American & $12-33$ \\
Latino & $16-36$ \\
White & $16-36$ \\
\hline
\end{tabular}


The current study used a sampling frame of full time, first time freshman students at UofL who either took or did not take GEN 101 their first semester to generalize findings to all full time, first time freshmen at UofL who are not international students. The sampling frame had GEN 101 enrollment patterns as the common characteristic of analysis. A sampling frame is a list of available people from which the study sample is taken and from which a representative sample is drawn to represent a greater population (Creswell, 2012). Since I am a student at the UofL and also was employed here at the onset of the data collection, the sample used is a convenience sample. The data was easily accessible and I had prior knowledge of the GEN 101 concerns due to my involvement with TRIO Student Support Services and with campus retention committees and initiatives. It was my exposure to the course and my work in increasing retention at UofL that ultimately led me to this study topic.

Although convenience sampling is less daunting than other types of sampling techniques, it has some limitations. The first and most obvious in this study would be the inability to freely generalize any of the study findings to college students attending other colleges and universities. A second issue with convenience sampling would be its nonprobabilistic nature (Creswell, 2012). Due to the lack of random sampling employed in convenience sampling, the probability of being able to extrapolate results to a greater population is small; however, since this study is intentionally narrow in that it analyzes outcomes of one unique course at one specific institution, the non-probabilistic nature is less of a concern since it is meant to inform curricula at UofL and not elsewhere. However, since UofL FYE course is similar in content and purpose as other courses in different institutions, it can be used to inform FYE curriculum and design on a broader 
level in conjunction with other studies, but with caution. The concerns surrounding convenience sampling will be discussed in greater detail in the limitations section of this study.

\section{Procedures}

Once the data were secured from IR, the data were cleaned and students with missing data were removed. String variables like race, gender, first generation status, and campus residency were recoded in SPSS version 22 to reflect a numeric value. Variables were then analyzed for descriptive statistics to determine representative participants in each ethnic/racial category and binary gender categories. A multiple regression analysis was then run to identify predictors of first semester college GPA and a logistic regression to identify predictors of fall-fall retention.

As with all studies, study validity was a concern. History, maturation, regression, mortality, and selection are all potential threats to internal validity (Creswell, 2012). Fortunately, mortality was not a threat due to the ex post facto nature of the data, nor was regression since there were no pre- and post-tests administered as part of the study design. To address the threat of history, which is defined as the passing of time between GEN 101 completion and the collection of data, college GPA data utilized in this study is a timely reflection of end of first semester grades. However, it is important to mention that GEN 101 is an eight week course, and there is no way of determining what influence eight weeks without enrollment in a GEN 101 course during the latter half of the semester might have on participants. This will be discussed at greater length in the limitations section of this study. Another method I used to reduce threats to internal validity was removing participants from the study if they did not successfully complete 
the course with a $\mathrm{C}$ or better. It is important to note here that a recent study from the University of Arizona found that students who earn a $\mathrm{C}$ in gateway courses are significantly less likely to graduate than students who earn A's or B's (Kovacs, 2016). In addition, federal data indicates that first-generation, low-income, underrepresented students are least likely to do well in gateway courses (Kovacs, 2016). As such, it can be argued that earning a $\mathrm{C}$ in GEN 101 should not be used as a measure of success.

Nonetheless, a $\mathrm{C}$ average, or a 2.0, is the minimum GPA required for graduation from UofL, so using $\mathrm{C}$ as the measure of success for GEN 101 aligns with UofL guidelines for success and is therefore an apt measure for this study. Since the course itself is used as a variable in both regression models in the study, successful completion of it is necessary. Measuring GPA immediately at the end of the first semester and utilizing $\mathrm{C}$ as the baseline measure of success reduced chances of additional unmeasured interventions influencing study outcomes. Maturation was not a significant issue in this study since all participants were of the same grade level and presumably between the ages of 17 and 19; however, there is no way to control for the rates unique individuals within each group might mature.

\section{Statistical Analysis}

To address the three research questions proposed earlier in this chapter, regression analyses were used. Since empirical studies measuring FYE academic outcomes include or focus on fall-to-fall retention and end of semester college GPA (Jamelske, 2009; Potts \& Schultz, 2008; Raymondo, 2003) and since they are directly tied to FYE outcomes, they are appropriate as dependent variables in the regression models. 


\section{CHAPTER IV}

\section{RESULTS}

The purpose of this study was to determine if there is a relationship between successful completion of GEN 101, fall-to-fall retention, and first semester GPA across race/ethnicity and gender. This chapter provides results of whether successful GEN 101 completion is correlated with increased fall-to-fall retention the first semester after immediately taking the course. It also provides results regarding the correlation between successful GEN 101 completion and increased first-semester GPA and if race/ethnicity and gender has a significant influence on the dependent variables. In this chapter, results from a number of analyses aimed at addressing the research questions are provided, including cross tabulations, multiple regression, and logistic regression.

\section{Variables Used in the Regression Models}

First semester college GPA and fall-to-fall retention were the dependent variables of this study. SES, first generation status, fall-to-fall retention, campus residency, gender, race, GEN 101 completion, high school GPA, and ACT scores were the independent variables entered into the model. Table 8 outlines the definition of these variables.

Table 8

Variables in the Regression Model

Variable

\section{Definition}




\section{Dependent Variables}

First semester GPA

Fall-to-fall retention

Independent Variables

ACT score

High school GPA

Campus residency

SES

Gender

Race/ethnicity

White

African American

Latino

GEN 101 Completion

Fall

Spring

None

First generation

Cumulative GPA after first semester of matriculation (i.e. fall GPA).

Enrollment status in the fall after first year of matriculation.

ACT composite score.

Unweighted high school GPA as reported on high school transcripts submitted to UofL.

Status of a student living on campus ( $1=$ yes, $2=$ no).

Low-income status as determined by Pell eligibility (1=yes, $2=$ no).

Gender reported by institution $(0=$ female, $1=$ male $)$.

Students having origins in any of the original peoples of Europe, the Middle East, or North Africa as White $(0=$ White). Whites served as the reference category. Students having origins in any of the black racial groups of Africa (1 =African American Students of Cuban, Mexican, Puerto Rican, South or Central American, or other Spanish culture or origin, regardless of race ( $2=$ Latino).)

Students who completed GEN 101 during the fall semester of their first year $(0=$ fall $)$

Students who completed GEN 101 during the spring semester of their first year (1=spring)

Students who did not take GEN 101 in their first year (2=none).

Students whose parents have earned a college degree (including Associate's degree) $(1=$ yes, $2=$ no)

\section{Descriptive Statistics}

The students in the sample were grouped into three categories: (a) those who completed GEN 101 in the fall, (b) those who completed it in the spring, and (c) those who did not take GEN 101 during their first year at UofL. Students who took GEN 101 during the spring semester are not the focus of this study, but are referenced in this 
chapter nonetheless. After running an initial descriptive statistical analysis, I was able to confirm Kathryn Adamchik's statement that the majority of first time students enroll in GEN 101 their first semester ( $n=3,009$ for fall compared with $n=97$ for spring) (K.

Adamchik, personal communication, June 14, 2016). Across the three cohorts included in this analysis, an unexpected finding was the number of first year students not taking GEN 101 any semester during their first year $(n=4,427)$ exceeded those who did.

\section{ACT Score and High School GPA Distributions}

As shown in Table 9 students who did not take a GEN 101 course their first year of college had a higher mean ACT score than those who took it in their first semester $(M$ $=26.23, S D=3.97 ; M=23.69, S D=3.491$ respectively). Descriptive statistics revealed students who chose to take the course in the spring had the lowest mean ACT score $(M=$ 23.49, SD 3.28) across the three groups. The same trend was seen in high school GPA with the spring completers having the lowest average $(M=3.21, S D=.51)$ and those not taking it during any semester of their first year having the highest average $(M=3.63, S D$ $=.44)$.

Table 9

Academic Characteristics of Students by Timing of GEN 101 Completion

\begin{tabular}{lllll}
\hline GEN 101 Completion & Variable & $\mathrm{N}$ & $\mathrm{M}$ & $\mathrm{SD}$ \\
\hline Fall & ACT Score & 3,009 & 23.69 & 3.49 \\
& High School GPA & 3,009 & 3.43 & .45 \\
Spring & ACT Score & 97 & 23.49 & 3.28 \\
& High School GPA & 97 & 3.21 & .51 \\
None & ACT Score & 4,427 & 26.23 & 3.96 \\
& High School GPA & 4,427 & 3.62 & .44 \\
\hline
\end{tabular}

\section{Socioeconomic, First Generation, Residency, and Retention Distributions}


Looking at GEN 101 enrollment by socioeconomic status (SES), first generation status, and residency, I find that most low SES students (as measured by Pell eligibility) enrolled in the spring semester (48\%) followed by the fall semester (42\%) (Table 10). Only $32 \%$ of low SES students did not take GEN 101 their first year. The fall semester showed the highest percentage of first generation students $(20 \%)$ enrolled. Students who completed GEN 101 in the fall also were retained at slightly higher rates than spring completers and non-completers (80\%, 78\%, and 78\% respectively) (Table 10).

When I analyzed campus residency using individual cohorts, the statistics fluctuated. In the fall 2012 cohort, the highest percentage of students living on campus did not take GEN 101 anytime during their first year (23\%). For the fall 2013 cohort, the highest on-campus percentage were those taking the course in the spring (31\%), but changed with the fall 2014 cohort, with the lowest percentage taking it in the spring (19\%) and the highest not taking it at all (32\%). Although it is useful to see the breakdown by cohort year, the differences between each cohort did not change any findings or conclusions of the study.

Table 10

Group Comparisons: Frequencies Based on Low SES, First Generation, Residency,

\section{Retention}

\begin{tabular}{llll}
\hline & Fall & Spring & None \\
\cline { 2 - 4 } Low SES & \multicolumn{3}{c}{ Percent } \\
First Generation & 20 & 48 & 32 \\
On-campus Residency & & 20 & 17 \\
2012 & 22 & & \\
2013 & 26 & 15 & 23 \\
2014 & 27 & 31 & 29 \\
Fall-to-fall Retention & 80 & 19 & 32 \\
\hline
\end{tabular}


As shown in Table 11, a crosstabulation between campus residency and fall-tofall retention revealed that across all three cohorts, students who lived on campus were retained at higher rates, regardless of GEN 101 completion status; however, the fall 2012 cohort showed the smallest difference. Seventy-nine percent of students in the fall 2012 cohort who lived on campus were retained through the following fall and $78.8 \%$ of offcampus students were retained over the same timeframe. For the fall 2013 cohort, fall-tofall retention rates for on-campus residents rose to $86 \%$ in comparison to $76 \%$ for offcampus students. In fall $2014,84.5 \%$ of students who lived on-campus were retained through the next fall in comparison to $76.6 \%$ of those who lived off-campus.

Table 11

Retention by Campus Residency and GEN 101 Completion Across Cohorts

\begin{tabular}{lcc}
\hline Participant Cohort & On-campus Retention (\%) & Off-campus Retention $(\%)$ \\
\hline Fall 2012 & 79 & 78.8 \\
Fall 2013 & 86 & 76 \\
Fall 2014 & 84.5 & 76.6 \\
\hline
\end{tabular}

A comparison between Tables 10 and 11 indicate a one percent difference in retention rates between on-campus students overall vs. on-campus students who took GEN 101 in the fall (79\% vs. $80 \%$ respectively). This indicates only a slight difference between retention rates when GEN 101 completion is considered along with campus residency across all three cohorts.

\section{Race and Gender Descriptives}

After running a cross tabulation with cases sorted by race, gender, and GEN 101 completion, findings indicated that racial/ethnic minority students may have the greatest benefit from taking GEN 101 courses when compared with White students. Findings also 
suggest male students, regardless of race or ethnicity, are more susceptible to lower retention rates. Across all three cohorts, African American female students who took GEN 101 in the fall were retained at higher rates than those who did not take it at all during their first year ( $84 \%$ vs. $80 \%$ respectively) (Table 12). This also was the case for African American male students (83\% vs. $72 \%)$. Across all three cohorts, there was no difference in retention rates for Latina students who took GEN 101 in the fall and those who did not take it during their first year (79\% vs. 79\%). For Latino students, those who took GEN 101 in the fall were retained at higher rates than those who did not take it during their first year (79\% vs. $73 \%$ respectively). Across all three cohorts, White female students who took GEN 101 in the fall were retained at lower rates than those who did not take it at all during their first year $(79.5 \%$ vs. $81 \%)$. White male students who took GEN 101 in the fall had similar findings to their female counterparts with lower retention rates for those taking GEN 101 in the fall when compared with those who did not take it their first year (78\% vs. 77\%) (Table 12).

Table 12

Descriptive Statistics, Retention by Race, Gender and GEN 101Completion Status

\begin{tabular}{lccc}
\hline & African American & Latino & White \\
\cline { 2 - 4 } Male, GEN 101 Fall Completion & \multicolumn{3}{c}{ Retention (\%) } \\
Yes & 83 & 79 & 78 \\
No & 72 & 73 & 77 \\
Female, GEN 101 Fall Completion & & & \\
Yes & 84 & 79 & 79 \\
No & 80 & 79 & 81 \\
\hline
\end{tabular}

\section{Regression Analysis}


This study utilized multiple and logistic regression analysis to predict the outcome variables, which were first semester GPA and fall-to-fall retention. Regression analysis requires assumptions of independence of observations, normal distribution, a linear relationship between the dependent variable and the predictor variables, no multicollinearity, and homoscedasticity (Stevens, 2009). According to Stevens, (2009), the assumption of independence of observations is very important for any analysis involving ANOVA and MANOVA (as is the case with regression). Although ensuring that observations are normally distributed also are important, he indicates that violating this assumption will have only a slight effect on significance levels. Stevens also asserts that although we assume a linear model is appropriate when predicting the relationship between independent and dependent variables, it is possible a more complex model like a curvilinear model may be needed to predict the outcome variable more accurately. As such, a perfectly linear relationship may not always be tenable.

Multicollinearity occurs when there is a reasonably high intercorrelation among predictor variables (independent variables) in a regression model. According to Stevens (2009), a violation of this assumption can pose a serious problem to a researcher for three reasons: (a) because the predictors in the model are fighting for the same variance, it will significantly limit the size of $R$, (b) it confounds variables in a model, making it difficult for the researcher to determine the importance of any given variable, and (c) it increases the variances of the regression coefficients, making the prediction equations unstable. The last assumption of homoscedasticity or homogeneity of variance becomes more important when working with unequal group sizes as is the case with this study. A violation of this assumption can result in more liberal $F$-statistics leading to a higher 
probability of rejecting the null hypothesis e often than we would like, but many researchers do not find this too serious of a problem (Stevens, 2009).

\section{Test of Assumptions}

Before running the regression models, regression assumptions of independence of errors and of observations, normal distribution, a linear relationship between the dependent variable and the predictor variables, no multicollinearity, and homoscedasticity were tested. The independence of observations assumption was met through the research design since each case is that of an individual student and no cases are repeated in the data set. A Durbin-Watson test for independence of errors revealed a test statistic of 1.946. This test statistic demonstrated independence of errors since values closer to 2 and between 1 and 3 are ideal in regression models as a rule of thumb (Field, 2005). I tested for normal distribution via a visual inspection of a histogram for first semester GPA. It appears that a normal distribution has been met. A normal P-P Plot of standardized residuals indicates the focus predictor variables have a linear relationship with first semester GPA. A visual inspection of the plot of standardized residuals with a fit line resulted in a flat fit line indicating homoscedasticity was not violated. Lastly, an examination of tolerance values for the focus variables GEN 101 completion, race/ethnicity, and gender and also for the remaining predictor variables indicate a variance inflation factor (VIF) of 1 , so multicollinearity also was not an issue in the model.

\section{Pearson Correlation for Multiple Regression Model}

Before completing the multiple regression, I ran a 1-tailed Pearson Correlation to test the strength of the model using variables of race/ethnicity, gender, GEN 101 
completion, and first-semester college GPA and to determine if they were appropriate to include in the model. With the $\mathrm{p}$-value set to $p=.01$, Table 13 illustrates a significant positive correlation was found between race/ethnicity and first-semester college GPA, $r=$ $.064, p=.000$. No significant correlation was found between GEN 101 completion and first-semester college GPA, $r=-.001, p=.479$. A significant negative correlation was found between gender and first-semester college GPA, $r=-.147, p=.000$. Although a negative correlation can at times create a suppressive effect on other predictors potentially weakening a regression model, gender will still be included in the model since it is a key variable of interest.

Table 13

Multiple Regression Correlation: Racelethnicity, GEN 101 Completion, Gender, and First Semester College GPA

\begin{tabular}{lllll}
\hline & GEN 101 & Race/ethnicity & Gender & Colleg \\
\hline & \multicolumn{4}{c}{ Correlations (r) } \\
\cline { 2 - 4 } GEN 101 & 1.000 & $.075^{*}$ & $.066^{*}$ \\
Race/ethnicity & $.075^{*}$ & 1.000 & $.07^{*}$ \\
Gender & $.066^{*}$ & $.057^{*}$ & 1.000 \\
First Semester College GPA & -.001 & $.064^{*}$ & $-.147^{*}$ \\
\hline
\end{tabular}

*significant at $p=.01$; dependent variable is First Semester College GPA

\section{Multiple Regression}

I ran a multiple regression analysis to determine the main variables that predict first semester college GPA. The first variables entered in model 1 were the main study variables of race/ethnicity, gender, and GEN 101 completion. They were entered using the ENTER method. The adjusted $\mathrm{R}^{2}=.026$ or $2.6 \%$ of the variance was explained for first semester college GPA due to the liner combination of the predictors in the model (Table 15, Model One). The ANOVA table indicated an $F$-statistic of $F(3,7529)=$ 
68.946, $\mathrm{p}<.05$. The model was significant at $\alpha=.05, \mathrm{p}<.05$. Standardized coefficients on the SPSS output Coefficients Table indicated gender $(\beta=-.151)$ was a stronger predictor of first semester GPA than race $(\beta=.072)$ or GEN 101 completion $(\beta=.004)$ (Table 14). The unstandardized regression equation is $\hat{y}=2.747+.113$ (race/ethnicity) $+.004(\mathrm{GEN}$ 101 completion) - .300(gender) (Table 14, Model One).

Although previous analyses indicated the model was fit, I ran a second model with all predictor variables entered, i.e. variables of race/ethnicity, gender, GEN 101 completion, first-gen status, SES, campus residency, ACT score, fall-to-fall retention, and high school GPA using forced entry (enter method). According to Field (2005), it is a good strategy to include predictor variables when there are sound theoretical reasons to think they will predict an outcome. I chose to run a second model because each predictor contributes to the model based on a priori theory. All variables were entered into the second model using the ENTER method, i.e. high school GPA, first generation status, gender, race/ethnicity, GEN 101 completion, fall-to-fall retention, SES, ACT scores, and campus housing. The model summary follows:

Table 14

Model Summary and ANOVA Table, Multiple Regression Model 2

\begin{tabular}{ll}
\hline Model 2 & \\
\hline $\mathrm{R}$ & .663 \\
$\mathrm{R}^{2}$ & .439 \\
Adjusted $\mathrm{R}^{2}$ & .438 \\
Standard Error of the Estimate & .7449011924 \\
Change Statistics & \\
R2 Change & .439 \\
F Change & 653.660 \\
Df1 & 9 \\
Df2 & 7514 \\
Sig. F Change & .000
\end{tabular}




\begin{tabular}{lll}
\hline ANOVA & & \\
\hline Sum of Squares & & \\
& Regression & 3264.315 \\
& Residual & 4169.352 \\
& Total & 7433.667 \\
df & & \\
& Regression & 9 \\
& Residual & 7514 \\
& Total & 7523 \\
Mean Square & & \\
& Regression & 362.702 \\
& Residual & .555 \\
F-statistic & & 653.660 \\
Significance & & .000 \\
\hline
\end{tabular}

Table 15 indicates model two resulted in an adjusted $\mathrm{R}^{2}=.438$, indicating approximately $44 \%$ of the variance explained in first semester GPA can be accounted for by the linear combination of the predictors in the model. The ANOVA table shows $F(9,7514)=$ 653.660, $\mathrm{p}<.05$ (Table 13). The model was significant at $\alpha=.05, \mathrm{p}<.05$.

In the Coefficients Table on the SPSS output, all predictors were significant except for race/ethnicity, $p=.836$ (Table 15, Model Two). In fact, race/ethnicity made the smallest contribution to the model, $\beta=-.002$, followed by first generation status, $\beta=$ .034. This was an unexpected finding considering a priori theory suggests racial/ethnic minority students do not typically fare as well academically as their White counterparts (Hunn, 2014). The two predictors that carried the most weight in predicting first semester GPA, were fall-to-fall retention, where $\beta=-.422$, and high school GPA, where $\beta=.326$ (Table 15, Model Two). Results of the second model also indicated campus residency had an inverse predictive effect on first semester GPA. This finding also was surprising because it contradicts much of the existing research that indicates campus residency helps to increase student success outcomes based on increased social and academic integration 
opportunities, but may be explained through a study by DeAngelo (2014), who found that FYE courses are more beneficial for students who live off-campus since they are at greater risk of lowered performance and dropping out after the first year. What was not surprising was that both high school GPA and ACT scores were positively connected to first semester GPA, i.e. the higher those scores, the better we can predict increased first semester GPA. The unstandardized regression equation for model two is $\hat{y}=1.087$ .003 (race/ethnicity) -.091 (GEN 101 completion) -.194(gender) +.019 (ACT score) + $.703(\mathrm{HS}$ GPA $)+.140(\mathrm{SES})-1.028$ (Retention) +.089 (first gen) -.083 (campus housing) In model one and model two, the F-statistics were both significant, but model two had a higher F-statistic indicating it is a better model for predicting the outcome variable (Field, 2005).

\section{Practical Significance and Effect Size}

Adjusted $R^{2}$ is a useful measure of effect sizes in regression (Field, 2005). According to Field (2005), just because a study results in a statistically significant test statistic, it does not mean the effect being measured is meaningful. Effect sizes provide a measure of the importance of a finding, and Pearson's correlation (r) is a useful measure of this ( $\mathrm{R}^{2}$ for regression). Field indicates effect size measures of $\mathrm{r}=.10$ (small effect), $\mathrm{r}$ $=.30$ (medium effect), and $\mathrm{r}=.50$ (large effect). An online PowerPoint for a college statistics course indicates the $\mathrm{R}^{2}$ measure is somewhat different, i.e. $\mathrm{R}^{2}=.01$ (small effect), $\mathrm{R}^{2}=.06$ (medium effect), and $\mathrm{R}^{2}=.15$ (large effect) (jtemplin.coe.uga.edu). In the multiple regression analysis, the main effects model summary (Table 13) indicates the adjusted $\mathrm{R}^{2}$ value was .438 , so approximately $44 \%$ of the variance was explained by the linear combination of the variables in the model. This reveals a large effect size. 
In studies like this one that have large sample sizes, statistical significance will be found in most analyses when alpha is set to .05 (Stevens, 2009). As such, the statistical significance reported throughout this chapter must be viewed cautiously. APA $6^{\text {th }}$ edition indicates "for the reader to appreciate the magnitude or importance of a study's findings, it is almost always necessary to include some measure of effect size in the Results section" (34). This is so the practical significance of the study can be ascertained by the reader. The practical significance helps us understand if statistical significance has any practical implications. Since the effect size of $\mathrm{R}^{2}$ was large, we can ascertain that the findings are important in a practical sense.

Table 15

Models One, Two, and Three Interaction Effects, Multiple Regression Values, $a=.05$

\begin{tabular}{|c|c|c|c|c|}
\hline & $\mathrm{b}$ & $\beta$ & Adjusted $\mathrm{R}^{2}$ & \\
\hline & \multicolumn{3}{|c|}{ Model One } & \\
\hline (Constant) & 2.747 & & .026 & \\
\hline Race/Ethnicity & .113 & .072 & & \\
\hline Gender & -.300 & -.151 & & \\
\hline \multirow[t]{3}{*}{ Gen 101 Completion } & .004 & .004 & & \\
\hline & $\mathrm{b}$ & $\beta$ & Adjusted $\mathrm{R}^{2}$ & \\
\hline & \multicolumn{3}{|c|}{ Model Two } & \\
\hline (Constant) & 1.087 & & .438 & \\
\hline Race/Ethnicity & -.003 & -.002 & & \\
\hline Gen 101 Completion & -.091 & -.089 & & \\
\hline Gender & -.194 & -.098 & & \\
\hline $\mathrm{ACT}$ & .019 & .077 & & .000 \\
\hline High School GPA & .703 & .023 & & .000 \\
\hline SES & .140 & .068 & & \\
\hline Retention & -1.028 & -.422 & & \\
\hline First Gen & .089 & .023 & & \\
\hline \multirow[t]{3}{*}{ Campus Residency } & -.083 & -.038 & & \\
\hline & $\mathrm{b}$ & $\beta$ & Adjusted $\mathrm{R}^{2}$ & \\
\hline & \multicolumn{3}{|c|}{ Interaction Effects Two-Way } & \\
\hline (Constant) & 1.014 & & .439 & \\
\hline Race/Ethnicity & -.015 & -.010 & & \\
\hline Gen 101 Completion & -.068 & -.067 & & \\
\hline
\end{tabular}




\begin{tabular}{llll} 
Gender & -.040 & -.020 \\
ACT & .020 & .079 & \\
High School GPA & .705 & .327 & \\
SES & .140 & .068 & \\
Retention & -1.024 & -.420 & \\
First Gen & .089 & .023 & \\
Campus Residency & -.085 & -.039 & \\
GEN 101*race & .006 & .015 & \\
GEN 101*gender & -.070 & -.093 & Adjusted R ${ }^{2}$ \\
\hline & $\mathrm{b}$ & $\beta$ & \\
\hline & \multicolumn{3}{c}{ Interaction Effects Three-Way } \\
\cline { 2 - 3 } (Constant) & .934 & & .440 \\
Race/Ethnicity & .014 & .007 & \\
Gen 101 Completion & -.068 & -.067 & \\
Gender & -.049 & -.024 & \\
ACT & .020 & .079 & \\
High School GPA & .705 & .327 & \\
SES & .142 & .068 & \\
Retention & -1.023 & -.420 & \\
First Gen & .089 & .023 \\
Campus Residency & -.084 & -.038 \\
GEN 101*race & -.005 & -.011 \\
GEN 101*gender & -.062 & -.082 \\
GEN 101*race*gender & -.052 & -.025 & \\
\hline
\end{tabular}

\section{Interaction Effects}

As previously stated, the F-statistics in models one and two are both significant, but since model two has a higher F-statistic, it is a better model for predicting the outcome variable. As such, I entered two interaction effects in model two: (a) GEN $101 *$ race/ethnicity, and (b) GEN $101 *$ gender. The addition of the interaction effects resulted in another statistically significant model, $p=.000$. The F-statistic was $F(11$, $7512)=537.242$. The interactions of GEN $101 *$ race/ethnicity was not statistically significant, but the interaction of GEN 101 * gender was statistically significant (at $\alpha=.05$, $p=.646$ and $p=.000$ respectively). The model summary follows:

Table 16 


\begin{tabular}{lll}
\hline Interaction Effects & & \\
\hline $\mathrm{R}$ & & .664 \\
$\mathrm{R}^{2}$ & .44 \\
Adjusted $\mathrm{R}^{2}$ & & .439 \\
Standard Error of the Estimate & .7442150809 \\
\hline ANOVA & & \\
\hline Sum of Squares & & \\
& Regression & 3273.100 \\
& Residual & 4160.567 \\
& Total & 7433.667 \\
df & & \\
& Regression & 11 \\
& Residual & 7512 \\
Mean Square & Total & 7523 \\
& & \\
& Regression & 297.555 \\
F-statistic & Residual & .554 \\
Significance & & 537.242 \\
\hline
\end{tabular}

As indicated by adjusted $\mathrm{R}^{2}$, more variance was explained in the interaction effects model when compared with the main effects model $\left(\mathrm{R}^{2}=.439 \mathrm{vs} \mathrm{R}^{2}=.438\right.$ respectively), but the difference did not appear significant. Jaccard, Turrisi, and Wan (1990) indicate "if an interaction effect is present, the difference between the two $\mathrm{R}^{2}$ values should be statistically significant (barring a Type I error)" (21). The significance is tested using a hierarchical multiple regression F-statistic equation (Jaccard, Turrisi, \& Wan, 1990):

$$
\mathrm{F}=\frac{\left(\mathrm{R}_{\text {two }}^{2}-\mathrm{R}^{2}{ }_{\text {one }} /\left(\mathrm{k}_{2}-\mathrm{k}_{1)}\right.\right.}{\left(1-\mathrm{R}_{\mathrm{two}}^{2}\right) /\left(\mathrm{N}-\mathrm{k}_{2}-1\right)}
$$

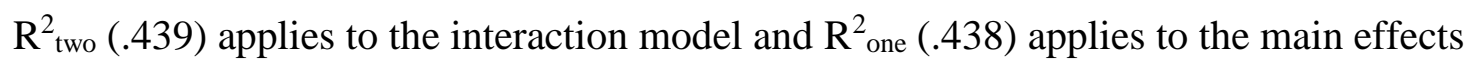
model. The number of predictors in the interaction model is represented as $\mathrm{k}^{2}(11)$ and the number of predictors in the main effects model is $\mathrm{k}^{1}(9)$. $\mathrm{N}$ refers to the total sample number $(\mathrm{N}=7,539)$. After applying the statistics generated by SPSS to the formula above, 
the interaction effects were $\mathrm{F}=6.708$. For three $\left(\mathrm{k}_{2}-\mathrm{k}_{1}\right)$ and 7,527 degrees of freedom $\left(\left(\mathrm{N}-\mathrm{k}_{2}-1\right)\right.$, the difference between the interaction effects and main effects were not significant.

As a means of cross referencing the hierarchical multiple regression test results, I considered ANOVA statistics to determine if the interaction effects model improved upon the main effects model. Field (2005) states that if a regression model is good, then we would expect a large improvement in prediction. This improvement would make the MS regression large and the MS residual small (Field, 2005). The interaction effects model indicated a smaller mean square (MS) regression $\mathrm{MS}_{\text {regression}}=297.555$ than the

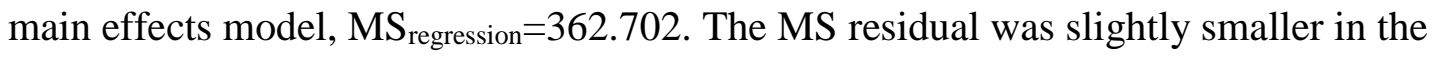
interaction effects model than the main effects model $\left(\mathrm{MS}_{\text {resideual }}=.554 \mathrm{vs}\right.$.

$\left.\mathrm{MS}_{\text {residual }}=.555\right)$. The omnibus F-statistic was smaller in the interaction effects model than in main effects model, $F(11,7512)=537.242$ vs. $F(9,7514)=653.660$ respectively. Although both models were significant at $p=.000$ and allowed me to reject the null hypothesis that all means were equal, both Field (2005) and Jaccard, Turrisi, and Wan (1990) indicate the interaction effects for the multiple regression in this study should be ignored.

Despite findings that my interaction effect model did not add a significant contribution to the original model, in order to directly address my research question, I added one more interaction effect, GEN 101*race*gender to explore if it would create a better model. The new interaction model also was not a significant improvement on the model two main effects model. In the 3-way interaction model, adjusted $\mathrm{R}^{2}=.440$ indicating $44 \%$ of the variance was explained (which does not differ much in a practical 
sense from the $43 \%$ variance explained in the 2-way interaction effects model). Although the new 3-way interaction effects model was also statistically significant, $p=.000$, Fstatistics indicated it had an even smaller F-statistic than the 2-way interaction effects model, $F(12,7511)=493.226$. As such, I will not discuss interaction effects as part of my results.

\section{Logistic Regression Statistics}

A binary logistic regression analysis for main effects was performed to determine the main variables that predict fall-to-fall retention. All predictors. i.e. race/ethnicity, gender, ACT scores, high school GPA, first semester college GPA, SES, first generation status, campus residency, and GEN 101 completion were included in the model using the Enter method. GEN 101 completion, gender, SES, first generation status, campus residency, and race/ethnicity were entered as categorical variables for SPSS dummy coding. The contrast used was "indicator." Baseline reference categories included White (race), male (gender), has Pell (SES), is first generation (first generation status), lived on campus (campus residency), and did not take GEN 101 during their first year in college (GEN 101 completion). The intercept model indicated the model correctly predicted $78.9 \%$ of fall-to-fall retention cases.

The model summary for Block 2 is outlined in Table 16. Nagelkerke $\mathrm{R}^{2}=.376$. Nagelkerke $\mathrm{R}^{2}$ is a pseudo- $\mathrm{R}^{2}$ and does not account for $37 \%$ of the variance explained, but instead represents the reduction (in proportion) of the absolute value of the loglikelihood measure (Table 17). Chi square omnibus tests indicated a statistically significant model, $\chi^{2}(11, \mathrm{~N}=7,539)=2081.648, \mathrm{p}<.05$ (Table 18$)$. The model correctly 
classified $85 \%$ of the cases and the omnibus Hosmer and Lemeshow Test resulted in $\chi^{2}=12.108, \operatorname{df}(8), p=.146$, indicating model fit.

Table 17

Model Summary, Logistic Regression, Block 1

\begin{tabular}{ll}
\hline Block 1 & \\
\hline-2 Log Likihood & 5673.414 \\
Cox \& Snell R & .242 \\
Nagelkerke $\mathrm{R}^{2}$ & .376 \\
\hline
\end{tabular}

Table 18

Omnibus Tests of Model Coefficients, Logistic Regression, Block 1

\begin{tabular}{ll}
\hline Block 1 & \\
\hline Chi-square & 2081.648 \\
df & 11 \\
Sig. & .000 \\
\hline
\end{tabular}

As illustrated in Table 19, standardized regression coefficients showed first semester college GPA, race/ethnicity (specifically identifying as African American), and spring GEN 101 enrollment were the strongest contributors to the model. High school GPA and ACT scores were the weakest contributors, indicating the least predictive ability for fall-to-fall retention.

Odds ratio $(\operatorname{Exp}(B))$ revealed the odds of females being retained after their first year were 1.196 times greater than males (or $19.6 \%$ greater chance to be retained than their male counterparts), all else held constant. The odds of students who identified as African Americans being retained after their first year were .574 that of students who identified as White (or they had a retention rate that was $57 \%$ that of Whites). Table 19 also indicates the odds of students who identified as Latinos being retained after their first year were 
.810 that of Whites (or they had a retention rate that was $81 \%$ that of Whites), all else held constant. We also see that the odds of retention after the first year for students who took GEN 101 in the fall were .917 that of those who did not take it at all during their first year (or they had a first year retention rate that was $91.7 \%$ that of non-GEN 101 takers) and .410 for spring GEN 101 takers as compared with the baseline group (or they had a first year retention rate that was $41 \%$ that of the non-takers).

Table 19 also illustrates some unexpected findings. Specifically, the odds of being retained during the first year decreased for students from higher SES backgrounds (as indicated by non-Pell eligibility) and also decreased for students who do not identify as first generation. The likelihood of students being retained after their first year increased for those who lived off campus, but decreased for any student who lived on campus during their first year of college. The suggestion that students from higher SES backgrounds and non-first generation students have lower first year retention odds may have something to do with loans that students who do not qualify for need-based aid may have to take out. The literature indicates that need-based aid is positively correlated to retention, especially for minority students, so retention can be compromised when students become reliant on loans to pay for college (Chen, 2011; Titus, 2006). In addition, the mandatory freshman live-on policy at UofL means freshmen living off campus likely lived within close proximity of the University. As such, it is possible students who lived off campus did not experience homesickness and related concerns of being away from home for the first time. The literature suggests that homesickness can cause students both retention and GPA issues (Sun, Hagedorn, \& Zhang, 2016; Woosley \& Shepler, 2011). 
Table 19

Binary Logistic Regression, Main and Interaction Effects for Fall-to-Fall Retention

\begin{tabular}{|c|c|c|c|c|c|c|}
\hline Main Effects & $\mathrm{B}$ & S.E. & Wald & df & Sig. & $\operatorname{Exp}(B)$ \\
\hline \multicolumn{7}{|l|}{ Race (White) } \\
\hline Race, African American & -.555 & .118 & 22.034 & 1 & .000 & .574 \\
\hline Race, Latino & -.211 & .167 & 1.583 & 1 & .000 & .810 \\
\hline \multicolumn{7}{|l|}{ Gender (Male) } \\
\hline Gender, female & .179 & .072 & 6.198 & 1 & .013 & 1.196 \\
\hline ACT Score & -.036 & .011 & 10. & 1 & .001 & .964 \\
\hline High School GPA & -.013 & .090 & .020 & 1 & .886 & .987 \\
\hline First Semester College GPA & -1.317 & .041 & 1038.8 & 1 & .000 & .268 \\
\hline \multicolumn{7}{|l|}{ SES, (has Pell) } \\
\hline SES, no Pell & -.258 & .073 & 12.480 & 1 & .000 & .772 \\
\hline \multicolumn{7}{|l|}{ First Generation (is first gen) } \\
\hline First Generation, no & -.158 & .086 & 3.357 & 1 & .067 & .854 \\
\hline \multicolumn{7}{|l|}{ Campus Residency (on campus) } \\
\hline Campus Residency, off campus & .120 & .074 & 2.596 & 1 & .170 & 1.127 \\
\hline \multicolumn{7}{|l|}{ GEN 101 ( none) } \\
\hline GEN 101, fall & -.086 & .073 & 1.404 & 1 & .236 & .917 \\
\hline GEN 101, spring & -.892 & .295 & 9.135 & 1 & .003 & .410 \\
\hline Constant & 3.233 & .334 & 93.582 & 1 & .000 & 25.358 \\
\hline Interaction Effects, Two-Way & $\mathrm{B}$ & S.E. & Wald & df & Sig. & $\operatorname{Exp}(B)$ \\
\hline \multicolumn{7}{|l|}{ Race (White) } \\
\hline Race, African American & -.446 & .162 & 7.546 & 1 & .006 & .640 \\
\hline Race, Latino & -.434 & .252 & 2.971 & 1 & .085 & .648 \\
\hline
\end{tabular}


Gender (Male)

Gender, female

$\begin{array}{llllll}.076 & .096 & .624 & 1 & .429 & 1.079\end{array}$

ACT Score

$\begin{array}{llllll}-.037 & .011 & 11.066 & 1 & .001 & .963\end{array}$

High School GPA

$\begin{array}{lllllll}-.017 & .090 & .034 & 1 & .853 & .983\end{array}$

First Semester College GPA

$\begin{array}{llllll}-1.315 & .041 & 1031.9 & 1 & .000 & .268\end{array}$

SES, (has Pell)

SES, no Pell

$\begin{array}{llllll}-.255 & .073 & 12.078 & 1 & .001 & .775\end{array}$

First Generation (is first gen)

First Generation, no

$\begin{array}{llllll}-.158 & .086 & 3.349 & 1 & .067 & .854\end{array}$

Campus Residency (on campus)

$\begin{array}{llllllll}\text { Campus Residency, off campus } & & .125 & .074 & 2.802 & 1 & .094 & 1.133\end{array}$

GEN 101 ( none)

GEN 101, fall

$\begin{array}{llllll}-.180 & .106 & 2.903 & 1 & .088 & .835\end{array}$

GEN 101, spring

$\begin{array}{llllll}-1.293 & .396 & 10.683 & 1 & .001 & .274\end{array}$

GEN 101(none)*Gender(male)

$\begin{array}{lllllll}\text { GEN 101(fall)*Gender(female) } & .199 & .139 & 2.044 & 1 & .153 & 1.221\end{array}$

$\begin{array}{lllllll}\text { GEN 101(spring)*Gender(female) } & 1.038 & .620 & 2.802 & 1 & .094 & 2.823\end{array}$

GEN 101(none)*Race(White)

GEN 101(fall)*Race (Black) $\quad \begin{array}{lllllll}\text { G } & -.227 & .226 & 1.010 & 1 & .315 & .797\end{array}$

$\begin{array}{lllllll}\text { GEN } 101 \text { (fall)* Race (Latino) } & .395 & .335 & 1.395 & 1 & .238 & 1.485\end{array}$

$\begin{array}{lllllll}\text { GEN 101(spring) * Race (Black) } & .027 & .749 & .001 & 1 & .971 & 1.027\end{array}$

$\begin{array}{llllllll}\text { GEN } 101 \text { (spring) * Race (Latino) } & .614 & 2.465 & .062 & 1 & .803 & 1.848\end{array}$

\begin{tabular}{lllllll} 
Constant & 3.233 & .334 & 93.582 & 1 & .000 & 27.392 \\
\hline Interaction Effects, Three-Way & B & S.E. & Wald & df & Sig. & Exp(B) \\
\hline
\end{tabular}

Race (White) 
Race, African American

Race, Latino

Gender (Male)

Gender, female

ACT Score

High School GPA

First Semester College GPA

SES, (has Pell)

SES, no Pell

First Generation (is first gen)

First Generation, no

Campus Residency (on campus) $\begin{array}{llllll}-.446 & .462 & 7.549 & 1 & .006 & .640\end{array}$

$\begin{array}{llllll}-.434 & .252 & 2.971 & 1 & .085 & .648\end{array}$

$\begin{array}{llllll}.076 & .096 & .627 & 1 & .428 & 1.079\end{array}$

$\begin{array}{llllll}-.037 & .011 & 11.108 & 1 & .001 & .963\end{array}$

$\begin{array}{llllll}-.017 & .090 & .036 & 1 & .849 & .983\end{array}$

$\begin{array}{llllll}-1.315 & .041 & 1032.4 & 1 & .000 & .268\end{array}$

$\begin{array}{llllll}-.254 & .073 & 12.046 & 1 & .001 & .775\end{array}$

$\begin{array}{llllll}-.156 & .086 & 3.270 & 1 & .071 & .856\end{array}$

$\begin{array}{llllllll}\text { Campus Residency, off campus } & .124 & .075 & 2.789 & 1 & .095 & 1.132\end{array}$

GEN 101 ( none)

GEN 101, fall

$\begin{array}{llllll}-.184 & .109 & 2.878 & 1 & .090 & .832\end{array}$

GEN 101, spring

$\begin{array}{llllll}-1.147 & .399 & 8.245 & 1 & .004 & .318\end{array}$

GEN 101(none)*Gender(male)

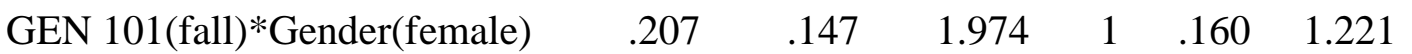

$\begin{array}{lllllll}\text { GEN 101(spring)*Gender(female) } & .573 & .726 & .623 & 1 & .430 & 2.823\end{array}$

GEN 101(none)*Race(White)

$\begin{array}{lllllll}\text { GEN 101(fall)*Race (Black) } & -.180 & .284 & .401 & 1 & .527 & .836\end{array}$

$\begin{array}{lllllll}\text { GEN } 101 \text { (fall)* Race (Latino) } & .366 & .424 & .745 & 1 & .388 & 1.442\end{array}$

GEN 101(spring) * Race (Black) $\quad \begin{array}{lllllll} & -1.078 & 1.244 & .751 & 1 & .386 & .340\end{array}$

$\begin{array}{lllllll}\text { GEN } 101 \text { (spring) * Race (Latino) } & -17.03 & 40192 & .000 & 1 & 1.00 & .000\end{array}$

GEN(none)*Gender(male)*Race

(White) 
GEN(fall)*Gender(female)*Race (Af. Am)
GEN(fall)*Gender(female)*Race (Latino) $\begin{array}{llllll}-.089 & .327 & .075 & 1 & .785 & .914\end{array}$ GEN(spring)*Gender(female)*Ra ce (Af. Am) GEN(spring)*Gender(female)*Ra ce (Latino)

$\begin{array}{llllll}.051 & .449 & .013 & 1 & .910 & 1.052 \\ 2.082 & 1.608 & 1.677 & 1 & .195 & 8.023 \\ 18.130 & 40192 & .000 & 1 & 1.00 & 7475053 \\ 3.313 & .340 & 94.892 & & .000 & 27.474\end{array}$

Constant

Table 20 indicates the CI for the variables in the model.

Table 20

Binary Logistics Regression, Main Effects Confidence Intervals

\begin{tabular}{|c|c|c|}
\hline \multirow[t]{2}{*}{ Main Effects } & \multicolumn{2}{|c|}{ C.I. $95 \%$} \\
\hline & Lower & Upper \\
\hline \multicolumn{3}{|l|}{ Race (White) } \\
\hline Race, African American & .455 & .724 \\
\hline Race, Latino & .583 & 1.125 \\
\hline \multicolumn{3}{|l|}{ Gender (Male) } \\
\hline Gender, female & 1.039 & 1.376 \\
\hline ACT Score & .943 & .986 \\
\hline High School GPA & .827 & 1.178 \\
\hline First Semester College GPA & .247 & .290 \\
\hline \multicolumn{3}{|l|}{ SES, (has Pell) } \\
\hline SES, no Pell & .669 & .891 \\
\hline \multicolumn{3}{|l|}{ First Generation (is first gen) } \\
\hline First Generation, no & .722 & 1.011 \\
\hline \multicolumn{3}{|l|}{ Campus Residency (on campus) } \\
\hline Campus Residency, off campus & .974 & 1.304 \\
\hline \multicolumn{3}{|l|}{ GEN 101 ( none) } \\
\hline GEN 101, fall & .796 & 1.058 \\
\hline GEN 101, spring & .230 & .731 \\
\hline
\end{tabular}

After comparing lower and upper limits for the means in the sample, many of the CI were narrow, which indicated more precise estimates. As outlined in Table 20, the predictors 
with very narrow estimates were ACT scores, campus residency, and first semester GPA. More moderate ranges were based on identifying as an African American, identifying as a first generation student, SES, and gender. The widest ranges were found in identifying as Latino and taking GEN 101 in the spring. A larger percentage of predicators fell in the moderate to narrow range, which alludes to a stronger chance we have captured the population means in the sample.

\section{Practical Significance and Effect Size, Main Effects}

The effect size for logistic regression cannot be ascertained in the same way as multiple regression (i.e. correlation coefficients). Instead, odds ratio is used to determine effect size and practical significance of the magnitude of study findings. The logistic regression main effects model showed statistical significance, but practical significance wavered depending on the variables being analyzed. To illustrate, females had a 1.196 greater chance of being retained after their first year than males $(19.6 \%$ greater chance of retention) and this statistic had a significant p-value in the model. This matters in a practical sense because it suggests an almost $20 \%$ increase in the odds of being retained for females when compared with males. African American students had lower odds of being retained than Latinos and Whites. The statistics for African Americans have more useful application than for Latinos because it indicates UofL is retaining White students at roughly twice the rate of African American students and although Latino students are not being retained at the same rate as Whites, the gap is not that wide. This is supported by the $\mathrm{p}$-value for the Latino variable not having any statistical significance at $\alpha=.05$, $(p=.208)$. The sample size for Latinos was significantly smaller than that of Whites and African Americans, which naturally would affect the practical application of any findings 
for this demographic. If African American students are not begin retained at similar rates of other students, UofL may likely have to revisit retention strategies for this population.

\section{Logistic Regression Interaction Effects}

Although the Omnibus chi-square test for the Block 1 logistic regression model was statistically significant, I included interaction effects based on a priori theory to strengthen the model. The following interactions were added to the model: (a) GEN 101 completion* gender, where males and students not taking GEN 101 in either the fall or spring were used as reference groups, and (b) GEN 101*race, where White students and students not taking GEN 101 in either the fall or spring were used as reference groups. Interaction analysis in logistic regression should use "hierarchically well-formulated" models (Jaccard, 2001). This means all the lower order predicators that are components of the interactions should also be included separately in the model, as was the case of the model in this study. Chi square omnibus tests indicated a statistically significant model, $\chi^{2}(17, \mathrm{~N}=7,539)=2088.912, \mathrm{p}<.05$. Nagelkerke $\mathrm{R}^{2}=.377$ (Tables 20 and 21$)$. The model correctly classified $85 \%$ of the cases and the Hosmer and Lemeshow Test resulted in $\chi^{2}=8.171, \mathrm{df}(8), p=.417$. Since an insignificant $p$-value is desirable for model fit in the Hosmer and Lemeshow Tests of significance, results suggest the main effects model was improved as a result of adding the interaction terms and resulted in a better model fit than the main effects model ( $p=.417$ vs. $p=.146$ respectively); however, hierarchical tests of change should be conducted to test the significance of the model improvement (Jaccard, 2001).

Table 21

Model Summary, Interaction Effects, Block 1 


\begin{tabular}{ll}
\hline Block 1 & \\
\hline-2 Log Likelihood & 5666.150 \\
Cox \& Snell R & .242 \\
Nagelkerke $R^{2}$ & .377 \\
\hline
\end{tabular}

Table 22

Omnibus Tests of Model Coefficients, Interaction Effects, Block 1

\begin{tabular}{ll}
\hline Block 1 & \\
\hline Chi-square & 2088.912 \\
df & 17 \\
Sig. & .000 \\
\hline
\end{tabular}

In order to test the importance of the highest order interaction term (in this case, GEN $101 *$ race), I compared the main effects model with the interaction effects model to analyze the fit. When comparing the main effects logistic model with the interaction effects model, Jaccard (2001) suggests conducting a hierarchical test of changes in the $\chi^{2}$ values of both models and to discount interaction effects if the difference in model fit is trivial. I have included two partial equations based on his proposed ones to illustrate how this would be calculated. The $\mathrm{D}$ values represent dummy coding of the main predicator variables:

$$
\begin{aligned}
& \text { Logit(pie })=\alpha+\beta_{1} D_{F}+\beta_{2} D_{\text {Blackl }}+\beta_{3} D_{\text {Latino }}+\beta_{4} D_{\text {fall }}+\beta_{3} D_{\text {spring }} \\
& \text { Logit(pie })=\alpha+\beta_{1} D_{F}+\beta_{2} D_{\text {Blackl }}+\beta_{3} D_{\text {Latino }}+\beta_{4} D_{\text {fall }}+\beta_{3} D_{\text {spring }}+ \\
& \beta_{4} D_{\mathrm{F}} D_{\text {Black }}+\beta_{5} D_{\mathrm{F}} D_{\text {Latino }} \ldots
\end{aligned}
$$

The first equation relates to the main effects model and the second is a part of the interaction effects model. Jaccard suggests subtracting the $\chi^{2}$ value for the main effects model from the $\chi^{2}$ for the interaction effects model. The $\chi^{2}$ value for the main effects was $\chi^{2}=2081.648(\mathrm{df}=11)$. The $\chi^{2}$ value for the interaction effects model was $\chi^{2}=2088.912$ $(\mathrm{df}=17)$. The value difference is $2088.912-2081.648=7.264$. The degrees of freedom 
are $17-11=6$. As per Jaccard, I consulted a table of critical $\chi^{2}$ values for $\alpha=.05$, with df $=6$ to find the critical value. The critical value is 12.59 (Field, 2005), which indicates the interaction effects have a trivial contribution to the model since the calculated value is smaller than the critical value.

Although my interaction effects model did not add value to the original model, for the sake of addressing my research questions, I added a 3-way interaction term. Like before, in order to test the importance of the highest order interaction term (in this case, GEN 101*race*gender), I compared the main effects model with the 3-way interaction effects model to analyze the fit and ascertain if interaction effects were insignificant (Jaccard, 2001). As per Jaccard, (2001), I repeated the hierarchical test of changes in the $\chi^{2}$ values of the models. Jaccard suggests subtracting the $\chi^{2}$ value for the main effects model from the $\chi^{2}$ for the 3-way interaction effects model. The $\chi^{2}$ value for the main effects was $\chi^{2}=2081.648(\mathrm{df}=11)$. The $\chi^{2}$ value for the 3 -way interaction effects model was $\chi^{2}=2090.884(\mathrm{df}=21)$. The value difference is $2090.884-2081.648=9.236$. The degrees of freedom are $21-11=10$. As per Jaccard, I consulted a table of critical $\chi^{2}$ values for $\alpha=.05$, with $\mathrm{df}=10$ to find the critical value. The critical value is 18.31 (Field, 2005), which indicates the interaction effects has a trivial contribution to the model since the calculated value is smaller than the critical value. Once again, the interaction effects are not worth mentioning and so the main effects model will be my focus.

\section{Summary of Main Results}

Multiple regression analysis was used to determine the prediction strength of GEN 101 completion, race/ethnicity, gender, ACT scores, high school GPA, first 
semester college GPA, SES, first generation status, and campus residency (i.e. model two). Findings suggested fall-to-fall retention was the strongest predictor of first semester GPA $(\beta=-1.028)$, followed by high school GPA $(\beta=.703)$, then gender $(\beta=-.194)$. Gender was the strongest predictor of first semester GPA than either race/ethnicity $(\beta=-$ .003 ) or GEN 101 completion $(\beta=-.091)$. Statistical significance was found in both the main effects model and in the interaction effects model, but omnibus hierarchical tests indicated the difference was trivial. As such, main effects were the focus of discussion.

Binary logistic regression was used to determine the predictive strength of the predictor variables on fall-to-fall retention. First semester college GPA had the greatest predictive strength in the Block 1 model $(\beta=-1.317)$ followed by taking GEN 101 in the spring $(\beta=-.892)$ and identifying specifically as an African American student $(\beta=-$ .555). Odds ratio revealed female students had a $17.9 \%$ greater chance of being retained into their second year than their male counterparts, all else held constant. African American students had less of a chance of being retained than White students, i.e. they had a retention rate that was $57 \%$ that of Whites. Latino students also had less of chance of being retained than Whites, i.e. that had a retention rate that was $81 \%$ that of Whites. Latinos were retained at greater rates than African Americans, indicating that of the three racial categories, African Americans had the smallest chance of being retained into their second year.

Binary logistic regression also suggested that GEN 101 completion did not have as great an effect on retention as it did on first semester GPA. Students who took GEN 101 in the fall had a fall-to-fall retention rate that was $91.7 \%$ that of those who did not take it at all during their first year. Spring GEN 101 takers had a retention rate that was 
$41 \%$ that of the non-GEN 101 takers. These finding suggest that taking GEN 101 in the fall promotes better retention rates than taking it in the spring, but may not be the ultimate solution to retention since non-takers fared slightly better than fall takers and since when the groups were analyzed for student level characteristics of race/ethnicity and gender, spring GEN 101 completion became more significant for the outcome. In Chapter 5, I will discuss how these findings address the research questions this study attempted to answer. 


\section{CHAPTER V \\ DISCUSSION}

The purpose of this study was to predict the impact of FYE programs on firsttime, first year freshmen in terms of first to second year retention rates and GPA, and more specifically whether differences exist by race/ethnicity and gender. I addressed three questions in this research study:

1. How does successful completion of a FYE course predict fall-to-fall first year retention rates and GPA for African American and Latino college students in comparison to White college students?

2. How does successful completion of a FYE course predict fall-to-fall first year retention rates and GPA for college men in comparison to women?

3. How does the intersectionality of race and gender predict fall-to-fall retention rates and GPA for African American and Latino college men and women who successfully complete a FYE course?

\section{Research Question Answers}

In providing an answer to research question one, descriptive analysis suggested that FYE outcomes differed based on race/ethnicity. African American and Latino students appeared to have the greatest benefit from taking GEN 101 courses when compared with White students; however, African American students appeared to have a greater retention benefit when compared with Latino students. African American students 
who took GEN 101 in the fall were retained at significantly higher rates (a $4 \%-11 \%$ increase in retention rates) than those who did not take it at all during their first year while Latino students who took GEN 101 in the fall showed a more modest increase (up to a $6 \%$ increase in retention rates). White students showed a $1.5 \%-2 \%$ difference in retention rates between fall GEN 101 completers and those who did not take it during their first year, which was the most modest increase between the three racial/ethnic groups.

After controlling for variables such as ACT score, high school GPA, first semester college GPA, SES, first generation status, and campus residency in the regression model, the impact of GEN 101 on student outcomes appears to be different than described above. What remained consistent was that regression findings suggested GEN 101 completion did not similarly predict fall-to-fall first year retention rates across race/ethnicity because African American students and Latino students were retained at lower rates than White students, regardless of GEN 101 completion status. As such, even after controlling for variables, African American and Latino students were less likely to persist. In addition to statistical findings that suggest African American and Latino students are less likely to persist in comparison to White students, regression statistics also indicated students who took GEN 101 in the spring, regardless of race, were also less likely to persist than those who took it in the fall. To illustrate, statistical findings suggest taking GEN 101 in the spring may have a negative relationship for retention as evidenced by the negative Beta coefficient for the GEN 101 spring completion variable $(\beta=-.892)$. Additionally, log odds suggest students who took GEN 101 in the fall had a fall-to-fall retention rate that was $91.7 \%$ that of those who did not take it at all during their first year. 
Log odds indicated spring GEN 101 takers had a retention rate that was $41 \%$ that of the non-GEN 101 takers. These findings suggest taking GEN 101 in the fall is associated with greater odds of fall-to-fall retention when compared with taking GEN 101 in the spring.

In addition to the question of race/ethnicity as it relates to fall-to-fall retention, research question number one also explores the association of GEN 101 and race/ethnicity as they pertain to first semester college GPA. When accounting for GEN 101 completion, regression statistics findings suggested race/ethnicity had a very small negative association with first semester GPA when compared with the other variables in the model $(\beta=-.002)$ and was the only variable with no statistical significance. High school GPA and fall-to-fall retention had the strongest statistical association. The moderating effect of GEN 101 on race/ethnicity is challenging to discuss. Recall that in Chapter 4, although the interaction effects model was significant, the interaction effect specific to GEN 101 crossed with race/ethnicity was not significant ( $p=.646)$ and did not strengthen the model. Hierarchical tests did not warrant further analysis of the interaction model, and as such, do not warrant a detailed discussion of the interaction results. However, what is warranted is a discussion of why GEN 101 completion does not appear to have a significant association with first semester GPA when the interaction of race/ethnicity are considered. Although some of the literature indicates race/ethnicity is not a strong mediating variable for FYE outcomes (Rogerson and Poock, 2013), these findings still were unexpected because much of the extant literature suggests African American and Latino students traditionally do not perform as well academically as their 
White counterparts (Harper, 2015; Hunn, 2014) and FYE interventions like GEN 101 can mediate this difference (Berry, 2014; Jamelske, 2009).

The literature indicates, however, that there are many variables at play for racial/ethnic minority students as it pertains to academic performance. As such, it is likely, I did not capture all the variables in the regression model associated with academic performance for African American and Latino students. This may explain why the interaction effects mentioned in the preceding paragraph did not improve the regression model in a statistically significant way. To illustrate how the regression model may not capture all the variables that are associated with academic performance, consider that minority students attending PWIs like UofL often deal with issues surrounding racial stereotypes that drain energy that could be invested instead in academic studies (Harper, 2015; Osborne, 2001). One specific example is that African American males who attend public research universities like UofL are presumed to have gained admittance through athletic prowess and not academic ability and may be treated differently by peers, faculty, and staff as a result (Harper, 2015). Harper (2015) and Osborne (2001) discusses the idea of "stereotype threat," defined as a threat that arises when a minority student is afraid of being judged based on stereotypes about the racial/ethnic group to which they identify. They espouse fear of confirming negative misperceptions can generate negative performance outcomes. Specifically, stereotype threat increases anxiety in minority students, which for African American and Latino students resulted in lower test scores than for Whites (Osborne, 2001).

If you recall the discussion of the purpose of FYE courses outlined in Chapter 1, they are primarily designed to increase academic performance and retention rates via 
opportunities for academic integration and social integration (Goodman \& Pascarella, 2006; Rogerson \& Poock, 2013-2014). However, despite the increased number of racial/ethnic minority students and women attending college, the main structure of FYE has not changed much from what was intended to serve White, middle- or upper-class males (Barefoot, 2000). For African American and Latino students, this can create lack of institutional fit (Barefoot), which negates the purpose of FYE programing for students belonging to these groups. To illustrate, if the stereotype threat discussed in the preceding paragraph is a variable at play in this current study, FYE courses like GEN 101 would do little to mediate this effect if its curriculum does not address diversity specific content. This lack of diversity-focused content is particularly significant given that social and academic integration occurs best for racial/ethnic minorities in colleges and universities with a diversity culture (Braxton, 2004; Talbert, 2012; Thompson \& Fretz, 1991; Tierney, 1992, 1999).

In addition to stereotype threat, extant literature identifies additional variables and constructs associated with racial/ethnic minority student outcomes that were not included in the regression models that possibility could have resulted in different study outcomes had they been included. For example, attendance, embeddedness, attrition intention, and attitude were included in a recent study by Prasad, Showler, Ryan, Schmitt, and Nye (2017). Their study focused on how attitude and motivation are associated with academic performance for students who identify as racial/ethnic minorities. Racial/ethnic minority students have lower levels of embeddedness, i.e. connections in and with their institutions than White students according to study results, which suggests it is an important construct to consider when looking at student outcome associations for racial/ethnic minority 
students. Grit also is a main construct often included in studies assessing student outcomes of GPA and persistence (Akos \& Kretchmar, 2017; Duckworth, Peterson, Matthew, \& Kelly, 2007; Prasad, Showler, Ryan, Schmitt, \& Nye, 2017). Akos and Kretchmar (2017), Duckworth, Peterson, Matthew, and Kelly (2007), and Prasas, Showler, Ryan, Schmitt, and Nye (2017) found increased grit significantly predicted firstyear GPA in college students, i.e. an average student with low grit would likely earn a 3.0 first-year GPA, where an average student with high grit would likely earn a 3.35 (Akos \& Kretchmar, 2017). Duckworth et al. (2007) found increased grit was associated with increased persistence in students at West Point and Akos and Kretchmar found decreased grit was associated with less decisiveness about what to study and increased chances that students would change their majors. Although Akos and Kretchmar did not find significant differences in grit scores across race/ethnicity and gender, they did find that racial/ethnic minorities tended to rate themselves lower on self-reported grit scales than Whites. They explain this phenomena through implicit bias and negative stereotypes that students of the African American community may implicitly believe to be true about themselves, putting another spin on the previously mentioned stereotype threat.

Research question number two considers the moderating effect of GEN 101 completion on retention and first semester college GPA in relation to gender. Descriptive findings suggested FYE outcomes differed based on gender and males benefited most from taking GEN 101 on the retention outcome regardless of race/ethnicity (Chapter 4, Table 12). The greatest benefit percentage-wise, however, was with African American males. Eighty-three percent of African American male GEN 101 completers were retained vs. $72 \%$ of those who did not take GEN 101 during their first year. White males 
revealed the smallest gap percentage-wise in fall-to-fall retention between completers and non-completers. As such, the study suggests FYE outcomes are more strongly associated with male student retention - specifically, for males who identify as African American. This finding did not surprise me because it mirrors that of Bai and Pan (2009) who found FYE outcomes are positively associated with being male. Additional literature indicates males have lower retention rates than females, especially when they are African American or Latino (Wood, 2014). This may be explained by extant research findings that suggest racial/ethnic minority males tend to come from lower income levels than White males, are more likely to be first-generation students, tend to earn lower grades, and tend to devote less time to studying or getting involved in campus activities (Strayhorn, 2014; Wood, 2014). As such, race/ethnicity may likely be serving as a proxy for both SES and first generation variables in the regression model as well as for constructs like motivation and likely would affect regression findings, but more on this later. Keeping in mind that FYE courses are designed to promote academic and social integration and tend to be most beneficial for those most underprepared for navigating college, i.e. first generation students, low-income students, and those entering college with little or no study skills, logically, GEN 101 would then have the greatest outcome for racial/ethnic minority males if the above characteristics hold true.

Regression statistics differed somewhat from the descriptive results outlined in the previous paragraph and suggested female students were retained into their second year at a $7.9 \%$ higher rate than males when GEN 101 was not considered. Based on the literature previously discussed, I anticipated larger baseline retention percentages for female students in general. I suspect the addition of variables like SES and campus 
residency likely played a part in the results since they should have had a mediating effect on retention outcomes even when GEN 101 completion was not considered (Porter \& Swing, 2006; Schudde, 2011). Although taking GEN 101 at any time during the first year was associated with increased fall-to-fall retention rates of females, the increase was not statistically significant. It is worth noting that spring GEN 101 completion for females resulted in fall-to-fall retention odds that were $82 \%$ greater than that of males who did not take GEN 101 at all during their first year.

In relation to first semester GPA, the Means table function in SPSS revealed females had higher mean first semester college GPA's than males $(M=2.94$ vs. $M=2.65$ respectively), regardless of GEN 101 completion status. The effect size was $\eta^{2}=.022$. Field (2013) indicates eta square $\left(\eta^{2}\right)$ can be computed to practical significance (r) using the square root of the eta square value. In this case $\sqrt{ } .022=0.14, \mathrm{r}=0.14$, which results in a small effect size and is not of practical significance. After GEN 101 completion was considered, mean first semester GPA for fall GEN 101 completers regardless of gender was $M=2.81$. The mean first semester GPA for all spring completers regardless of gender was $M=2.24$, and for students not taking GEN 101 at all during their first year regardless of gender, $M=2.80$. Although fall GEN 101 completion was associated with slightly higher first semester college GPA, the effect size of this finding was $\eta^{2}=.004$. Since $\sqrt{ } .004=.06, \mathrm{r}=.06$, these findings suggest that the association of GEN 101 completion as it pertains to first semester college GPA has even less practical significance than the difference in GPA's between males and females alone. Despite having little practical significance, for the sake of gaining a clearer picture of fall GEN 101 completion and its association to first semester GPA as it pertains to gender, I ran a 
case processing summary using SPSS that was limited to the first 100 cases. Results found an association between fall GEN 101 completion and higher mean first semester GPA's for males than females $(M=2.911$ vs. $M=2.76$ respectively $)$. These findings mirror my prior study findings that for males, GEN 101 completion (especially that for fall completers) is associated with better outcomes for males than females.

The third research question attempts to answer the degree to which intersectionality of race/ethnicity and gender predict fall-to-fall retention and first semester college GPA for GEN 101 completers. Descriptive results indicated fall GEN 101 completion was more strongly associated with fall-to-fall retention for African American male students, followed by Latino male students when compared with African American female and Latina counterparts. White male students indicated the smallest benefit of all male groups (i.e. only a $1 \%$ retention gain between those who took GEN 101 in the fall and those who did not take it all during their first year of college) (Chapter 4, Table 11). African American female students had a 4\% retention increase when fall completers were compared with non-completers, but White females did not demonstrate any retention gains from fall GEN 101 completion. Instead, the retention rates decreased $1 \%$ for White females who took GEN 101 in the fall when compared with White females who did not take it at all during their first year (Chapter 4, Table 12). Consequently, it appears GEN 101 fall completion had the most significance within the African American student population, with African American males who completed GEN 101 in the fall being retained at much higher rates (comparatively, with non-completers) than their female counterparts. 
Regression statistics suggested the 3-way interaction effects of GEN 101, race/ethnicity, and gender did not improve the main effects model. Besides not improving on the model, 3-way interactions are difficult to interpret (Karen, talkstats.com). However, for the sake of addressing the research question, I will note here that there were no significant outcomes of the 3-way interactions at $\alpha=.05$, but this model suggests that African American females who take GEN 101 in the fall have an odds ratio that is .914 that of White males who did not take GEN 101 at all (i.e. they had retention rates that were $91 \%$ that of White male non-GEN 101 completers) (Chapter 4, Table 19).

In answering the question about how the interaction effect of GEN 101, race/ethnicity, and gender may be associated with first semester GPA, findings were mixed. The 3-way interaction term was significant at $p=0.17$, but had a negative Beta coefficient ( $\beta=-.052)$. Gender by itself was not significant, but the factor became significant when crossed with GEN $101(\mathrm{p}=.001)$ or with both GEN 101 and race/ethnicity $(\mathrm{p}=.017)$ in an interaction term which indicated gender had some association with first semester college GPA. However, what that association is was unclear in the regression models. If I consider the findings from the Means analysis that indicated females have higher GPA's than males in conjunction with the comparison chart that indicated males have higher GPA's than females after taking GEN 101 in the fall semester, I think I can safely infer that GEN 101 completion influences first semester GPA as it pertains to gender (being a male) when taken in the fall, but determining in the 3-way interaction how race may play a part was more complicated.

Existing literature may offer some insight in the association of race/ethnicity and gender as it relates to GEN 101 student outcomes. The research suggests that cultural 
climates of high schools can privilege one gender over the other in certain subjects (DiPrete \& Buchman, 2013 as cited in Bottia, Giersch, Mickelson, Stearns, \& Moller, 2016) and learning opportunities may be distributed within high schools along gender lines with respect to special education, gifted and talented tracking, and access to various school resources (Aikman \& Unterhalter, 2005; Southworth \& Mickelson, 2007 as cited in Bottia et al. 2016). The research also suggests females tend to have higher GPA's because of self-imposed pressures to do well academically that are based on feeling like imposters in higher education settings (King \& Cooley, 1995). Females also are more likely to suffer from imposter syndrome resulting in a greater need to prove themselves which can be associated with perfectionism and higher GPA (Henning, Ey, \& Shaw, 1998; King \& Cooley). The research also suggests that race/ethnicity plays a large part in how students are tracked in high school (Oakes, 2005; Watanabe, 2008 as cited in Bottia). Extant research also espouses the race/ethnicity and gender of high school students can have an impact on how academic and social opportunities shape them, which in turn affects how prepared they are for college (Lucas \& Berends, 2002; Southworth and Mickelson, 2007as cited in Bottia).

In addition to high school experiences differing by race/ethnicity, like tracking which can affect students' college readiness, extant research indicates there may be a difference between how students are raised based on their race/ethnicity and gender and this difference may be associated with GPA outcomes. Varner and Mandara (2013) note that African American females tend to outperform African American males academically, not only in college, but throughout the entire educational pipeline. Their research suggests this difference is based largely on differential parenting practices that affect self- 
belief and behaviors in adolescent boys and girls. They found African American parents' academic expectations were higher for their daughters than their sons (especially mothers), that parents communicated more with their daughters than their sons, and that this communication was positively associated with higher GPA's. The study also indicated that gaps in GPA and test scores narrowed when parenting practices were more similar (Varner \& Mandara, 2015). However, African American parenting did not completely mediate the effect of gender on GPA because when parenting practices were equal, females still academically outperformed males. Differences in parental treatment of males and females also have been studied in White families with similar results. Specifically, mothers are likely to have more educational expectations for daughters, but grant more autonomy to sons (Raley \& Bianchi, 2006; Tucker, McHale, \& Crouter, 2003).

For Latino families, parenting influences on academic outcomes are more complicated and depend on immigrant status and how traditional the family may be. In more traditional Latino families, research indicates Latinas are likely to be socialized toward modesty and males toward hyper-masculinity (Arredondo, 1991 as cited in Lopez, 2014) which contributes to females entering college with less confidence in their academic abilities and males entering college over confident in their abilities (Lopez, 2014). This overconfidence may help explain why Latinos experience more difficulty with academic and social integration in comparison with Latinas (Lopez) because overconfident students may not initially seek the academic or social support they may need. Lopez indicates that despite different levels of self-efficacy for Latinos and Latinas upon entering college, Latinas tend to gain confidence in their academic abilities during 
their first year of college while Latinos tend to lose confidence based on first year outcomes. Interestingly, being Latina or Latino was not unique to this finding. Females, regardless of race/ethnicity, have increasing academic self-concept (which increased the magnitude of GPA association) the longer they remain in college while males have decreasing academic self-concept (which decreased the magnitude of GPA association) (Cokley, Awad, Smith, Jackson, Awosogba, Hurst, Stone, Blondeau, \& Roberts, 2015). As you can see, for African American, Latino, and White college students, the intersectionality of race/ethnicity and gender can certainly contribute to how prepared and confident a student matriculating to UofL might be. This intersectionality muddies associations of GEN 101 outcomes in complicated ways. My study findings are important in light of the changing racial/ethnic demographics at UofL and across U.S. colleges and universities; however, I propose some cautions to generalizing too broadly to higher education institutions in the next section.

\section{Generalizability}

The findings of this study should only be generalized to students attending UofL who are enrolled in the College of Arts and Sciences. Due to the localized nature of the research, generalizing these outcomes to students enrolled in other FYE interventions, even if they are housed within UofL, is problematic. It also may be unwise to generalize these findings to African Americans and Latinos at UofL without considerations of the differences that exist between subpopulations within racial and ethnic groups. For example, all Black students in the sample were grouped as African American and findings were reported collectively, which does not account for differences of experiences and cultures across Afro-Caribbean groups, Africans, or other Black 
subcultures. Similarly, all Latino students were classified as such and neither race nor specific cultures and experiences were accounted for, which can muddy interpretations of findings. As such, findings specific to race/ethnicity should be generalized to each respective minority groups only with caution. Although I caution against broad generalizability, the results of this study do have some wide practical implications because it directly assesses correlations between FYE interventions and student success outcomes of many U.S. colleges and universities. In this sense, application of study findings is relevant across U.S. institutions. This will be addressed further in the Implications for Practice and Why this Study Matters sections of this chapter. The limitations discussed in the next section also should be considered when generalizing the findings of this study.

\section{Limitations}

Great care was taken to ensure the sample analyzed in this study represented the majority population of African American, Latino, and White first-year students attending the University of Louisville. Non-degree seeking students, part-time students, and International students were removed from the sample to capture more closely the experiences of traditional American college students and align with the samples used in existing literature. Although this study was carefully designed and executed, it has limitations. Five limitations were identified and will be addressed in the first section of this chapter, especially as they relate to study findings previously discussed.

\section{GEN 101 Sample}

Only students who entered UofL in the College of Arts and Sciences (A\&S) were included in this sample. This accounts for $43 \%$ of the undergraduate population (K. 
Adamchik, personal communication, August 29, 2016) which is significant enough to represent the greater student population. As stated in Chapter 3, the majority of first time students enroll in GEN 101 their first semester (K. Adamchik, personal communication, June 14, 2016). Those who enroll in the fall generally have timely admission to UofL and so are scheduled for earlier orientation sessions. This would allow them a greater chance of fitting GEN 101 in their schedules during their first semester. All students are advised and encouraged to take GEN 101 their first semester, and it is arguable that those who do also may be more conscientious students inclined to listen to advisors.

Those who fail to register for the course their first semester may have reasons ranging from schedule conflicts to forgetfulness or over confidence in their abilities to be successful without the course. As such, there may be some innate and unmeasured differences between students who take GEN 101 in the fall versus those who take it in the spring or do not take it at all during their first year. These differences could have muddied the findings of this study. For example, if we are to believe that students who take GEN 101 in the fall are more diligent and conscientious, i.e. they met their obligation of taking the required course early on and they applied to the UofL early which would have provided them better access to the course, we have to keep in mind that the study findings suggesting GEN 101 has better GPA outcomes for fall takers may be a result of unmeasurable mediating effects. However, this does not appear to be a major limitation of the study.

The ACT Composite score has a reliability of .96 and is designed to measure factors most important for college success (Robbins, Casillas, \& Oh, 2008). However, ACT scores for this sample do not indicate the students who took GEN 101 in the fall 
were any more prepared or unprepared for college than those who took it in the spring or those who did not take it their first year. To illustrate, the lowest ACT score of the fall takers was a 12 in comparison to a 15 for the spring takers and a 17 for those who did not take it their first year. One could argue the lowest ACT scores occurred in the fall semester because these students were pushed more deliberately by advisors to enroll in the fall due to their scores. Additionally, the highest ACT score only differed by one point across all three groups indicating limited variation across scores.

What is also noteworthy are characteristics of the types of students who might matriculate under the purview of A\&S. An illustration of this is that students who enroll to UofL with undeclared majors automatically are assigned to A\&S. The literature indicates that some students with undecided majors may have a greater tendency to be academically unprepared, developmentally unprepared, or may intentionally want to dabble in various subjects before making a decision (Reinheimer \& McKenzie, 2011). This inability or unwillingness to declare a major can lead to academic and social disconnection (Reinheimer \& McKenzie). Tinto (1993) espouses that students who are disconnected and who are not socially or academically integrated into a college or university are less likely to be retained than students who matriculate with a major in mind (as cited in Reinheimer \& McKenzie, 2011). This would increase the possibility that students taking GEN 101 may be of a different caliber or in a different place upon matriculation than students taking other non-A\&S FYE courses at UofL and may be important for the implications of curriculum development for the course.

In addition, in comparison to other UofL colleges, A\&S does not require as competitive an ACT score or high school GPA for admission consideration as other 
colleges. To illustrate, the J. B. School of Engineering requires a minimum ACT math and science composite score of 25 and a $3.0 \mathrm{GPA}$ or an ACT math and science composite score of 24 and a 3.5 GPA for admission (Retrieved from http://louisville.edu/speed/admissions/undergraduate). In comparison, A\&S has admitted students with ACT scores as low as 14 and high school GPA's as low as 2.0. Although non-A\&S students are free to take GEN 101 if they choose, it is not a graduation requirement for them and so an overwhelming majority instead enroll in the required FYE courses mandated by their perspective majors.

In sum, due to differences in admissions criteria for A\&S and other UofL colleges, the majors housed under A\&S, and the GEN 101 graduation requirement for A\&S students, an unavoidable study limitation is created. Specifically, the sample used in the study may have lower ACT scores in general than non A\&S students and may have a potential to be underprepared. As such, the results should only be generalized to UofL students outside of A\&S with caution. Despite this, since A\&S enrolls the highest percentage of UofL students, this is mitigated by the fact that the study captures a representative population of UofL students.

\section{The Federal Pell Grant as a Proxy for SES}

A second limitation of this study was using the Federal Pell Grant to capture the SES status of the sample. A Pell grant is awarded to college students using four main criteria: 1) the student's Expected Family Contribution (EFC), 2) the college/university cost of attendance, 3) enrollment status, and 4) if the student enrolls for some or all of the academic year (Retrieved from https://ed.gov/programs/fpg/index.html?exp=0). According to the Department of Education's website, the EFC takes into account what 
the student has earned (and assets if the student is independent), the parents' income and all assets (if the student is dependent), the size of the family's household, and the number of family members (excluding parents) attending college. It is calculated using a formula that accounts for a percentage of net income (remaining income after subtracting allowances for basic living expenses and taxes) and a percentage of net assets (assets remaining after subtracting an asset protection allowance) (Retrieved from https://ed.gov/programs/fpg/index.html?exp=0).

Because the Pell award considers more than just income, it is possible for a student from an upper middle class family to be awarded a full or partial Pell. For example, a family of four (two parents and two children) who make $\$ 150,000$ a year can conceivably receive a Pell grant if both children are in college and if the cost of the attendance of those colleges are high. Although using Pell as a low-income proxy is not a flawless way to determine SES, researchers conclude that receipt of a Federal Pell Grant is a reasonable proxy to determine a student's income bracket (Baum \& O’Malley, 2003; Ehrenberg, Zhang, \& Levin, 2005; Guida \& Figuli, 2012; Heller, 2002).

\section{First-Generation Status}

First-generation status at UofL is determined from admission applications and is self-reported. Self-reported data can be problematic because it is not validated and the researcher must trust that the information is accurate and consistent across the board. In this study, it is possible that students failed to self-report as first-generation or that they falsely self-identified as first-generation, especially if they did not clearly understand the definition of a first-generation student when filling out the college application. Since it is not feasible to determine the accuracy of this variable, the questions of whether a student 
in the sample is really first-generation would be a fair one. However, according to Baird (1976), Laing, Sawyer, and Noble (1988), and Noble and Sawyer (1988), the accuracy of self-reported background data is high when the information being sought after is transparent and clearly worded (as cited by Gonyea, 2005).

\section{Convenience Sampling}

Convenience sampling was used in this study. As a former employee of UofL who worked one-on-one with students in the TRIO Student Support Services program, data for the study was easily accessible up until my departure from the institution, which influenced my choice to focus on the FYE course specifically offered at UofL as opposed to another institution. One of the limitations of convenience sampling is it may produce a situation where a researcher cannot be fully sure that individuals in the sample represent the population (Creswell, 2012). However, since the sample represents first year UofL students in A\&S across three individual cohorts and the study is intended to predict outcomes for first year UofL students in A\&S, the sample is directly drawn from the population it is intended to study. For this reason, it is safe to assume this limitation was mitigated.

\section{Threats to Internal Validity}

GEN 101 is an eight-week course that occurs during the first half of the semester in which it is given. This course structure in addition to the variances in course delivery across sections lends itself to threats to the internal validity of the study. According to Creswell (2012), threats to internal validity are problems in drawing correct inferences about whether the covariation between the independent variable(s) and the outcome 
variable(s) reflects an actual relationship, causal or otherwise. There is one threat to internal validity identified in this study, which is history.

History is defined as the passing of time between the start of a study and the end or between a pretest and posttest or any activity that may influence the outcome of a study (Creswell, 2012). It was a threat to this study because of the time that passed for individuals in the sample after the eight weeks GEN 101 was completed. Roughly eight more weeks of the semester remained after the end of the course. During those eight weeks, possible events, lessons, discussions, or interventions may have occurred in the lives of the individuals of the sample that could have influenced their first semester GPA or retention. Given the study findings indicated fall semester GEN 101 completers received statistically significant GPA impact, it may be fair to question other interventions or occurrence a first year student might encounter during the latter half of the semester that might influence GPA as well. For example, tutoring or supplemental instruction may have been sought after by some of the students in the sample after midterms. History becomes even more significant for spring completers and those who do not take GEN 101 at all during their first year.

One of the ways the literature suggests mediating threats to internal validity is to have individuals in the sample undergo the same activities from start to finish (Creswell); however, due to the ex post facto nature of this study, this was not possible. One of the ways the study design mitigated this threat was by limiting the cohorts included in the model (i.e. only three) and thereby avoiding as much noise in the model as possible. Similar studies follow students over the course of many years and also use data obtained from IPEDS over many more cohorts. 


\section{Threats to External Validity}

Threats to external validity occur when problems that threaten a researcher's ability to make inferences from a sample and correctly apply it to a population exists, which can affect generalizability (Creswell, 2012). In this particular study, the existing threat to external validity can be seen as an issue between the interaction of when and where the GEN 101 courses are held and the actual delivery of the course - or what Creswell (2012) refers to as "interaction of setting and treatment." Delving deeper, this becomes a limitation of fidelity. This is an uncontrollable limitation, but a very significant one to mention.

Fidelity is defined as the extent to which the delivery of an intervention adheres to the original program model (Mowbray, Holter, Teague, \& Bybee, 2003). In simpler terms, fidelity means conformity across all administrations of a treatment - or in the case of this study - conformity across all sections of GEN 101 courses. In a study like this where findings suggest program or intervention effectiveness, fidelity is key. The significance of measuring or being able to ensure fidelity is important given the rising demand of professionals to utilize evidence-based practices (Mowbray et al.). It becomes even more important if the findings from this research are used to inform GEN 101 practices at UofL moving forward.

In GEN 101 courses, fidelity is encouraged through syllabi that contain mandated course content and materials. Staff are trained to teach GEN 101 (and thus are normalized in some way) and syllabi is reviewed and approved by A\&S leadership to ensure conformity of activities, lessons, and subject matter; however, there are differences across GEN 101 sections that organically exist: (a) Instructors have their own delivery styles 
and personal characteristics and form different relationships with students, (b) there are differences in the time of day each section is held and how often and how long each class is per week, (c) there are also differences in how the class content is administered, and (c) instructors still have subjective authority over grading.

Another possible area where fidelity can be compromised in GEN 101 courses is through "program drift" which the literature indicates is common in community settings like a classroom (Mowbray, Holter, Teague, \& Bybee, 2003). During any given class period, a lesson may take on various lives across sections due to student makeup, instructor personality, and direction of classroom discussion. There is no way for me to measure if "program drift" occurred in the GEN 101 courses individuals in the selected sample attended.

Threats to external validity is mitigated in this study via the choice of using GEN 101 as my course of reference given its fidelity construct. It is also mitigated by my choice to study only one FYE intervention at one institution. Since the literature indicates that "programs are usually not static and often undergo substantial changes overtime" (Mowbray, Holter, Teague, \& Bybee, 2003), compromises to fidelity is also limited by my choice to focus on only three specific cohorts matriculating right after the other (i.e. cohorts 2012, 2013, and 2014), thus increasing the chances that the content of the GEN 101 FYE courses were more similar to each other than different. Limitations and limited generalizability previously discussed do not indicate this study was not an important one because there exists many implications for practice across various colleges and universities.

\section{Implications for Practice}


Despite that the study findings should not be generalized to institutions outside of UofL or to FYE courses other than GEN 101, the results of this study have implications that can be useful to other colleges and universities because it directly assesses correlations between FYE interventions and student success outcomes that are established goals of many colleges and universities. As such, the findings are relevant, especially when UofL's similarity to other public institutions are considered. UofL is similar to average public colleges and universities in terms of selectivity in that it is not a highly selective institution. Institutional profile information from various college and university websites indicate UofL also is similar to other public institutions in terms of average ACT scores for incoming freshman classes. Specifically, UofL's average freshman ACT score is 25 and ACT data across Kentucky public institutions indicate Morehead State University, Murray State University, Western Kentucky University, Eastern Kentucky University, Northern Kentucky University, and the University of Kentucky all have average freshman ACT scores ranging from 21.7 - 25.4 (Retrieved from http://ir.eku.edu/sites/ir.eku.edu/files/files/Fast\%20Facts.pdf; http://www2.moreheadstate.edu/files/units/ira/2011_2012_Profile_FINAL_v2.pdf; http://www.uky.edu/IRPE/fast_facts/fact_booklet/fact_booklet1112.pdf; http://louisville.edu/institutionalresearch/institutional-researchplanning/Just \%20the\%20Facts\%202013\%20Use\%20this\%20one.pdf; http://wkunews.wordpress.com/2014/08/15/newest-hilltoppers-more-college-ready-thanbefore/ ). The average ages of undergraduate students also are similar across the previously mentioned Kentucky institutions when compared with UofL. To illustrate, the average age of a UofL undergrad is 22 , and the average undergraduate ages of the 
aforementioned institutions range from $19-24$ (Retrieved from

http://www.collegeportraits.org/KY/EKU/print;

http://careerservices.nku.edu/employers.html;

http://www.collegeportraits.org/KY/UK/print; https://bigfuture.collegeboard.org/collegeuniversity-search/university-of-louisville;

http://wku.edu/instres/documents/2012_fact_book.pdf). UofL also has a comparable freshman retention rate across Kentucky public institutions although the range has greater spread in this category. UofL's freshman retention rate is $77.1 \%$, and the range for other public institutions in the Commonwealth of Kentucky is $64.1 \%-80 \%$ (Retrieved from http://www2.moreheadstate.edu/files/units/ira/2011_2012_Profile_FINAL_v2.pdf; http://www.gohigherky.org/campustour/undergraduate/3803/Murray_State_University/M urray_State_University3.html; http://colleges.usnews.rankingsandreviews.com/bestcolleges/northern-kentucky-university-9275;

http://louisville.edu/institutionalresearch/institutional-researchplanning/Just\%20the\%20Facts\%202013\%20Use\%20this\%20one.pdf; http://www.wku.edu/instres/documents/02_student_profile.pdf ).

In addition to UofL's similarity to other public institutions in light of selectivity, undergraduate age, average ACT scores, and freshman retention rates, the purpose of UofL's GEN 101 course mirrors FYE courses of other public institutions both within the Commonwealth and across the US in terms of purpose and design. For example, Morehead State University (MSU) has many FYE course offerings with the purpose of integrating their students into the academic fabric of the institution. According to MSU's First Year Seminar Faculty Resource Manual, the purpose of their FYE courses are "to 
establish the expectations of life and study in an academic setting and as a local, national, and global citizen .... The foundations of communication and intellectual skills are introduced in this course ...." and it is designed to "provide a common introduction to academic life and success at Morehead State University" (Retrieved from www.moreheadstate.edu/). Comparable to GEN 101, MSU's FYE courses are required for freshmen and are generally taken in the first or second semester after matriculation (MSU First Year Seminar Faculty Resource Manual). The design and purpose of GEN 101 also is comparable to that of Minnesota State University Mankato. I reviewed a syllabus of a First Year Experience Seminar from the university and it indicated their FYE student learning outcomes address academic and social integration in similar ways as GEN 101. Mirroring GEN 101's curriculum, Minnesota State University Mankato's FYE curriculum includes a library tour, campus involvement, deliberate structured interactions with academic advisors, journal writing and reflections to track personal values and goals, presentations from staff representing campus resources like the Office of Student Financial Aid, and discussions surrounding choices of major and class selection (Retrieved from www.mnsu.edu/newstudent/seminar/recommended_syllabus_fyex_100.pdf).

Implications suggest it is clear that despite any positive gains FYE courses may provide for students, those gains may not be sufficient on their own to ensure long-term student success. To illustrate, the UofL's GEN 101 course is required for graduation for A\&S students and other UofL colleges have their own required FYE courses tied to their majors, yet graduation and retention rates are still low. In response, UofL has changed admission requirements over the past few years to bring in students with higher ACT 
scores with the hope of boosting overall retention and graduation rates. In my opinion, this is a peculiar response to the challenge of graduating students, but is a typical one across U.S. colleges and universities. Instead of admitting "smarter" students, we should determine how we are failing students on an institutional level and make necessary adjustments. Colleges and universities need to consider more carefully the quality of services offered and how central and accessible support and retention initiatives like tutoring and supplemental instruction are on campus. Since the study results indicate GEN 101 gains were not enough to ensure lasting college success, (i.e. little practical significance on the first semester GPA variable overall and only marginal gains on the retention outcome depending on race and gender), institutions also should look at FYE as a small piece of a bigger picture and provide a longitudinal service similar in scope to support students in necessary ways throughout the duration of their college attendance.

Another implication of study findings is the possibility that colleges and universities may need to reconsider best practices to come up with better practices for student success outcomes. Certainly, FYE interventions historically have been a best practice across many institutions, but the research is equivocal and does not indicate FYE courses provide consistent gains for college students. Research suggests FYE courses provide better student success outcomes for students who identify as a racial or ethnic minority or for students who enter college with little social capital, like first generation students. But why is this and is this true for all FYE courses regardless of the institution? Barton and Donahue (2009) espouse FYE courses all have the same goal, which is to assist students with being successful in college, but they hold that difference in underlying philosophies, assumptions about what is needed by students to be successful, 
cognitive psychology approaches, and so on create distinctions in the courses that change outcomes.

\section{Recommendations for Content Change}

Although curriculum design was not the purpose of this study and I consequently did not engage in thorough content analysis of GEN 101, the findings of this study in conjunction with extant literature may indicate the importance of considering course content as it pertains to student outcomes. The findings of this study suggest that GEN 101 does not produce even outcomes for students. Specifically, there is little practical significance for White students to take the course as a graduation requirement and even less so for White females since it does not improve their odds of a higher GPA, nor increased graduation rates in any significant ways. Consequently, it may be fair to argue that the course should be shut down since it does not produce desirable outcomes across all student populations. This is especially true when the cost of supporting GEN 101 is weighed against the benefits and the responsibility that state institutions like the UofL have to be good stewards of state financing is considered. Despite this, my recommendation moving forward is not to shut down the course, but instead to make changes to the curriculum in order for it to better accommodate the needs of all incoming students, regardless of race/ethnicity and gender. Since seminar quality and conceptual approaches matter in FYE courses (Barton \& Donahue, 2009; Porter \& Swing, 2006), we should approach GEN 101 changes from that angle.

The literature espouses that FYE courses are correlated with student success. Barton and Donahue (2009) indicate FYE courses are shown to be associated with positive student transition experiences, increased student retention, and increased 
graduation rates. Some research suggests participation in FYE related courses and seminars predict increased first to second year retention probability (Berry, 2014; Singell \& Waddell, 2010; Turner \& Thompson, 2014). Since there is evidence that FYE courses have some successful outcomes, shutting down GEN 101 may have negative consequences, especially for African American and Latino males. Extant literature holds that FYE and first-year transition courses tend to have the greatest effects on student populations from low SES backgrounds, students with first-generation status (Glenn \& Schultz, 2008), students who are academically underprepared (Tuckman \& Kennedy, 2011), and students who live off campus (DeAngelo, 2014; Potts \& Schultz, 2008). Although some of my study findings contradicted preexisting research in relation to campus residency, what was consistent was increased outcomes based on race. This make sense when considering racial/ethnic minorities tend to be from lower SES backgrounds and enter college more underprepared than Whites because of the tendency for them to matriculate from inferior high schools (Swail, Cabrera, Lee, \& Williams, 2005; Tinto, 1993). The more prepared a student is, the more social capital s/he has, and the more opportunity for faculty and peer interactions, the less influential GEN 101 and other FYE courses may be for that student. The practical implication of this is ending GEN 101 may not have an effect on students who matriculate to UofL with family support and social and cultural capital, but it likely would have an impact on students who already are at a disadvantage because of the student-level characteristics they bring with them to college. As such, I argue it is not wise to do away with GEN 101, which would result in removing any benefit it offers to the segment of the UofL students who enter college with more challenges than their counterparts. 
The literature indicates that sense of belonging is an important motivator for persisting in college for African American and Latino students, but not for White students (Murphy \& Zirkel, 2015), so institution-level characteristics like whether or not a FYE course in question is housed at a PWI is significant when looking at FYE outcomes. Many minority students who matriculate into a PWI will face challenges their White counterparts will not face. To illustrate, a White student who turns to REACH at UofL for tutoring will likely have a different experience than an African American student due to the racial make-up of the REACH tutors. It is not enough to tell students that REACH is a resource, but instructors for GEN 101 will need to help equip the students to prepare for potentially off-putting experiences while utilizing the resources they are telling them to use. As such, their need for support and resources will be different based on studentlevel characteristics, and the content of GEN 101 should address these differences.

Since UofL is a PWI, my recommendation is to ensure that minority specific resources are presented to students with the same emphasis as other resources. I also would recommend allowing space for discussions about diversity and student experiences in this course based on the identities they may hold. If it is not feasible to alter the GEN 101 curriculum in this way, then a summer orientation course before matriculation may be useful since research indicates that for racial/ethnic minorities, early pre-matriculation connection to an institution (i.e. embeddedness) can help them develop a sense of belonging and increase their desire to stay enrolled (Prasad, Showler, Ryan, Schmitt, \& Nye, 2017). Although the research in this area is equivocal, some studies claim institutions that promote opportunities for diversity related interactions show statistically significant increased second-year retention compared with those that do not (DeAngelo, 
2014). In addition, the literature on a whole suggests a positive correlation between a college or university's diversity culture and student retention (Astin, 1975; Talbert, 2012; Thompson \& Fretz, 1991; Tierney, 1992, 1999).

Changes to the GEN 101 curriculum that might ensure more level student outcomes would include teaching them personal skills and habits outside of the traditional FYE model. Often, the challenges students face in college have little to do with academic ability, study skills, or social capital and instead are part of an inability to cope with difficult circumstances or to think ahead and consider consequences for actions. As such, I feel implementing curriculum in GEN 101 that addresses coping skills, grit, resiliency, and critical thought are also important for student success outcomes. In a 2013 interview, Angela Lee Duckworth indicates grit, in particular, leads to student success outcomes where talent may be lacking (Perkins-Gough, 2013). She also indicates "grit predicts success over and beyond talent. When you consider individuals of equal talent, the grittier ones do better" (15). In the same interview, Duckworth espouses many gifted and talented students are fragile and do not know how to fail or struggle. She states being gifted does not mean you are hardworking or passionate about anything. Prasad, Showler, Ryan, Schmitt, and Nye (2017) also found grit to be an important factor in academic performance and retention. They found one of the constructs of grit (grit consistency) was positively related to first semester college GPA and negatively associated to drop out intentions. They also determined the type of tasks students are required to accomplish and how these tasks align with their "distinct motivational capabilities" may best predict success (Prasad et al., 2017). TRIO Student Support Services staff attempted to teach students about grit and being resilient when 
faced with adversity (among other things) through the incorporation of On Course in a pilot FYE program.

In fall 2005, TRIO Student Support Services piloted a FYE program using TRIO students and members of the Cultural Center's African American Male Initiative. The On Course model was used in the pilot. On Course is a student-centered student success model created by Skip Downing that forces students to engage in reflection and introspection about habits and choices. Students engaging in On Course participate in activities and lessons that promote holistic views of themselves. They analyze and discuss case studies relevant to student circumstances, reflect on courses of actions, keep learning journals, and apply lessons to their own lives. They are taught how to collaborate across differences, how to handle challenging circumstances with faculty and with peers, and how to make proactive decisions. They learn about managing setback, redesigning goals based on current situations, and developing the necessary grit to power through difficulties. The students in the pilot took a pre- and post-test. The pre-test and post-test measured their level of grit and resilience before the course and after the course and the post-test assessment overwhelmingly indicated students were able to make smarter choices, engage in better critical analysis of behavior and situations, had a more developed sense of self, and were better prepared to handle college stressors (TRIO Student Support Services, Post-Test, On Course, 2015).

I spoke with Katie Adamchik in early 2016 regarding the outcome of the pilot and it was well-received by her. Katie shared the results with A\&S leadership who embraced the idea of incorporating On Course in future GEN 101 sessions. Before I left UofL in September 2016, plans were in the works to have all A\&S advisors trained in On Course 
delivery and implementation as a way to improve GEN 101 outcomes; however, per a recent phone conversation with $\mathrm{A} \& \mathrm{~S}$ advising, On Course has not been implemented into the GEN 101 curriculum and the instructors remain untrained in its delivery (A\&S receptionist, personal conversation, January 23, 2017). The Dean is currently working to convince A\&S staff of the benefits of On Course and hopes to have instructors trained and the curriculum revised to incorporate the On Course model in due time (A\&S receptionist, personal conversation, January 23, 2017).

\section{Recommendations for Change in Requirement}

GEN 101 is required for all students who graduate from A\&S. Although the majority of students take the course in the fall of their first year (and advisors encourage students to do so), a few take it in the spring and some wait until their second year or later. Based on the findings of this study, taking GEN 101 after the fall semester has less of a predictive effect on GPA and retention. As such, it is curious to me that there is a mandate for all students (regardless of year) take it as a graduation requirement. Instead of simply recommending it to students during orientation, I recommend A\&S advisors automatically register all first time students who matriculate in the fall in a fall GEN 101 section and all first time students who matriculate in the spring in a spring section. Using this strategy, GEN 101 would be taken when it would have the most impact for each first time student.

\section{Why this Study Matters}

Although this study had limited generalizability and some limitations, it was still an important study to conduct. As outlined in Chapter 1, the purpose of FYE interventions are to provide first time students with the tools to be successful in college. 
The demographics of students on college campuses are changing to reflect increased enrollment of racial/ethnic minorities and women (Clauss-Ehlers \& Parham, 2014), but despite this trend of increased diversity, the "predominate structure of the first college year . . is the same basic structure that was designed for a population of White, middleor upper-class males who constituted the vast majority of college students . . ." twenty years ago (Barefoot, 2000, p. 13). This can be problematic for students who identify as racial/ethnic minorities because it can create "a serious lack of institutional fit" (13). In addition, the literature indicates that on average, racial/ethnic minorities neither perform as well academically nor graduate at the same rates as their White counterparts (Hunn, 2014). Because of the challenges of being a racial/ethnic minority and being a woman in a traditionally male dominated system, it is important to conduct research that predicts the impact FYE courses have on students who do not identify as White or male.

Additionally, there is a gap in the research pertaining to outcomes of FYE courses for African Americans and Latinos and males and females in a heterogeneous course setting. This is unfortunate given that FYE courses have become the norm for students in their first year of college (DeAngelo, 2013). If it is the norm, and in the case of UofL also a graduation requirement, it is important to study and document how an FYE experience like GEN 101 may influence student success, if at all. The results of this study will be especially helpful to the UofL in light of its strategic plan to increase graduation rates and its diversity initiatives. FYE courses are meant to provide students with a preliminary foundation to increase their chances of college success through academic and social integration (Goodman \& Pascarella, 2006). The literature suggests these courses can be especially beneficial for racial/ethnic minorities or below average females (Berry, 2014; 
Jamelske, 2009). As such, if GEN 101 continues to be a graduation requirement for students in A\&S, it make sense to try to ascertain if the course is doing what it is designed to do, and if so, for whom.

\section{Recommendations for Future Research}

This study should be repeated in a few years after implementation of On Course is complete. This repetition would be important to see if Skip Downing's On Course in the GEN 101 curriculum results in positive statistical change on outcome variables for students regardless of race/ethnicity and gender. Since the focus of On Course is more holistic in nature and addresses non-cognitive factors for college success like resilience, grit, coping skills, and proactivity as well as the usual suspects like time management, goal setting, and study skills, it likely would result in different outcomes than found in this study. I suspect that with the focus of GEN 101 shifting from teaching about academic resources and goal setting and leaning more towards the On Course model of personal responsibility, student-level characteristics of race/ethnicity and gender may not have as much of a mediating effect on the outcomes as they did in this study.

This study also should be repeated using a mixed methods model. The triangulation stemming from the mixture of quantitative and qualitative analyses would provide a deeper understanding of any future research questions (Creswell, 2012). Specifically, after running a regression analysis on respective GPA and retention data for future cohorts, the researcher should host a focus group where students whose data are represented in the quantitative portion of the study have the opportunity to provide qualitative feedback about their retention and GPA statuses and the role GEN 101 played, if any in their academic success. A focus group also would allow for participant feedback 
regarding the usefulness of the content of the GEN 101 courses, which would further guide future content development. 


\section{REFERENCES}

Akos, P., \& Kretchmar, J. (2017). Investigating grit at a non-cognitive predictor of college success. The Review of Higher Education, 40(2), 163-186. doi: https://doi.org/10.1353/rhe.2017.0000

Alarcon, G., \& Edwards, J. (2013). Ability and motivation: Assessing individual factors that contribute to university retention. Journal of Educational Psychology, 105(1), 129-137. doi:10.1037/a0028496

Allen, J., Robbins, S., Casillas, A., \& Oh, I. (2008). Third-year college retention and transfer: Effects of academic performance, motivation and social connectedness. Research in Higher Education, 49(7), 647-664. doi:10.1007/s11162-008-9098-3

Astin, A. (1975). Preventing students from dropping out. San Francisco, CA: Jossey-Bass Publishers.

Aultman, B. (2014). Keywords: Cisgender. TSQ: Transgender Studies Quarterly, 1(1-2), 61-62. doi: 10.1215/23289252-2399614

Bai, H., \& Pan, W. (2009-2010). A multilevel approach to assessing the interaction effects on college student retention. Journal of College Student Retention, 11(2), 287-301. doi:10.2190/CS.11.2.g

Barefoot, B. (2000). The first-year experience: Are we making it any better. About Campus, 4(6), 12.

Barton, A., \& Donahue, C. (2009). Multiple assessments of a First-Year Seminar pilot. The Journal of General Education, 58(4), 259-278. 
Baum, S., \& O'Malley, M. (2003). College on credit: How borrowers perceive their education debt. Journal of Student Financial Aid, 33(3), 7-19.

Bean, J. (1980). Dropouts and turnover: The synthesis and test of a causal model of student attrition. Research in Higher Education, 12(2), 155-187.

Berger, J., \& Milem, J. (1999). The role of student involvement and perceptions of integration in a causal model of student persistence. Research in Higher Education, 40(6), 641-664.

Berry, M. (2014). The effectiveness of extended orientation first year seminars: A systematic review and meta-analysis (Unpublished doctoral dissertation). University of Louisville, Louisville, Kentucky.

Bettinger, E., \& Baker, R. (2011). The effects of student coaching in college: An evaluation of a randomized experiment in student mentoring (No.w16881). National Bureau of Economic Research. Retrieved from https://cepa.stanford.edu/sites/default/files/bettinger_baker_030711.pdf

Bonner, T. (1986, Sept/Oct). The unintended revolution in America's colleges since 1940. Change: The Magazine of Higher Learning, 18(5), 44-51. doi:10.1080/00091383.1986.9940575

Bottia, M., Giersch, J., Mickelson, R., Stearns, E., \& Moller, S. (2016). Distributive justice antecedents of race and gender disparities in first-year college performance. Social Justice Resource, 29, 35-72. doi:10.1007/s11211-015-0242-x

Bourdieu, P., \& Passeron, J. (1977). Reproduction in education, society, and culture. Beverly Hills, CA: Sage Publishing.

Braxton, J., \& Brier, E. (1989). Melding organizational and interactional theories of 
student attrition: A path analytic study. The Review of Higher Education, 13(1), 47-61.

Braxton, J., Jones, W., Hirschy, A., \& Hartley III, H. (2008). The role of active learning in college student persistence. New Directions for Teaching and Learning, 2008(115), 71-83. doi:10.1002/t1.326

Braxton, J., Hirschy, A., \& McClendon, S. (2004). Understanding and reducing college student departure. ASCHE-ERIC Higher Education Report, 30(3), xi-97.

Braxton, J., \& Lien, L. (2000). The viability of academic integration as a central construct in Tinto's interactionalist theory of college student departure. In John Braxton, (Ed.), Reworking the student departure puzzle (pp. $11-28)$. Nashville, TN: Vanderbilt University Press.

Breier, M. (2010). From 'financial considerations' to 'poverty': Towards a reconceptualisation of the role of finances in higher education student dropout. Higher Education, 60, 657-670. doi:10.1007/s10734-010-9343-5

Brooks, M., Jones, C., \& Burt, I. (2013). Are African-American male undergraduate retention programs successful? An evaluation of an undergraduate AfricanAmerican male retention program. Journal of African American Studies, 17, 206221. doi:10.1007/s12111-012-9233-2

Cabrera, A., Nora, A., \& Castaneda, M. (1993). College persistence: Structural equations modeling test of an integrated model of student retention. The Journal of Higher Education, 64(2), 123-139.

Cabrera, A., Nora, A., Terenzini, P., Pascarella, E., \& Hagedorn, L. (1999). Campus 
racial climate and the adjustment of students to college: A comparison between White students and African-American students. The Journal of Higher Education, 70(2), 134-160.

Cabrera, A., Deil-Amen, R., Prabhu, R., Terenzini, P., Chul, L., \& Franklin Jr., R. (2006). Increasing the college preparedness of at-risk students. Journal of Latinos and Education, 5(2), 79-97.

Caison, A. (2004). Determinants of systematic retention: Implications for improving retention practice in higher education. Journal of College Student Retention, 64(4), 425-441.

Chen, R. (2012). Institutional characteristics and college student dropout risks: A multilevel history analysis. Research in Higher Education, 53(5), 487-505. doi:10.1007/s11162- 011-9241-4

Chen, R., \& St. John, E. (2011). State financial policies and college student persistence: A national study. The Journal of Higher Education, 82(5), 629-660.

Clark, M. H., \& Cundiff, N. (2011). Assessing the effectiveness of a college freshman seminar using propensity score adjustments. Research in Higher Education, 52, 616 - 639. doi:10.1007/s11162-010-9208-x

Clauss-Ehlers, C. \& Parham, W. (2014). Landscape of diversity in higher education: Linking demographic shifts to contemporary university and college counseling center practices. Journal of Multicultural Counseling and Development, 42(2), 69-76. doi:10.1002/j.2161-1912.2014.00045.x

Cokley, K., Awad, G., Smith, L., Jackson, S., Awosogba, O., Hurst, A., Stone, S., 
Blondeau, L., \& Roberts, D. (2015). The roles of gender stigma consciousness, imposter phenomenon and academic self-concept in the academic outcomes of women and men. Sex Roles, 73, 414-426. doi:10.1007/s11199-015-0516-7

Collier, P., \& Morgan, D. (2007). "Is that paper really due today?": Differences in firstgeneration and traditional college students' understanding of faculty expectations. Higher Education, 55(4), 425-446. doi:10.1007/s10734-007-9065-5

Creswell, J. (2012). Educational Research: Planning, Conducting, and Evaluating Quantitative and Qualitative Research (4th ed.). Boston, MA: Pearson Education, Inc.

Davidson, C. \& Wilson, K. (2013-2014). Reassessing Tinto’s concepts of social and academic integration in student retention. Journal of College Student Retention, 15(3), 329-346.

Davis, J. (1966). The campus as a frog pond: An application of the theory of relative deprivation to career decisions of college men. American Journal of Sociology, 72(1), 17-31.

Davis, B. J. (1992). Freshman seminar: A broad spectrum of effectiveness. Journal of the Freshman Year Experience, 4(1), 79-94.

DeAngelo, L. (2014). Programs and practices that retain students from the first to second year: Results from a national study. New Directions for Institutional Research, 2013(160), 53-75. doi:10.1002/ir.20061

Desjardins, S., Ahlburg, D., \& McCall, B. (2002). A temporal investigation of factors related to timely degree completion. Journal of Higher Education, 73(5), 555581. 
Duckworth, A., Peterson, C., Matthews, M., \& Kelly, D. (2007). Grit: Perseverance and passion for long-term goals. Journal of Personality and Social Psychology, 92(6), 1087-1101.

Durkheim, E. (1961). Suicide. (J. Spaulding \& G. Simpson, trans.). Glencoe, France: The Free Press.

Ehrenberg, R., Zhang, L., \& Levin, J. (2005). Crafting a class: The tradeoff between merit scholarships and enrolling lower-income students. Cambridge, MA: National Bureau of Economic Research.

Field, A. (2005). Discovering statistics using SPSS. London, England: SAGE Publications.

Forsman, J., Linder, C., Moll, R., Fraser, D., \& Anderson, S. (2014). A new approach to modeling student retention through an application of complexity thinking. Studies in Higher Education, 39(1), 68-86. doi:10.1080/03075079.2011.643298

Gansemer-Topf, A., \& Schuh, J. (2006). Institutional selectivity and institutional expenditures: Examining organizational factors that contribute to retention and graduation. Research in Higher Education, 47(6), 613-642. doi:10.1007/s11162006-9009-4

Gibbons, M., \& Woodside, M. (2014). Addressing the needs of first-generation college students: Lessons learned from adults from low-education families. Journal of College Counseling, 17, 21-36. doi:10.1002/j.2161-1882.2014.00045.x

Gilardi, S., \& Guglielmetti, C. (2011). University life of non-traditional students: Engagement styles and impact on attrition. The Journal of Higher Education, 82(1), 33-53. 
Gonyea, R. (2005). Self-reported data in institutional research: Review and recommendations. New Directions for Institutional Research, 127, 73-89.

Good, C., Rattan, A., \& Dweck, C. (2012). Why do women opt out? Sense of belonging and women's representation in mathematics. Journal of Personality and Social Psychology, 102(4), 700-717. doi:10.1037/a0026659

Goodman, K., \& Pascarella, E. T., (2006). First-year seminars increase persistence and retention: A summary of the evidence from How College Affects Students. Peer Review, 8(3), 26-28.

Grebennikov, L., \& Shah, M. (2012). Investigating attrition trends in order to improve student retention. Quality Assurance in Education, 20(3), 223-236.

Gross, J., \& Berry, M. (2015). The relationship between state policy levers and student mobility. Research in Higher Education, 57(1), 1-27. doi: 10.1007/s11162-015$9377-8$

Guida, Jr. A., \& Figuli, D. (2012). Higher education's gainful employment and 90/10 rules: Unintended "scarlet letters" for minority, low-income, and other at-risk students. The University of Chicago Law Review, 79(1), 131-158.

Harper, S. (2015). Black male college achievers and resistant responses to racist stereotypes at predominately White colleges and universities. Harvard Educational Review, 85(4), 646-674.

Hausmann, L., Schofield, J., \& Woods, R. (2007). Sense of belonging as a predictor of intentions to persist among African American and White first-year college students. Research in Higher Education, 48, 803-839. doi:10.1007/s11162-0079052-9 
Heller, D. (2004). Pell Grant recipients in selective colleges and universities. The Century Foundation Issue Brief Series. Center for the Study of Higher Education, The Pennsylvania State University.

Henning, K., Ey., S., \& Shaw, D. (1998). Perfectionism, the imposter phenomenon and psychological adjustment in medical, dental, nursing, and pharmacy students. Medical Education, 32, 456-464.

Herzog, S. (2005). Measuring determinants of student return vs. dropout/stopout vs. transfer: A first-to-second year analysis of new freshmen. Research in Higher Education, 46(8), 883-928. doi:10.1007/s11162-005-6933-7

Hoffman, M., Richmond, J., \& Salomone, K. (2003). Investigating "sense of belonging" in first-year college students. Journal of College Student Retention, 4(3), 227-256.

Hunn, V. (2014). African American students, retention, and team-based learning: A review of the literature and recommendations for retention at predominately White institutions. Journal of Black Studies, 45(4), 301-314. doi: $10.1177 / 0021934714529594$

Hurtado, S., Carter, D., \& Spuler, A. (1996). Latino student transition to college: Assessing difficulties and factors in successful college adjustment. Research in Higher Education, 37(2), 135-157.

Hurtado, S., Han. J., Saenz, V., Espinosa, L., Cabrera, N., \& Oscar, S. (2007). Predicting transition and adjustment to college: Biomedical and behavioral science aspirants' and minority students' first year of college: Research in Higher Education, 48, $841-887$.

Ishitani, T. (2006). Studying attrition and degree completion behavior among first- 
generation college students in the United States. Journal of Higher Education, 77(5), 861-885.

Jaccard, J. (2001). Interaction Effects in Logistic Regression. Thousand Oaks, CA: Sage Publications.

Jaccard, J., Turrisi, R., \& Wan, C. (1990). Interaction Effects in Multiple Regression. Newbury Park, CA: Sage Publications.

Jamelske, E. (2009). Measuring the impact of a university first-year experience program on student GPA and retention. Higher Education, 57(3), 373-391. doi:10.1007/s10734-008-9161-1

Jessup-Anger, J. (2011). What's the point? An exploration of students' motivation to learn in a First-Year Seminar. The Journal of General Education, 60(2), 101-116.

Jones, W. (2010). The impact of social integration on subsequent institutional commitment conditional on gender. Research in Higher Education, 5, 687-700. doi:10.1007/s11162- 010-9172-5

Kalsbeek, D. (2013). Framing retention for institutional improvement: A 4 P's framework. New Directions for Higher Education, 161. doi:10.1002/he.20041

Karen. (2008, August 8). Re: Three-way interactions in regression [Web log comment]. Retrieved from talkstats.com

Kelly, J., LaVergne, D., Boone, H., Boone, D. (2012). Perceptions of college students on social factors that influence student matriculation. College Student Journal, 46(3), 653-664.

King, J., \& Cooley, E. (1995). Achievement orientation and the imposter phenomenon among college students. Contemporary Educational Psychology, 20, 304-312. 
doi: 10.1006/ceps.19951019.

Kovacs, K. (2016, September). When a C isn't good enough. Inside Higher Ed. Retrieved from https://www.insidehighered.com/news/2016/09/23/students-who-earn-csgateway-courses-are-less-likely-to-graduate-new-data-show

Kurantowicz, E., \& Nizinska, A. (2013). How students 'stay the course': Retention practices in higher education. Studies in the Education of Adults, 45(2), 135-147.

Laskey, M., \& Hetzel, C. (2011). Investigating factors related to retention of at-risk college students. Learning Assistance Review, 16(1), 31-43.

Loomis, S., \& Rodriguez, J. (2009). The individual-collective problem in education: The special cases of John Dewey and Human Capital Theory. Oxford Review of Education, 35(4), 509-521. doi:10.1080/03054980903072587

Lopez. J.D. (2014). Gender differences in self-efficacy among Latino College freshmen. Hispanic Journal of Behavioral Sciences, 36(1), 95-104.

Mamary, A. (2003). Interventions: An all-woman first year college seminar. Feminist Studies, 29(2), 453-460.

Mannan, A. (2007). Student attrition and academic and social integration: Application of Tinto's model at the University of Papua New Guina. Journal of Higher Education, 53, 147-165. doi:10.1007/s10734-005-2496-y

McQueen, H. (2009). Integration and regulation matters in educational transition: A theoretical critique of retention and attrition models. British Journal of Educational Studies, 57(1), 70-88. doi:10.1111/j.1467-8527.2008.00423.x

Mixon, F., \& Hsing, Y. (1994). College student migration and human capital theory: A research note. Education Economics, 2(1), 65-75. 
Mowbray, C., Holter, M., Teague, G., \& Bybee, D. (2003). Fidelity criteria:

Development, measurement, and validation. American Journal of Evaluation, 24(3), 315-340.

Murphy, M., \& Zirkel, S. (2015). Race and belonging in school: How anticipated and experienced belonging affect choice, persistence, and performance. Teachers College Record, 117(12), 1-40.

Murtaugh, P., Burns, L., \& Schuster, J. (1999). Predicting the retention of university students. Research in Higher Education, 40(3), 355-371.

Musoba, G., Collazo, C., \& Placide, S. (2013). The first year: Just surviving and thriving at an HSI. Journal of Hispanic Higher Education, 12(4), 356-368.

doi:10.1177/1538192713497222

National Conference of State Legislatures. (2015). Performance-based funding for higher education. Retrieved from http://www.ncsl.org/research/education/performancefunding.aspx

Nora, A. (1987). Determinants of retention among Chicano college students: A structural model. Research in Higher Education, 26(1), 31-59.

Nora, A. (2001-2002). The depiction of significant others in Tinto's "Rites of Passage": A reconceptualization of the influence of family and community in the persistence process. Journal of College Student Persistence, 3(1), 41-56.

Nora, A., Attinasi, Jr., L., \& Matonak, A. (1990). Testing qualitative indicators of precollege factors in Tinto's attrition model: A community college student population. The Review of Higher Education, 13(3), 337-356.

Nora, A. \& Cabrera, A. (1996). The role of perceptions of prejudice and discrimination 
on the adjustment of minority students to college. The Journal of Higher Education, 67(2), 119-148.

Nora, A., Cabrera, A., Hagedorn, L., \& Pascarella, E. (1996). Differential impacts of academic and social experiences on college-related behavioral outcomes across different ethnic and gender groups at four-year institutions. Research in Higher Education 37(4), 427-451.

O'Gara, L., Karp, M., \& Hughes, K. (2009). Student success courses in the community college: An exploratory study of student perspectives. Community College Review, 36(3), 195-218. doi:10.1177/0091552108327186

O’Keeffe, P. (2013). A sense of belonging: Improving student retention. College Student Journal, 47(4), 605-613.

Osborne, J. (2001). Testing stereotype threat: Does anxiety explain race and sex differences in achievement? Contemporary Educational Psychology, 26, 291310.

Oseguera, L., \& Byung, S. (2009). The influence of institutional retention climates on student persistence to degree completion: A multilevel approach. Research in Higher Education, 50(6), 546-569. doi:10.1007/s11162-009-9134-y

Pascarella, E., \& Terenzini, P. (1979). Interaction effects in Spady's and Tinto's conceptual models of college dropout. Sociology of Education, 52(4), 197-210.

Pascarella, E., \& Terenzini, P. (1980). Predicting persistence and voluntary dropout decisions from a theoretical model. Journal of Higher Education, 51, 60-75.

Paulsen, M., \& St. John, E. (2002). Social class and college costs: Examining the 
financial nexus between college choice and persistence. Journal of Higher Education, 73, 189-236. doi:10.0353/hje.2002.0023

Perkins-Gough, D. (2013). The significance of grit: A conversation with Angela Lee Duckworth. Educational Leadership, 71(1), 14-20.

Perna, L. W. (2000). Differences in the decision to attend college among African Americans, Hispanics, and Whites. Journal of Higher Education, 71(2), 117-141.

Perna, L. W. (2005). The benefits of higher education: Sex, racial/ethnic, and socioeconomic group differences. The Review of Higher Education, 29(1), 23-52. doi:10.1353/rhe.2005.0073

Porter, S., \& Swing, R. (2006). Understanding how first-year seminars affect persistence. Research in Higher Education, 47(1), 89-109. doi:10.1007/s11162-005-8153-6

Potts, G., \& Schultz, B. (2008). The freshman seminar and academic success of at-risk students. College Student Journal, 42(2), 647-58.

Prasad, J., Showler, M., Ryan, A. M., Schmitt, N., \& Nye, C. (2017). When belief precedes being: How attitudes and motivation before matriculation lead to fit and academic performance. Journal of Vocational Behavior, 100, 27-42.

Raley, S., \& Bianchi, S. (2006). Sons, daughters, and family processes: Does gender of children matter? Annual Review of Sociology, 32, 401-421.

Raymondo, J. (2003). The effect of an abbreviated Freshman Year Seminar program on student retention and student academic performance. Research for Educational Reform, 8(2), 46-55.

Reinheimer, D., \& McKenzie, K. (2011). The impact of tutoring on the academic success of undeclared students. Journal of College Reading and Learning, 41(2), 22-36. 
Rendón, L., Jalamo, R., \& Nora, A. (2000). Theoretical considerations in the study of minority student retention in higher education. In John Braxton, (Ed.), Reworking the student departure puzzle (pp. 11-28). Nashville, TN: Vanderbilt University Press.

Rhee, B. (2008). Institutional climate and student departure: A multinomial multilevel modeling approach. Review of Higher Education, 31(2), 161-183.

Rigali-Oiler, M., \& Kurpius, R. (2013). Promoting academic persistence among racial/ethnic minority and European American freshman and sophomore undergraduates: Implications for college counselors. Journal of College Counseling, 16, 198-212. doi:10.1002/j.2161-1882.2013.00037.x

Rogerson, C., \& Poock, M. (2013-2014). Differences in populating first year seminars and the impact on retention and course effectiveness. Journal of College Student Retention, 15(2), 157-172.

Ryan, F. (2004). The relationship between institutional expenditures and degree attainment at baccalaureate colleges. Research in Higher Education, 45(2), 97114.

Saenz, V., \&Barrera, D. (2007). What we can learn from UCLA's "First in My Family" data. Retention in Higher Education, 21(9), 1-3.

Schmid, C. (2001). Educational achievement, language-minority students, and the new second generation. Sociology of Education, 74, 71-87.

Schudde, L. (2011). The causal effect of campus residency on college student retention. The Review of Higher Education, 34(4), 581-610. doi:10.1353/rhe.2011.0023

Schwartz, J. (2012). Faculty as undergraduate research mentors for students of color: 
Taking into account the costs. Science Education, 96, 527-542. doi:

10:1002/sce. 21004

Shaw, E., \& Mattern, K. (2013). Examining student under- and over performance in college to identify risk of attrition. Educational Assessment, 18, 251-268. doi:10.1080/10627197.2013.846676

Singell, L., \& Waddell, G. (2010). Modeling retention at a large public university: Can at-risk students be identified early enough to treat? Research in Higher Education, 51, 546-572. doi: 10.1007/s11162-010-9170-7

Soldner, L., Lee, Y., \& Duby, P. (1999). Welcome to the block: Developing freshman learning communities that work. Journal of College Student Retention, 1(2), 115129.

Soria, K., \& Stebleton, M. (2012). First-generation students' academic engagement and retention. Teaching in Higher Education, 16(6), 673-685.

Spady, W. (1970). Dropouts from higher education: An interdisciplinary review and synthesis. Interchange, 1, 64-85.

Strayhorn, T. (2014). What role does grit play in the academic success of Black male collegians at predominately White institutions? Journal of African American Studies, 18, 1-10.

Stevens, J. P. (2009). Applied Multivariate Statistics for the Social Sciences (5th ed.). New York, NY: Routledge.

Stratton, L. S., O'Toole, D., Wetzel, J. (2007). Are the factors affecting dropout behavior related to initial enrollment intensity for college undergraduates? Research in Higher Education, 48(4), 453-485. doi:10.1007/s11162-006-9033-4 
Sun, J., Hagedorn, L., Zhang, Y. (2016). Homesickness at college: Its impact on academic performance and retention. Journal of College Student Development, 57(8), 945-957.

Swail, W., Cabrera, A., Lee, C., \& Williams, A. (2005). Latino students and the educational pipeline. Washington, DC: Educational Policy Institute. Retrieved from http://www.educationalpolicy.org/pdf/LatinoI.pdf

Talbert, P. (2012). Strategies to increase enrollment, retention, and graduation rates. Journal of Developmental Education, 36(1), 22-36.

Terenzini, P., \& Wright, T. (1987). Influences on students' academic growth during four years of college. Research in Higher Education, 26(2), 161-179.

Thomas, L. (2011). Do pre-entry interventions such as "Aimhigher' impact on student retention and success? A review of the literature. Higher Education Quarterly, 65(3), 230-250. doi: 10.1111/j.1468-2273.2010.00481.x

Thompson, C., \& Fretz, B. (1991). Predicating the adjustment of black students at predominately white institutions. Journal of Higher Education, 62(4), 437-450.

Tierney, W. (1992). An anthropological analysis of student participation in college. The Journal of Higher Education, 63(6), 603-618.

Tierney, W. (1999). Models of minority college-going and retention: Cultural integrity versus cultural suicide. Journal of Negro Education, 68(1), 80-92.

Tinto, V. (1975). Dropout from higher education: A theoretical synthesis of recent research. Review of Educational Research, 45(1), 89-125.

Tinto, V. (1987). Leaving college: Rethinking the causes and cures of student attrition. Chicago: The University of Chicago Press. 
Tinto, V. (1988). Stages of student departure: Reflections of the longitudinal character of student leaving. The Journal of Higher Education, 59(4), 438-455.

Tinto, V. (1993). Leaving college: Rethinking the causes and cures of student attrition (2nd Edition). Chicago: The University of Chicago Press.

Tinto, V. (1998). Colleges as communities: Taking research on student persistence seriously. The Review of Higher Education, 12(2), 167-177.

Tinto, V. (2009). Taking student retention seriously: Rethinking the first year of college. Syracuse University. Retrieved from http://faculty.soe.syr.edu/vtinto/Files/Taking\%20Student\%20Retention\%20Seriou sly.pdf

Tinto, V. (2012). Completing college: Rethinking institutional action. Chicago: University of Chicago Press.

Titus, M. (2006). No college student left behind: The influence of financial aspects of a state's higher education policy on college completion. The Review of Higher Education, 29(3), 293-317. doi:10.1353/rhe.2006.0018

Tucker, C., McHale, S., \& Crouter, A. (2003). Dimensions of mothers' and fathers' differential treatment of siblings: Links with adolescents' sex-typed personal qualities. Family Relations, 52, 82-89.

Tuckman, B., \& Kennedy, G. (2011). Teaching learning strategies to increase success of first-term college students. The Journal of Experimental Education, 79, 478-504. doi:10.1080/00220973.2010.512318

Turner, P., \& Thompson, E. (2014). College retention initiatives meeting the needs of millennial freshmen students. College Student Journal, 48(1), 94-104. 
University of South Carolina. (nd). History of the first university seminar and the university 101 program. Retrieved from http://sc.edu/univ101/aboutus/history.html

Van Gennup, A. (1960). The rites of passage. Chicago: The University of Chicago Press.

Varner, F. \& Mandara, J. (2015). Differential parenting of African American adolescents as an explanation for gender disparities in achievement. Journal of Research on Adolescence, 24(4), 667-680.

Watts, E. (1999). The freshman year experience, 1962 - 1990: An experiment in humanistic higher education (Unpublished doctoral dissertation). Queens University, Ontario, Canada.

WD Lewis. (2016, January 3). Kentucky: Preparing for performance-based funding in higher education [Web log post]. Retrieved from http://educationpolicymatters.com/2016/01/kentucky-preparing-for-performancebased- funding-in-higher-education/

Wilcoxson, L., Cotter, J., \& Joy, S. (2011). Beyond the first-year experience: The impact on attrition of student experiences throughout undergraduate degree studies in six diverse universities. Studies in Higher Education, 36(3), 33-352.

Windham, M., Rehfuss, M., Williams, C., Pugh, J., \& Tincher-Ladner, L. (2014). Retention of first-year community college students. Community College Journal of Research and Practice, 38, 466-477. doi:10.1080/10668926.2012.743867

Wood, J. (2014). Examining academic variables affecting the persistence and attainment of black male collegians: A focus on academic performance and integration in the two-year college. Race Ethnicity and Education, 17(5), 601-622. 
doi:10.1080/13613324.2012.733687

Woosley, S., \& Shepler, D. (2011). Understanding the early integration experiences of first-generation college students. College Student Journal, 45(4), 700-714.

Zamani, E. (2000). Sources and information regarding effective retention strategies for students of color. New Directions for Community Colleges, 112, 95-104.

Zech, L. (2015). Impact of freshman orientation class on subsequent college success (unpublished field research). Northwest Missouri State University, Maryville, MO. Retrieved from http://www.nwmissouri.edu/library/fieldstudies/2015/Zech,\%20Lee\%20Ann.pdf

Ziskin, M., Hossler, D., \& Kim, S. (2010). The study of institutional practices related to student persistence. Journal of College Student Retention: Research Theory \& Practice, 11(1), 101-121. doi:10.2190/CS.11.1.f 


\section{CURRICULUM VITAE}

NAME:

ADDRESS:

DOB:

AREAS OF INTEREST:

EDUCATION:

EXPERIENCE:
Nadine Cecilia Petty

Center for Diversity and Enrichment

16 North Clinton Street

University of Iowa

Iowa City, IA 52242-1323

Kingston, Jamaica - June 21, 1974

College student retention, at-risk student populations, college access, veteran/military student college transition and success, gender studies, race/ethnicity studies, higher education diversity and inclusion initiatives, organizational management and development, and higher education leadership.

Ph.D., Educational Leadership and Organizational Development, Postsecondary Education, 2017

University of Louisville

M.A.T., Secondary English Education, 1997

University of Rochester

B.A., English, 1996

University of Rochester

2015-present

Director, Center for Diversity and Enrichment

University of Iowa, Iowa City, IA

2011-2015

Director/PI, TRIO Student Support Services

University of Louisville, Louisville, KY 
2005-2011

SI Supervisor/Academic Specialist, TRIO Student Support Services

Southwestern Illinois College, Granite City, IL

2006-2011

Adjunct English Faculty

Southwestern Illinois College, Belleville, IL

2004-2005

Manager/Sales Representative

Lladro', Des Peres, MO

2002-2004

Project Manager, School of Engineering

Morgan State University, Baltimore, MD

1998-2004

English Teacher/Coach: Soccer, Track and Field, and

Badminton

Woodlawn High School, Baltimore, MD

2000-2001

Reader and Academic Assessor

Measurement Incorporated, Catonsville, MD

1998-1999

Reading Specialist

Occupational and Educational Training, Towson, MD

1997-1998

Special Education Teacher

William H. Lemmel Middle School, Baltimore, MD

RECOGNITIONS:

Award for Continued Outstanding Service

Morgan State University (STI Program)

Outstanding Academic Achievement

University of Rochester

Bausch \& Lomb Science Award and Scholarship

Bausch \& Lomb Incorporated

Award for Excellence in Chemistry

St. John's University The Women in Science Society 
Award for Excellence in Biology

St. John's University The Women in Science Society

PRESENTATIONS: $\quad$ Panelist, Local Conditions

Employee Resource Group Consortium Diversity Forum

Cedar Rapids, IA

October 7, 2015

MEMBERSHIPS:

Council for Opportunity in Education (COE)

Oct. 2011 - September 2015

Kentucky Association of Educational Opportunity Program Personnel (KAEOPP)

Oct. 2011 - September 2015

American College Personnel Association (ACPA)

July 2012 - June 2013

Mid-America Association of Educational Opportunity

Program Personnel (MAEOPP)

Nov. 2006 - Oct. 2011

Illinois Association of Educational Opportunity Program

Personnel (ILAEOPP)

Nov. 2006 - Oct. 2011

COMMITTEES:

Co-Chair, Talent@Iowa Human Resource Diversity

Committee

University of Iowa

February 2017 - present

Chair, Campus Inclusion Team Advisory Committee

University of Iowa

November 2016 - present

Convener, Student Success Team

University of Iowa

November 2016-present

Leadership Team, HHMI Grant - Supporting

Underrepresented Students in STEM

University of Iowa

March 2016 - January 2017 
Bias Assessment and Response Team (BART) Executive Committee

University of Iowa

January 2016 - March 2016

Peer-Mentor Focus Group/Selection Committee

University of Louisville

November 2014 - September 2015

Summer/Winter Bridge "Bridging the Academic Gap"

Committee

University of Louisville

September 2014 - September 2015

Financial Literacy Committee

University of Louisville

April 2012 - September 2015

President's Persistence to Graduation Retention

Committee

University of Louisville

August 2014 - October 2014

Chair, Student Activities Board

Southwestern Illinois College

Aug. 2007 - Oct. 2011 